\title{
Enriched Environment
}

A Treatment Centre for Transitional Youth with Mental Illness

By Lara Chow

A thesis submitted to the Faculty of Graduate and Postdoctoral Affairs

in partial fulfillment of the requirements for the degree of

Master of Architecture

Azrieli School of Architecture \& Urbanism

Carleton University

Ottawa, Ontario

(C) 2015

Lara Chow 


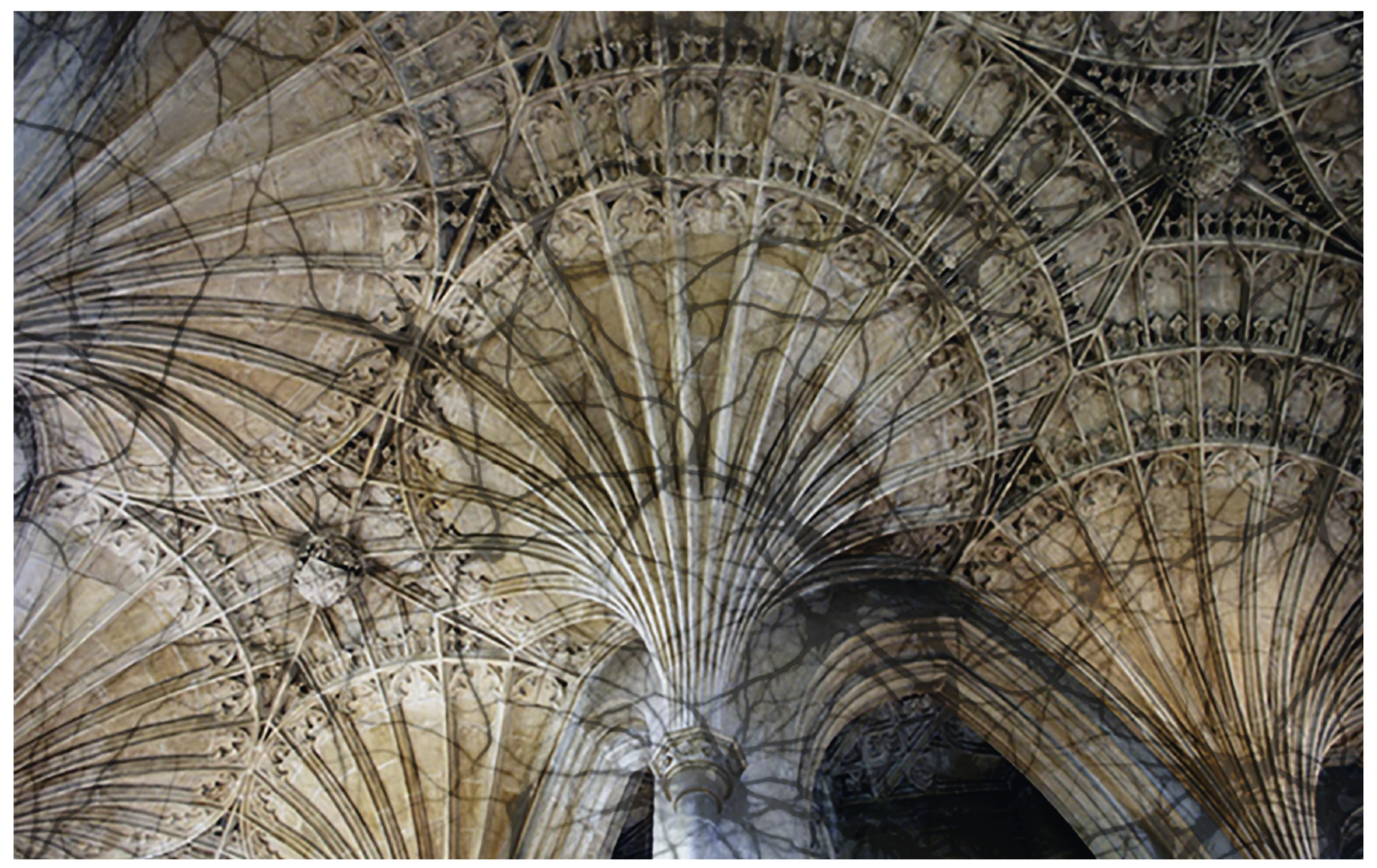

Figure 1: The complexity of neural connections metaphorically

embodied in the connections of architecture. 


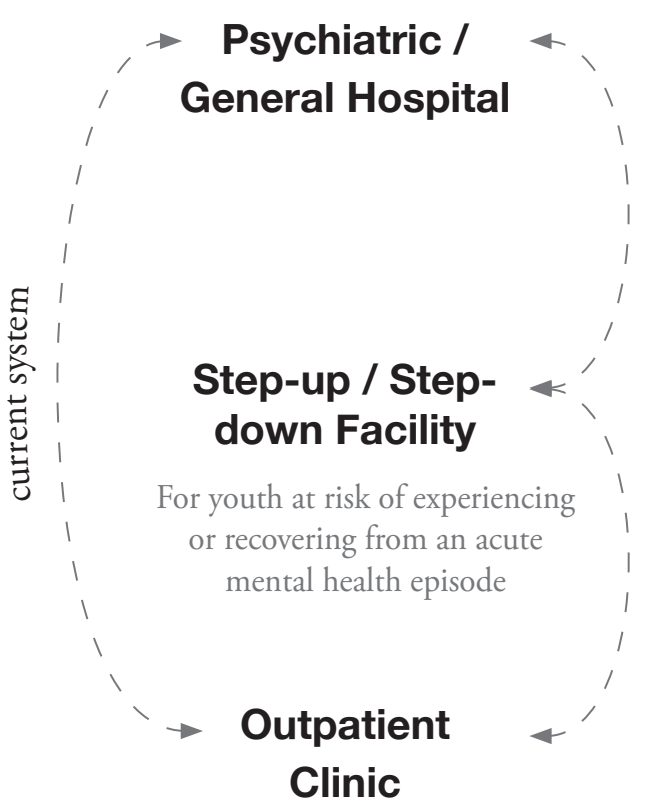

Figure 2: Diagram explaining the role of step-up/stepdown facilities.

\section{[ Abstract ]}

The number of transitional youth affected by mental illness is growing drastically. This age group, ages fifteen to twenty-five, experiences many major personal, interpersonal, and social transitions and events that can cause additional stress and anxiety. However, they often fall through the cracks of the mental health care system since a critical gap exists between the facilities and services offered for treatment. A new type of residential community care called 'step-up / step-down' facilities can provide a 'step up' option for youth at risk of an acute inpatient hospitalization, or a 'step down' option to assist in the seamless transition of youth re-entering the community following a hospitalization.

This thesis develops from an investigation into enriched environments, a concept explored by both neuroscience and neuroarchitecture. Through an analysis of existing research literature and scientific studies on healing spaces, neuroscience, and neuroarchitecture, this thesis goes on to explore, contextualize and then offer an architectural project that can serve to test out ideas for an enriched environment; an environment that is physically and psychologically beneficial to psychiatric patients. The links made between the research of enriched environments will be proposed by implementing a step-up / step-down facility in Ottawa with both inpatient and outpatient treatment specifically for transitional youth. Although each patient is different and disorders vary in severity, an understanding of how the brain functions and reacts to certain stimuli within the built environment will provide a preliminary starting point for design. The thesis recognizes that the causes for mental disorders are complex relationships between 
environmental, psychological, and biological factors, and though not attempting to put forth enriched environments as a 'cure' for mental illness, it is suggesting how architecture and design could play a more important even crucial role in their complex treatment. 


\section{[ Acknowledgements ]}

First and foremost I would like to express my sincerest gratitude to my thesis advisor, Federica Goffl, for all of the guidance during the past year. Without your unique and poetic way of approaching architecture this thesis would not have been possible.

To Roger Connah for all the moments of inspiration, and encouragement to pursue this topic. As well, Mariana Esponda for all the support throughout my years at Carleton.

To my dear friends Rachele Gunderson, Ali Bailey, and Sarah Ward, without you these past seven years would not have been half as much fun.

To my family -Andrei, Tara, Nani, and my guiding light Gung-Gung.

To my love, Dominik Rymsza for all the happiness, laughter, and love you have brought into my life.

Finally, I owe my deepest gratitude to my parents Don and Angela. I could not have done this without you. I am so grateful for all of the endless love, support, and encouragement throughout my lifetime. 


\title{
[ Table of Contents ]
}

\author{
ABSTRACT \\ ACKNOWLEDGEMENTS \\ TABLE OF CONTENTS \\ LIST OF ILLUSTRATIONS \\ INTRODUCTION
}

PART ONE Mental Illness \& Mental Health Facilities

1. Defining \& Diagnosing Mental Health \& Mental Illness

2. Mental Disorders \& Western Society

3. The Financial Cost of Mental Disorders

4. The Patient

5. Types of Facilities

6. The Design of Psychiatric Facilities

7. Precedent Analysis

PART TWO Architecture \& Neuroscience

1. The Emerging Field of Neuroarchitecture

ii. Developments \& Discoveries from Neuroscience 
2. Enriched Environments

i. Explained by Neuroscience

ii. Explained by Neuroarchitecture

\section{PART THREE The Project}

1. Site Analysis

2. Programming

3. Enriched Environment

i. Plans, Sections, \& Axonometrics

ii. A House Within A House

iii. A Storytelling: A Walk In Their Shoes

4. Conclusion

\section{ENDNOTES}

BIBLIOGRAPHY

\section{APPENDICES}

1. History of Mental Illness from Antiquity to Anti-Psychiatry

2. Definitions \& Etymology of Mental Illness 


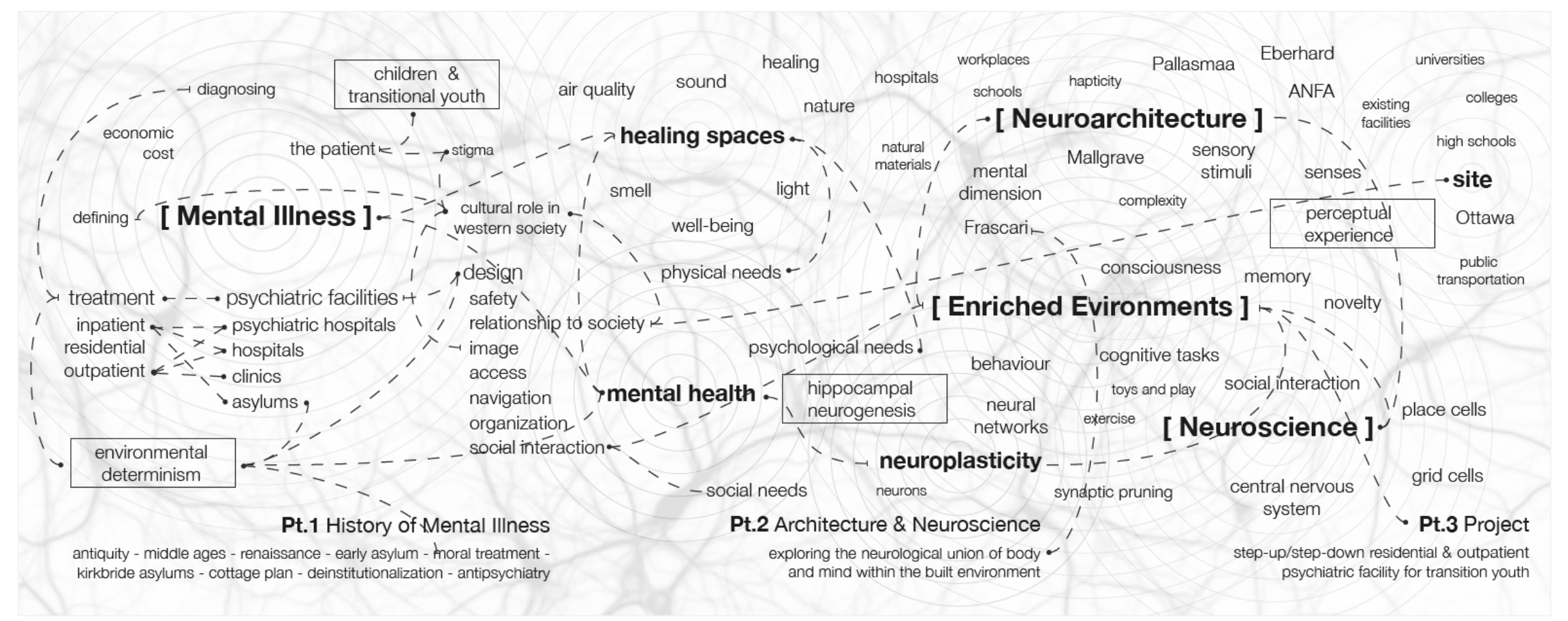

Figure 3: Mapping of thesis research and contents. 


\section{[ List of Illustrations ]}

Figure 1: The complexity of neural connections metaphorically embodied in the connections of architecture. Peterborough Cathedral image retrieved October 17, 2014 from http://upload. wikimedia.org/wikipedia/commons/8/87/Peterborough_Cathedral_fan_vaulting.jpg Neuron network image retrieved October 2, 2014 from http://annmaryliu.files.wordpress.com/2012/05/ neuron-network_invert.jpg

Figure 2: Mapping of thesis research and content.

Figure 3: Diagram explaining the role of step-up/step-down facilities.

Figure 4: Dendritic branching and spines in pyramidal neurons in parietal cortex in rats housed in standard laboratory cages (A) and rats in enriched environment (B). Retrieved January 2, 2015 from http://journal.frontiersin.org/Journal/10.3389/fnhum.2012.00060/full

Figure 5: Diagram of factors influencing mental health and well-being.

Figure 6: Diagram of transitions influencing mental health and well-being.

Figure 7: Courtyards can provide a connection with nature, visual and physical connections for wayfinding, and maximize natural lighting. White Arkitekter's winning proposal for the Aabenraa Psychiatric Hospital. Retrieved January 4, 2015, from http://www.deve.dk/p064aabenraa-psychiatric-hospital-1st-prize/

Figure 8: Diagram of age transition between CAMHS to AMHS.

Figure 9: Psychiatric Unit of Boras site plan. Retrieved October 20, 2014, from http://www. white.se/en/project/136-house-of-psychiatrics

Figure 10: Psychiatric Unit of Boras third floor plan. Retrieved October 20, 2014, Ibid. 
Figure 11: Psychiatric Unit of Boras interior rendering of patient room. Retrieved October 20, 2014, Ibid.

Figure 12: Psychiatric Unit of Boras rendering of interior courtyards. Retrieved October 20, 2014, Ibid.

Figure 13: YPARC Bendigo, view of front facade and main patient entrance. Retrieved October 20, 2014, from http://backstage.worldarchitecturenews.com/wanawards/project/youthprevention-and-recovery-care-y-parc/?source=search\&keyword=Bendigo\&selection=all

Figure 14: YPARC Bendigo, view of interior common areas. Retrieved October 20, 2014, Ibid. Figure 15: YPARC Bendigo, view of exterior courtyard. Retrieved October 20, 2014, Ibid.

Figure 16: "We Make Architecture, But Architecture Makes Us." Marco Frascari (Eleven Exercises in the Art of Architectural Drawing).

Figure 17: Place Cells. Retrieved January 2, 2015, from http://livedoor.4.blogimg.jp/ kiyosawaganka/imgs/2/5/25c731b4.gif

Figure 18: Grid Cells. Retrieved January 2, 2015, Ibid.

Figure 19: Diagram of neuron structure and connection. Retrieved January 3, 2015, from http:// mybrainnotes.com/neuron-brain-cell.gif

Figure 20: Diagram of typical Standard (a), Impoverished (b), and Enriched (c) housings for research studies. From Biological Psychology: An Introduction to Behavioral, Cognitive, and Clinical Neuroscience, Sixth Edition.

Figure 21: Diagram showing the potential connection between enriched environments and mental disorders.

Figure 22: A daydreaming brain: the yellow areas depict the default mode network from three different perspectives; the coloured fibres show the connections amongst each other and with the 
remainder of the brain. Image by Max Planck Institute. Retrieved March 1, 2015 from http://media. eurekalert.org/multimedia_prod/pub/web/67318_web.jpg

Figure 23: Simple cube diagram demonstrating the ability to have multiple truths. All the lines could be in the same plane, or the viewer could be looking at the top or bottom face of a three dimensional cube. Retrieved January 3, 2015 from Zeki, Semir. "The Neurology of Ambiguity." Consciousness and Cognition 13.1 (2004): 173-96. Web.

Figure 24: Map of existing psychiatric services and educational institutions for transitional youth in Ottawa.

Figure 25: Map identifying the surrounding area and site at 100 Cameron Avenue.

Figure 26: World Heritage Site: The Rideau Canal during the fall. Retrieved on January 5, 2015, from: https://c1.staticflickr.com/7/6034/7022847149_a51a0744498_z.jpg

Figure 27: Bank Street, a main street running through Old Ottawa South. Retrieved January 4, 2015, from: http://dianeandjen.com/wp-content/uploads/2011/04/DSC_0015_2109.jpg

Figure 28: Streetscape of Cameron Avenue.

Figure 29: Southeast view of site showing adjacent existing parking lot for multi-unit residential housing.

Figure 30: View of Rideau River Lane, southwest of site.

Figure 31: Map identifying site at 100 Cameron Avenue.

Figure 32: Conceptual massing and programming models.

Figure 33: Conceptual sketches for enriched environments.

Figure 34: Factors directly contributing to an enriched environment.

Figure 35 : Design strategy for the form and massing of the centre.

Figure 36: Site Plan 1:500 
Figure 37: Ground Floor Plan 1:150

Figure 38: Second Floor Plan 1:150

Figure 39: Circulation Diagram

Figure 40: Communal vs. Private / Semi-Private Spaces diagram.

Figure 41: Light study diagram.

Figure 42: Section A-A 1:150

Figure 43: Section B-B 1:150

Figure 44: Section C-C 1:150

Figure 45: Section D-D 1:150

Figure 46: Exploded axonometric diagram.

Figure 47: Ground floor axonometric diagram.

Figure 48: Exploded axonometric diagram.

Figure 49: Second floor axonometric diagram.

Figure 50: Massing model with enriched houses placed within.

Figure 51: Location of enriched houses placed within.

Figure 52: Interior view of the Coffee House.

Figure 53: Interior view of the Green House.

Figure 54: Interior view of the Bath House.

Figure 55: Interior view of the Play House.

Figure 56: Interior view of the Shifting House.

Figure 57: Interior view of the Dream House.

Figure 58: The enriched houses placed within. 
Figure 59: Exterior view of resident entrance off Cameron Avenue.

Figure 60: Interior view of lounge area and resident entrance from Cameron Avenue.

Figure 61: Interior view of daydreaming space.

Figure 62: Interior view of yoga / ftiness studio.

Figure 63: Interior view of central courtyard.

Figure 64: Interior view of creative space.

Table 1: Program for the step-up / step-down facility.

Table 2: The principle healing and enriched environment factors within specific spaces of the facility.

\section{Appendix 1}

Figure 1: The Ship of Fools by Hieronymus Bosch, c. 1490-1500, oil on board. http://www. arthistory.cc/auth/bosch/fools/fools.jpg

Figure 2: Engraving of Bedlam by William Hogarth, c. 1735.

Figure 3: Glasgow Asylum, first floor plan drawing.

Figure 4: York Retreat, first floor plan drawing.

Figure 5: York Retreat, hallway. Retrieved Feb. 20, 2014, from http://upload.wikimedia.org/ wikipedia/commons/b/bb/The_Retreat,_York._Fourth_Gallery._Wellcome_L0000646.jpg

Figure 6: Kirkbride Asylum Floor Plan.

Figure 7: Modified Kirkbride Asylum Floor Plan.

Figure 8: Fairfield Psychiatric Hospital, Bedforshire England, site plan.

Figure 9: Rockwood Asylum for the criminally insane. Kingston, Ontario, 2014. 


\section{[ Introduction ]}

Documentation of abnormal mental phenomenon - known through time variously as madness, lunacy, mania, and mental illness - can be traced back as far as the antiquity. However, throughout history, the exact environmental, biological, and psychological interactions that caused these phenomena has deeply puzzled physicians and society alike. During the 19th and 20th centuries, developing experimental research focused on the brain fueled biological theories attempting to understand the relationship between the central nervous system and mental illnesses. For instance, Jean Pierre Flourens' (1794-1867) studies focused on the removal or damage to the cerebral hemispheres, cerebellum, and brain stem of living animals to establish that these structures were necessary for cognitive functions, movement, and automatic functions, respectively. Camillio Golgi (1843-1926) also made a dramatic breakthrough in neuroscience, when he discovered a cell staining method that allowed for the visualization of individual nerve cells. ${ }^{1}$ Findings such as these have led to more current and promising developments in the study of mental illnesses. Scientists and researchers in neuroscience are now recognizing abnormalities of cellular and molecular formations in the nervous system as scientific reason for abnormal mental phenomena and are beginning to define and record specific biological determinants.

The dramatic biological discoveries in neuroscientific research have influenced several disciplines including philosophy, sociology, and psychology. Recently, this knowledge has begun to permeate through the discipline of architecture creating a promising area of study and research: neuroarchitecture. Neuroarchitecture offers a theoretical approach to the application of emerging 


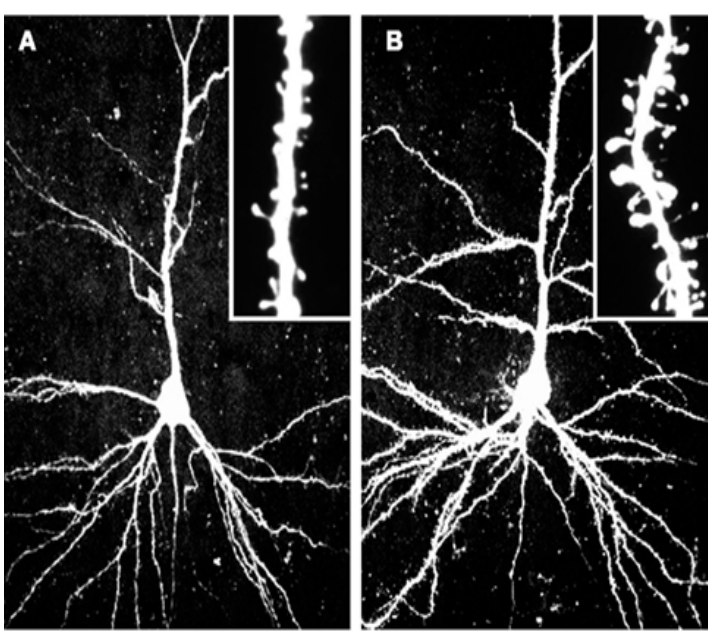

Figure 4: Dendritic branching and spines in pyramidal neurons in parietal cortex in rats housed in standard laboratory cages (A) and rats in enriched environment (B). scientific data from neuroscience to the discipline of architecture, and focuses on the neurological union of body and mind within the built environment. Current research is beginning to link the built environment to changes in behaviour, mood, and well-being on a cellular and molecular level. ${ }^{2}$ This expands on the evidence-based design approach, where design can be based on how humans respond to certain stimuli in the physical environment, by helping us understanding why we respond in such a way. As this knowledge permeates throughout the health care industry it is causing a shift in the guiding principles of health care design. To this day, health care facilities are designed as machines for efficiency, primarily focused on diagnosing and treating patients; the housing of medical equipment and allowing medical staff to perform tasks efficiently is the highest priority. However, an emerging movement emphasizing healing environments where the patient's relationship to the building, in terms of physical and psychological needs, is beginning to guide design decisions.

It is quite possible that a connection between the built environment and mental illnesses lies within studies on neuroplasticity. Following the revelation of the brains mutability and plasticity in the early 1940's, studies completed in the early 1960's on rats by neurochemist Edward L. Bennett, neuroanatomist Marian C. Diamond, and biological psychologists David Krech and Mark R. Rosenzweig, revealed that certain environments - enriched - lead to measurable changes in the brain's neurochemistry and neuroanatomy, such as the size and density of neurons, and dendritic branching and spine density (Fig.4). Following this discovery in the late 1980's, studies by York, Breedlove, and Diamond discovered that enriched environments also stimulated the formation of new neurons, a process called neurogenesis. This discovery revealed that neurogenesis continues in certain parts of the brain well into adulthood, and as a result affects the connectivity 
of neural networks. Additionally, the process of neurogenesis is beginning to be recognized as playing a potential role within the complex treatment of psychiatric and neurological disorders. Several lines of emerging evidence, including research by the Department of Psychiatry, University of Texas Southwestern Medical Center in 2012, suggest that neurogenesis represents a promising approach to treating and perhaps preventing mental illnesses such as addiction, depression, epilepsy, and schizophrenia. ${ }^{3}$

Despite some similarities between the brain's of animals and humans, what constitutes an enriched environment that produces neural changes may be harder to discern for humans due to the diversity and complexity of human experience. Although the scientific term 'enriched environment' - in terms of environments that create measurable changes within the human brain - is not specifically used, proponents in neuroarchitecture, including John Eberhard, Harry Mallgrave, Juhani Pallasmaa, and Marco Frascari, all theorize the implications of the built environment on the mind and body in relation to this emerging neuroscientific research. They explore the need for an architecture that enriches the human condition, an architecture that supports the mental realm, a place for one to think, imagine, and daydream - this is created through perceptual richness, ambiguity, metaphor and story telling.

The following thesis is divided into three parts that will explore psychiatry today, the relationship between architecture and neuroscience, including an investigation of enriched environments, and finally the design proposal for a step-up / step-down facility for transitional youth in Ottawa. 


\title{
[ Part One ]
}

Mental Disorders and Mental Health Facilities

\author{
The madman, understood not as one who is sick but as an established and \\ maintained deviant, as an indispensable cultural function, has become in \\ Western experience, the man of primitive resemblances. ${ }^{4}$ \\ - Michel Foucault (The Order of Things)
}

As Foucault points out, the perception of those affected with mental illness has depended on the society in which they exist. Various cultural, intellectual, and economical structures have determined how madness is known and experienced within a given society. The social construct of mental illness is therefore constantly changing and evolving throughout time.

\section{What is normal?}

The social construct of mental illnesses can be explained by asking the question what is normal? The answer to this question differs across the world on a global, national, regional, cultural, and individual scale. As described by historians Papiasvili and Mayers, "where behaviors of any era belong to the norm, and where they cross the abnormality border, can be assessed according to several criteria: historical/cultural, objective/universal/legal, subjective, and statistical". ${ }^{5}$ The

Historical-Cultural view states that certain behaviors, lifestyles, attitudes, perceptions, and thoughts might be deemed abnormal in one historical-cultural context and not in another. 
However, the objective/universal/legal view states that certain behaviors, lifestyles, attitudes, perceptions, and thoughts will be universally considered a product of abnormal mental phenomenon, regardless of the attributed etiology ${ }^{6}$

Another reason for the constantly changing definition of mental illness may lie behind the belief that mental disorders are not objectively real. Unlike an identifiable physical illness, such as a broken bone or tumor, mental disorders lack physical explanation visible to the human eye. For this, speculation of causes through time have been attributed to environmental, psychological, and mystical influences ranging from the Gods, magic, and even an excess of passion.

The following section provides a current view of the state of psychiatry including defining and diagnosing mental illness, the patient, the economic cost of mental illness, and the design of psychiatric facilities.

For a succinct history of abnormal mental phenomena from antiquity to anti-psychiatry including the examination of the evolving views and understanding of the mentally ill, causes of illness, types of treatment, and treatment facilities see Appendix 1. For a historical exploration of the etymology of mental illness, see Appendix 2. 


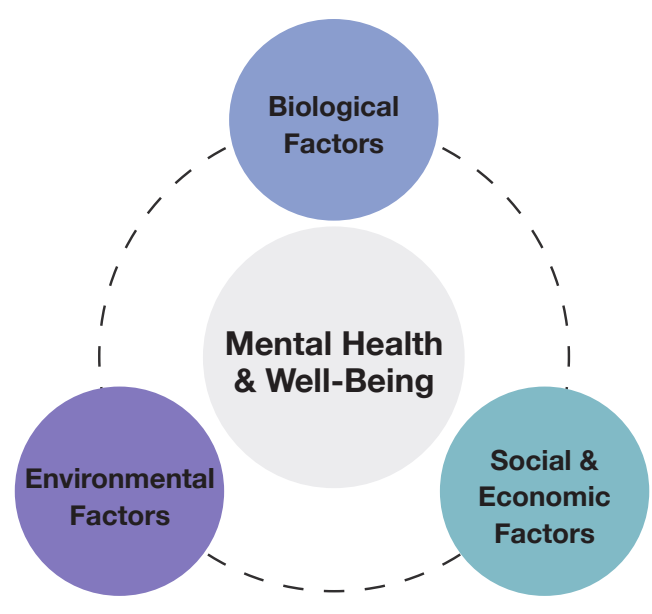

Figure 5: Diagram of factors influencing mental health and well-being.

\section{Defining \& Diagnosing Mental Health \& Mental Illness}

The definitions of mental health and mental illness continued to change from the mid-20th century to present time. The changes reflected a patient-focused definition of mental illnesses, and changed from an "absence of disease" model to one that stressed positive psychological function for mental health. ${ }^{7}$ Currently, the World Health Organization (WHO) defines mental health as "a state of complete physical, mental and social well-being, and not merely the absence of disease." The definition embraces feelings of positivity and enthusiasm about oneself in multiple aspects of life, regardless of the presence of a clinical illness - suggesting that achieving mental health can be a fluctuating lifelong process.

Due to the complexity of mental illnesses a universally understood definition for mental illness does not exist. No definition can adequately provide precise boundaries for the concept, consistently cover all situations, or cultural beliefs. ${ }^{9}$ Most contemporary definitions of mental illness recognize them as, "conditions that affect cognition, emotion, and behaviour". ${ }^{10}$ In contrast to earlier diagnosis-focused definitions, the new definition focuses on the limitations imposed on ones' personal capabilities. However, the ambiguity of the definition sometimes requires further elaboration from a diagnostic perspective. The Diagnostic and Statistical Manual of Mental Disorders, first released by the American Psychiatric Association in 1952, provides a standard language and classification manual for mental disorders. The fifth edition DSM-5 released in 2013 defined a mental disorder as: 
a syndrome characterized by clinically significant disturbance in an individual's cognition, emotion regulation, or behavior that reflects a dysfunction in the psychological, biological, or developmental processes underlying mental functioning. Mental disorders are usually associated with significant distress in social, occupational, or other important activities. An expectable or culturally approved response to a common stressor or loss, such as the death of a loved one, is not a mental disorder. Socially deviant behavior (e.g., political, religious, or sexual) and conflicts that are primarily between the individual and society are not mental disorders unless the deviance or conflict results from a dysfunction in the individual, as described above. ${ }^{11}$

The DSM-5 extends the definition of a mental disorder to include the psychological, biological, and developmental causes of the disorders that can be related to external environmental stimuli or events.

\section{Mental Disorders \& Western Society}

As noted earlier, the social construct of mental illness - its role in society - is constantly evolving. Currently, focus has been placed on the stigma attached and associated with mental illness. Stigma is defined by the Oxford Dictionary as, "a mark of disgrace associated with a particular circumstance, quality, or person". ${ }^{12}$ People suffering from mental illness often face discrimination due to the negative stereotypes and misconceptions associated with disorders. Unfortunately, these negative stereotypes can create serious consequences for mentally ill individuals such as the denial of health insurance, employment, and housing. ${ }^{13}$ They can also detour people from seeking help with up to $60 \%$ of people with a mental illness not seeking support in fear of being labeled..$^{14}$ 
Within the past century, these negative stereotypes have been perpetuated throughout media and play a large role in social attitudes towards the matter. The portrayal of mental disorders in film and television, beginning with in the late 1940's (Now, Voyager, 1942 and I Never Promised You a Rose Garden, 1977) and continuing today (Shutter Island, 2010 and Dark Shadows, 2012), often depict unrealistic, distorted, situations and treatments with violent, homeless and dangerous patients. ${ }^{15}$ However, groups and organizations focused on changing the misguided portrayal of mental illness in the media are attempting to resolve this in hopes of minimizing stigmatization.

Opening Minds, the largest systematic effort to stop stigma and discrimination in Canada, was conceived by the Mental Health Commission of Canada in 2009. The nationwide program focuses on improving education for mental health workers, health promotion, illness prevention, and earlier detection. They believe that the promotion of acceptance and better understanding of mental disorders will not only improve the individual quality of life but also the mental health care system as a whole. ${ }^{16}$

The current promotion for acceptance comes at a time where our understanding of mental illnesses has greatly changed from the past. Growing research on the biological determinants of mental illnesses can be explained as an illness through neurological terms, and are recognized as abnormalities of cellular and molecular formations in the nervous system and provide scientific reason for abnormal mental phenomena, proving that they are objectively real physical illnesses. 


\section{The Financial Cost of Mental Disorders}

In the 2005-2008 study entitled The Economic Burden of Illness on Canada, Neuropsychiatric Conditions ranked number one for the combined direct (physician care, drug, hospital care) and indirect (morbidity, mortality) costs of illness in Canada at 12.5 billion dollars - beating cardiovascular diseases (12.1 billion dollars) and injuries (8.1 billion dollars). As noted in the study, this number represents only a small portion of the total economic burden as it does not include workplace costs, third-party insurance costs, or the cost of mental health professionals who are not covered by the health insurance plans.

The Mental Health Commission of Canada estimates that the total cost of mental health care for the Canadian economy - including income support, productivity losses, private insurance claims, disability payments, caregiving, and costs associated with the jails, schools, and child welfare - to be at least fifty billion dollars a year, representing $2.8 \%$ of Canada's GDP. This number is expected to grow with cumulative costs rising over 2.3 trillion dollars by $2040 .{ }^{17}$ Two strategies suggested by the Mental Health Commission of Canada to lower future spending on neuropsychiatric diseases are firstly, the "promotion, prevention and early intervention targeted at children and families" and secondly, "programs that help people access treatment early, or help them stay out of hospital or out of the criminal justice system". ${ }^{18}$ 


\section{The Patient}

The extremely complex interactions between the individual's internal biological factors, such as genetics and epigenetics, and external psychological and environmental factors, such as a death in the family, divorce, or major life event, means that anyone can be affected by a disorder regardless of age, sex, economic status, or location. The World Health Organization estimated in 2001 that roughly 450 million people suffer from a mental or behavioral disorder worldwide. ${ }^{19}$

Currently in Canada, one in five people are affected by mental illness totaling an estimated 6.7 million people. ${ }^{20}$ Although disorders can affect anyone regardless of sex or age, statistics show that certain disorders are more prevalent in different sexes and ages. In Canada, the prevalence of mood and anxiety disorders in women is almost double that of men, and the percentage of men with substance abuse disorders is close to three times as many women. Age related disorders such as dementia generally appear and peak around 70 years old, and are expected to grow exponentially over the next 30 years. ${ }^{21}$

\section{Transitional Youth}

An alarming number of youth are living with mental illnesses, yet they are under represented and under supported in the mental health care system. Approximately $15-21 \%$ of young Canadians (roughly 1.04 million) have at least one diagnosable mental disorder. ${ }^{22}$ Supporting and assessing this population is critical since up to $75 \%$ of all mental illnesses begin to exhibit themselves prior 


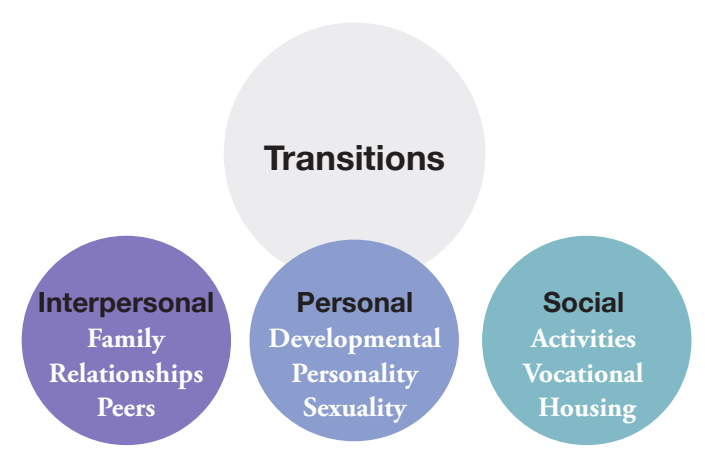

Figure 6: Diagram of transitions influencing mental health and well-being.

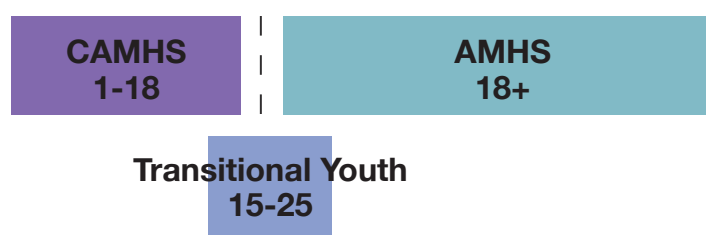

Figure 7: Diagram of age transition between CAMHS to AMHS. to the age of 24. Early detection is the key to preventing learning issues in school, substance abuse, conflict with the law, mental illness in adulthood, and suicide - suicide being the second leading cause of death among children and youth. ${ }^{23}$ However, barriers preventing proper treatment and prevention such as long wait times, fragmentation of services, funding, stigma, and geographic location result in one in six children not receiving any specialized mental health care.

In Ontario, the lack of care for children and youth has been recognized and strong efforts are being made to improve the mental health care system beginning with policy and framework. The province of Ontario released The Shared Responsibility: Ontario's Policy Framework for Child and Youth Mental Health in 2006, and envisions; "an Ontario in which child and youth mental health is recognized as a key determinant of overall health and well-being, and where children and youth grow to reach their full potential". ${ }^{24}$

Recent focus has been placed on transitional youth who are significantly at risk and vulnerable to falling through the cracks of the mental health system. In research studies, transitional youth are generally identified between the ages sixteen to twenty-five, however, some studies are more flexible and the age ranges between twelve and twenty-six. Additional to the existing critical developmental, social, and personal transitions - making them susceptible to additional stress and anxiety - this age group must also transition between child and youth mental health services (CAMHS) to adult mental health services (AMHS). Currently there lacks a seamless, coordinated, and integrated connection to support transitional youth as they transfer between services. As it stands, once a youth turns eighteen years of age they are transferred into AMHS, a decision based upon an institutional system, not based upon the needs and developmental level of the 
patient. ${ }^{25}$ This is a major fault in the system since it only takes into account chronological age, not development level. As stated in We've Got Growing Up To Do: A Transitions Policy Paper (2011), " $[\mathrm{M}]$ any young people do not develop the skills necessary to negotiate effective mental health transitions before their mid-twenties. As a result, the expectation that youth can successfully negotiate CAMHS/AMHS transitions without embedded supports and in the absence of an appropriate model of care is a rather unrealistic idea." ${ }^{26}$

Transitional youth within adult mental health care facilities also often feel scared and unsupported. The difference in age, development, maturity, support, and caregivers, can result in youth disengaging from mental health care system. Without a proper and effective connection between services and facilities, transitional youth will lack the support and care they crucially require. 


\section{Types of Facilities}

The severity and stage of an individual's illness determines the type of treatment received, which is broken up into three main types of care: inpatient, outpatient, and residential care. Stages of treatment are broken up into three types: crisis, rehabilitation, or reintegration, however the focus on mental health promotion has also created a rising stage in treatment, prevention.

\section{Inpatient Care: Psychiatric Hospitals \& General Hospital Psychiatric Wards}

Inpatient care is utilized for patients in rehabilitation with severe mental illnesses or patients in acute crisis - where an individual's illness temporarily worsens - that need to be admitted to a stationary facility. Patients posing a threat to themselves or others are often admitted to an inpatient program. Inpatient care provides a high level of supervision that requires around the clock care in specialized psychiatric hospitals or on a psychiatric ward of a general hospital. Admission of a patient is an extremely serious matter and is provided on a voluntary or involuntary basis. In Ontario, involuntary admission is a process controlled by The Ontario Mental Health Act, in which physicians have the right to hold a patient upon psychiatric assessment.

Inpatient services vary from facility to facility however, once patients are admitted they are assigned a room, either shared or private, and are under 24-hour care of a psychiatrist and the nursing team. In this situation patients have their days planned by the care team, and have a different treatment options and care strategies tailored to their needs following assessment. 
Security and safety is one of the main concerns in inpatient facilities, since some patients may pose a threat to themselves or others, therefore patients may be placed under suicide watch or as a last resort the use of seclusion and restraints may be used.

General hospital inpatient care is often a short hospitalization period (30 days or less) until the condition improves enough so that the person can be treated as an outpatient or the patient is transferred to a specialized psychiatric hospital. In 2009-2010 the average length of stay for a patient with a mental disorder in a general hospital in Canada was 18.3 days, and 80.5 days in a psychiatric hospital. ${ }^{27}$ The difference in length of stay can be attributed to the diagnosis, for instance schizophrenic and psychotic disorders that require a longer treatment process (on average 144.6 days) are more often treated in specialized psychiatric hospitals than in general hospitals. ${ }^{28}$

Previously the Provincial Psychiatric Hospitals were owned and funded by the government and operated under the Mental Health Act. Now, all Provincial Psychiatric Hospitals operate under the Public Hospitals Act and have been absorbed by the public hospital system. ${ }^{29}$ Following deinstitutionalization and subsequent restructuring of the mental health care system, funding for mental health facilities decreased, meaning a significant reduction in the number of beds in psychiatric hospitals. However by the year 2000, the number of psychiatric beds in general hospitals increased from 844 to $5,836 . .^{30}$ 


\section{Outpatient Care: Hospitals, Clinics, Community Centres, Schools, \& Offices}

The emergence of psychotropic drugs and advances in treatment methods has meant that people suffering from moderate mental illnesses no longer need to be treated as an inpatient in a hospital setting and can be treated in a "community based setting". A wide range of clinics, community centers, offices, and schools now provide outpatient community based care. However, outpatient services can also be administered within a hospital setting such as patient clinics or day programs for when patients from inpatient programs transition to partial hospitalization. Patients in day programs spend the majority of their day being treated in a hospital setting with doctors and nurses available and are able to return home at the end of the day.

Patients participating in outpatient care do not reside in facilities or require overnight stays and the stage of treatment is focused on rehabilitation and reintegration. Outpatient treatment is the most common type of treatment and varies considerably in treatment and therapy types. Outpatient treatment types include: group or individual therapy, support groups, and deep brain stimulation.

The funding of outpatient treatment can be covered by Canadian Provincial Medicare, insurance, or is an out of pocket expense for the patient. Outpatient treatment covered by Medicare such as an appointment with a psychiatrist is associated with extremely long wait times, up to a year wait for an appointment, resulting in those who can afford it paying on average $\$ 125$ dollars per visit to avoid waiting. 


\section{Residential Care: Houses \& Apartments}

Individuals that are unable to function independently due to a severe or chronic mental health problem require short or long-term residential treatment. Facilities range in size from a single family dwelling to a multi-unit apartment complex. These structures give patients the freedom to continue living in the community while also having access to support and stability. The majority of residential care facilities are publicly subsidized, and residents can pay a portion of their rent, food, and daily costs based on their annual income.

The level of support varies greatly in each type of residential facility. Not all structures offer in house medical care however supervision is available in most facilities. In certain residences staff can provide social and personal support services including homemaking and personal care; life skills; peer support; and employment support, and more clinical mental health support such as case management; outreach nursing, and assertive community treatment. ${ }^{31}$ 


\section{Psychiatric Facility Design}

Recently, the principles guiding health care design are changing. Facilities were formerly designed as a machine for efficiency, primarily focused on the diagnosing and treating of illnesses with focus being placed on housing medical equipment, not patients, and allowing medical staff to perform tasks at maximum efficiency. This generated noisy, chaotic, and hard to navigate spaces that paid little attention to the negative affects on a patient's physical and psychological wellbeing, including increased stress, anxiety, depression, recovery time, and pain medication. An emerging understanding now emphasizes the patient's relationship to the building, in terms of comfort and aiding healing, as a way to guide design decisions. This relationship between the built-environment and how we as humans are directly affected has created a new area of research called Evidence Based Design.

In health care, Evidence Based Design uses physiological and health outcome measures - length of stay, amount of pain medication, complication rates, and patient stress and mood - to evaluate the health benefits of environmental features in facilities. The first study to examine the impact of the environment on healing and behaviour was coordinated by Roger Ulrich in 1984. Ulrich was able to provide evidence between recovery time in hospital and amount of pain medication with the type of view from a window. Patients with access to views of nature were on average released a full day earlier than those viewing a brick wall. ${ }^{32}$ This study gained critical attention following its publication in Science magazine and has lead to a large array of behavioural and social studies on healing spaces. Although great amounts of knowledge has accumulated from evidence based 
design studies, it is still necessary to be critical of the data since each facility's program and needs are unique, and some studies may lack proper methodologies or research supporting their recommendations.

The following section examines characteristics of the built environment known to influence healing and behaviour, as well as additional special design considerations for psychiatric facilities.

\section{Healing Environments}

The built environment has the ability to change the way patients feel, how they behave, and how they heal in both positive and harmful ways. This can partially be attributed to our perceptions and experiences within a built space, which trigger the release of molecules into our bloodstream and affect both behaviour and well-being. ${ }^{33}$ A healing environment provides a space that is restorative - meaning it contributes positively to the physical and psychological needs of a patient. The senses play a large role in healing environments since how we perceive and experience the space around us is through seeing, hearing, smelling, touching, and tasting. Sensory stimuli are even more crucial to consider in the design of mental health facilities since people living with mental disorders can experience hyper or hyposensitivity to sensations that may result in the avoidance of specific situations or experiences, missing certain sensory stimuli and high states of arousal and emotional reactivity. ${ }^{34}$ 


\section{Seeing: Light \& Dark}

Access to too little or too much light can affect a patient's mood and healing. Multiple studies have revealed that it is not the colour of light, but rather the amount of illumination that has a direct impact on people. ${ }^{35}$ Direct sunlight ranges between 32,000 to 100,000 lux, in comparison to 200-700 lux for ordinary indoor lighting. Without enough exposure to natural sunlight patients are susceptible to negative changes in mood including depression, anxiety, and fatigue, and can have an adverse effect on healing.

For example, seasonal depressive disorder is caused by a lack of sunlight or prolonged exposure to artificial light or darkness. ${ }^{36}$ In contrast, when patients with depression were exposed to natural lighting healing improved. In 2006 a study took place in Edmonton Canada with patients suffering from varying forms of depression. Patients inhabiting brighter rooms were discharged on average 2.5 days sooner than those in low lighting conditions. ${ }^{37}$ Maximizing natural daylighting is an essential design component for psychiatric facilities since anxiety and depression account for nearly $79 \%$ of all psychiatric diagnoses..$^{38}$

On the other hand, too much light can adversely affect a patient's well-being. Bright lights used for hospital staff to perform tasks during the night can disrupt the natural sleep patterns of patients contributing to a lack of deep and restorative sleep (stages 3 and 4 of the R.E.M. sleep cycle). This can lead to increased anxiety, fatigue, and irritation, which in turn affect immune system function, infection resistance, and wound healing. 


\section{Hearing: Silence, Sound, \& Noise}

Unlike the equipment filled rooms of the intensive care unit or cardiac unit where technology used to monitor patients creates the majority of noise, the main source of loud noises in psychiatric facilities comes from the activities of the patients themselves. Too much or too little sound can have a direct impact on well-being. High levels of noise have been linked to an increase in blood pressure, elevated heart rate, and sleep deprivation. It has also been linked to adverse psychological health affects including stress, anxiety, and cognitive impairment. Providing spaces where patients can control their soundscape and escape environmental stressors such as loud activities may prevent irritation and aggressive behaviours. ${ }^{40}$

Although scientific evidence is minimal, sound has been attributed to improving mood and contributing to a calming and relaxing effect. Certain types of music and soothing natural sounds have been shown to produce a positive emotional response from patients. Positive sounds and music may not facilitate healing itself, but can aid in the reduction of environmental stressors.

\section{Smelling: Scents \& Odors}

The use of certain fragrant oils such as lavender, sandalwood, and eucalyptus, have been used since ancient times for their healing properties. Direct application of these oils to wounds provided an antibacterial effect and could also be used to treat inflammation. Besides the physical benefits of these fragrant oils, the smell itself has been shown to affect the psychological well-being of animals and humans. Multiple studies have shown that the scent of lavender eased tension, 
improved mood, and helps induce and prolong sleep. ${ }^{41}$ Scents can also be used to produce the opposite effect on sleep - rats exposed to the scent of lemon shortened the duration of sleep. ${ }^{42}$

The use of scents to treat psychiatric illnesses such as anxiety, depression, and cognitive disorders is called psychoaromatherapy. When essential oils are inhaled or applied to the skin they can exert measurable psychological effects. ${ }^{43}$ When a group of depressed males were split into two groups, those exposed to citrus fragrances and those not, the men participating in the active treatment group saw a significant reduction in the use of antidepressants. ${ }^{44}$ Another study included a group of one hundred patients with intractable epilepsy, one third of the patients who opted for aromatherapy treatment were no longer taking conventional anticonvulsants and were seizure free at the two year follow up. ${ }^{45}$

In contrast odors, or negative smells, have been observed to stimulate fear, anxiety, stress. ${ }^{46}$ While emerging evidence exists for the role of smell in healing, it is difficult to evaluate since it is closely linked to our own memories that produce subjective emotional reactions.

\section{Indoor Air Quality: Fresh Air \& Pollutants}

The quality of air within an indoor environment is one of the major components in sustainable building design. Utilizing operable windows for natural ventilation in the design of buildings is said to improve energy efficiency, but it can also improve the indoor air quality that affects the occupants well-being. Several claims have been made for the benefits of fresh air, however there is minimal conclusive clinical evidence on the positive affects of fresh air on healing. 
Poor indoor air quality, however, has been extensively studied and can create serious health risks both physically and psychologically. Exposure to indoor air pollutants such as lead, solvents, pesticides, and certain building materials, can lead to serious neurological and cognitive defects, such as impeding self regulatory behaviour in children, anxiety, depression, and concentration difficulties in adults. ${ }^{47}$ Proper ventilation and fresh air can improve people's health then by helping remove and dilute unwanted indoor air pollutants.

\section{Connecting with Nature}

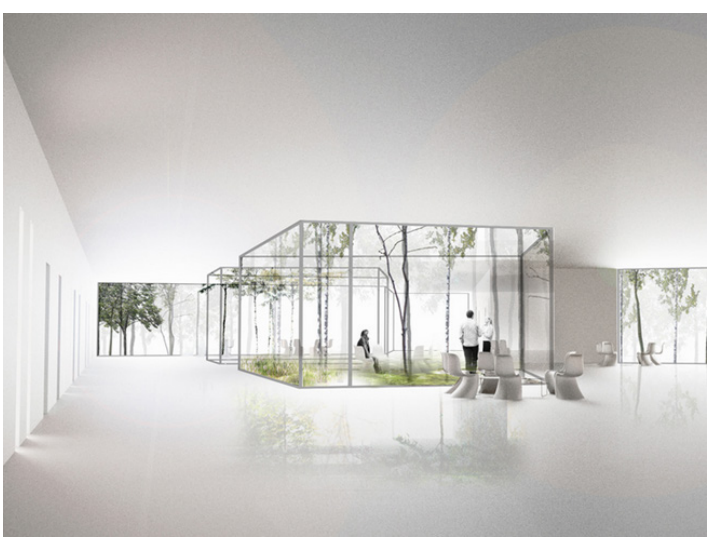

Figure 8: Courtyards can provide a connection with nature, visual and physical connections for wayfinding, and maximize natural lighting. White Arkitekter's winning proposal for the Aabenraa Psychiatric Hospital.
Research literature and scientific studies on nature's impact on healing and well-being is growing. The inherent healing properties of nature have been exploited since ancient times, but it is only recently that this topic has gained increasing attention from the scientific community - mainly beginning with Roger Ulrich's study in 1984. A more recent study exploring the relationship between viewing nature and positive well-being by Maller, Townsend, St. Leger et al. in 2008 concluded that, "viewing nature is positive for health, particularly in terms of recovering from stress, improving concentration and productivity, and improving the psychological state, particularly of people in confined circumstances such as prisons, hospitals, and high-rise apartments/highdensity living." ${ }^{38}$ This knowledge can be used in the design of psychiatric facilities - especially those that provide inpatient or residential treatment - to better the psychological state of those suffering from mental disorders. It is not only viewing nature that enhances well-being and healing, having access to nature is also beneficial. Studies show that just being in nature can be restorative and decrease cognitive fatigue and stress. ${ }^{49}$ 


\section{Additional Design Considerations for Psychiatric Facilities}

The design of a mental health treatment facility is a critical component of patient care. In comparison to other health care facilities and healing environments, mental health facilities require additional thought to features of design including its relationship to society, patient and

staff safety, navigation, and the psychological impacts of the built environment. Facility design may impact the attitudes, expectations, and opinions patients have about themselves, the staff that care for them, the services they receive, and the larger health care system in which those services are provided. Facility design also impacts the staffs perceptions, attitudes, and behaviors, and how they identify and interact with patients and the environment. ${ }^{50}$

\section{Relationship to Society \& Appearance}

The location of a mental health institution can shape its image in society. Institutions were previously located far away from urban centers in rural areas and allowed for the institution to be self-supporting and provide patients with a scenic and tranquil setting for healing. However, this perpetuated the negative stigma associated with the mentally ill. Many major facilities in Canada are now located within the urban fabric of cities in order to provide better accessibility to services, while also allowing patients to continue treatment in a familiar cultural, environmental, and community context. The immediate surrounding context, such as links to public transportation and the surrounding buildings, are also crucial to its success since creating connections and encounters between the community and patients may help patients reintegrate 
into the community, and eliminate fear while reducing stigmatization associated with mental disorders.

As with the location of a facility, the building's appearance also shapes its image in society. For this reason some mental health facilities are increasingly avoiding an institutional appearance - that carries a historical negative stigma from asylums - and opting for both an external and internal residential-like aesthetic. As stated in the 2010 Mental Health Facility Design Guide published by the Department of Veteran's Affairs, "creating a more familiar, therapeutic environment helps reinforce the recovery focus of the program and reduce institutional stigma often associated with mental health treatment facilities. To this end, interior and exterior features of mental health facilities are increasingly home-like in appearance and feel. Inpatient and residential facilities, where feasible, are single story or village-like, with multiple exterior courtyards bringing in more natural light and views of nature." 51

\section{Safety}

The requirement for a safe environment is a high priority in the design of mental health facilities. In early institutions the need for safety, control, and surveillance, often became the main objective of the design and resulted in a prison-like appearance and aesthetic. Today, the challenge is to accommodate the varying levels of security for patients and staff within each space of the building, while providing a healing environment. ${ }^{52}$ Safety concerns include minimizing physical threats and suicide, incorporating abuse resistant materials, furnishings, and fixtures, enhancing staff visibility and engagement with patients, and concealing patient records and medications. 
New studies are emerging that contradict previous safety concerns and provide evidence in support of more open environments. For instance, previously, inpatient environments utilized enclosed areas and physical barriers between staff and patients, such as enclosed nursing stations, as a means of insuring safety against patient aggression. Today, studies reveal that open environments and open concept nursing stations do not increase the safety risk for the staff. ${ }^{53}$ Instead, open nursing stations can help promote normal social interaction and engagement between staff and patients.

\section{Access}

The first impression when entering an inpatient psychiatric facility is essential and can largely influence whether the stay is experienced positively or negatively. Since admission to a psychiatric facility rarely happens at the will of the patient it is important to design an entrance that fosters positive feelings for both the patient and family/visitors. Small waiting areas should be provided for family and visitors adjacent to the admissions area since they are an important aspect of patient-centered design and create a welcoming environment where the patient and their family are valued.

\section{Navigation \& Organization}

The organization of interior spaces within psychiatric facilities should be easy to navigate for patients. Visual cues and landmarks should be used to help patients circulate throughout the building. Children, and patients with dementia or Alzheimer's, may be less likely to have the 
ability to use landmark selection and route examination strategies to help navigate unfamiliar areas - the use of familiar images can provide ease of navigation. ${ }^{54}$ Providing visual or physical connections, or using a diverse range of colours, textures, and materials for interior finishes can minimize the frustrations and panic of patients.

\section{The Psychological Needs of Patients}

Personal control within the built environment can lead to better mental health. A basic need of man is security and control, and since health care facilities are designed for machines, an individual may find it difficult to feel secure and be in control of their environment. ${ }^{55} \mathrm{~A}$ lack of personal control can lead to feelings of helplessness, anxiety, and depression - this can arise from certain aspects of the built environment such as long dead end corridors that can increase uncontrollable social interactions. ${ }^{56}$

Interaction is at the core of social life and human behaviour, "it is one of the tenets of sociology that the behavior of human beings can never be fully understood if one does not realize that the social actions of individuals are always oriented toward other human beings, and it is the interplay between the action of Self (Ego) and the expected or actual reaction of one or many others (Alters) which occupies the centre of the human stage." ${ }^{57}$ The built environment can influence the regulation of social interactions and should incorporate spaces that facilitate a range of social interactions from large spaces for public or group activities to small intimate spaces for solitude and privacy. Varying room sizes, room location, and permeability of rooms in psychiatric facilities can give patients a greater degree of social control and can promote social 
support and interaction. ${ }^{58}$ As Erich Fromm stated, "the insane person is one who has completely failed to establish any kind of union, and is imprisoned, even if he is not behind barred windows. The necessity to unite with other living beings, to be related to them, is an imperative need on fulfillment of which man's sanity depends." 59

The furniture placement within spaces can also influence positive social interactions, mood, and behaviour. Studies suggest that interaction between patients increase and passive behaviours decrease when chairs are arranged a table to face each other. ${ }^{60}$

Another aspect of social interaction controlled by the built environment in psychiatric buildings is crowding. The number of patients per room can be linked to psychological distress. Crowding from too many patients in the room can cause social stresses. Psychiatric patients with private rooms were most satisfied with their stay than those in multiple bed wards, but other benefits include a decrease in staff errors and other operational benefits. 


\section{Precedent Analysis}

As demonstrated earlier, following the closure of asylums a wide variety of contemporary treatment facilities have been implemented to help those with mental illness. Two case studies have been selected to demonstrate differing types of facilities for youth and transitional youth; The Psychiatric Unit of Borås, Sweden, and the Y-PARC residential facilities in Australia. These case studies will be critically analyzed and examined on the following:

- Patient: age, sex, type and severity of disorder

- Relationship to Society: urban, rural, bordering a city, link to public transportation, types of buildings surrounding the facility

- Building Style: new construction, renovation of existing unit, old building adapted

- Access: entrance points

- Treatment types: crisis, inpatient, outpatient, rehabilitation, prevention

- Organization: spatial, interior spaces, exterior spaces

- Healing Environments: light, sound, air quality, connection with nature, accommodating the psychological needs of patients. 


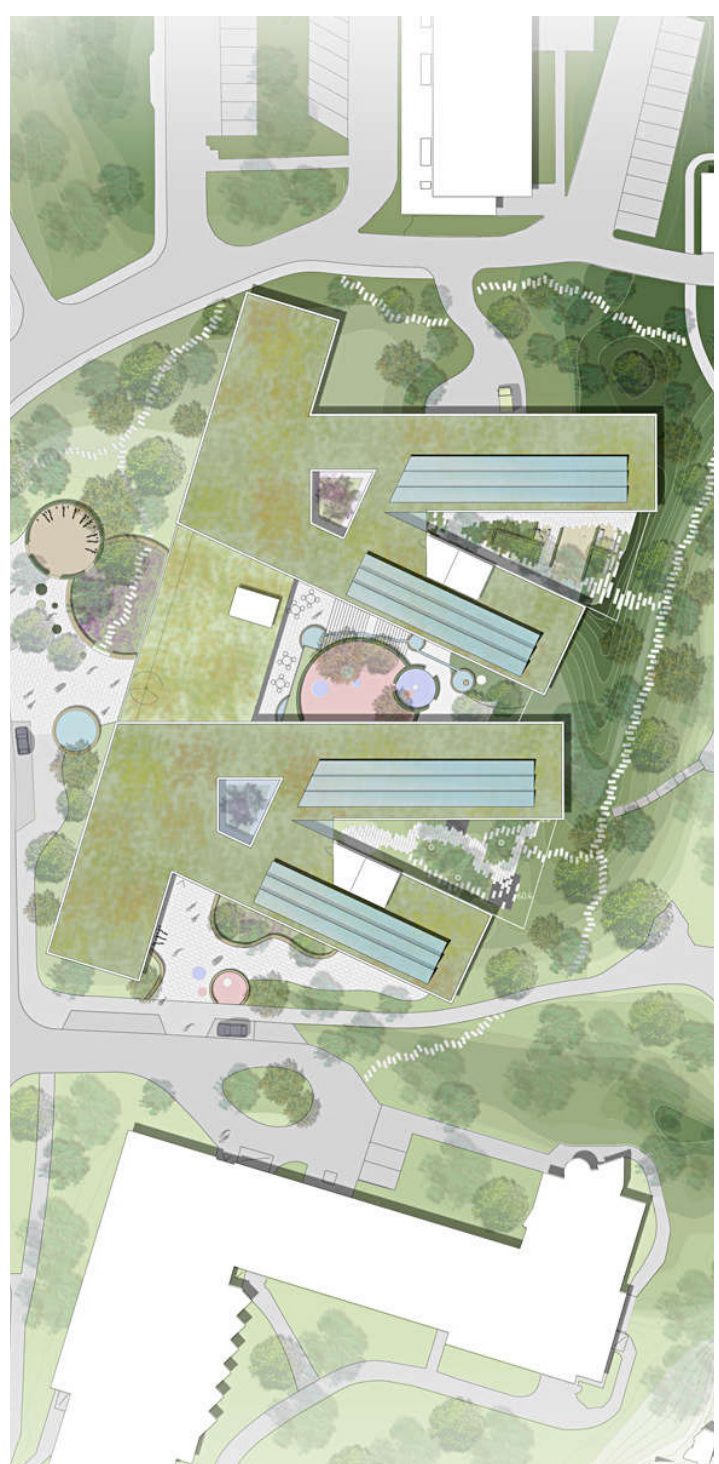

Figure 9: Psychiatric Unit of Boras site plan.

\section{Psychiatric Unit of Boras}

The proposed Psychiatric Unit of Boras will be located on the existing Southern Älvsborgs Hospital (SÄS) campus within the city of Boras. As described by the architects White Arkitekter $\mathrm{AB}$, "the general idea of the project is to create a clinic that has the dignity of a public building, but that does not feel like a closed institution. The overall vision of SÄS is that Psychiatry should not longer be stigmatized and isolated, but seen as an integrated part of the hospital, and the overall society." This is made possible by creating a freestanding building, located close to the existing healthcare infrastructure and also existing public transpiration (Fig. 9). The building is embedded within the gently sloping site and within the existing greenery and landscape.

The four-storey (11500 sq. m) facility includes an emergency department, an inpatient component able to accommodate eighty adult patients and ten child / youth patients, a rehabilitation unit, and an administration area. The second and third floor contains of six angled wards connected by a central spine (Fig. 10). Each ward has a "team" area for staff, community spaces for socialization and patient rooms, with the majority of the patient rooms being private with the exception of a few double occupancy rooms. Each patient room has a private bathroom and a private balcony for fresh air and to experience the views of the surrounding landscape. (Fig. 11). The angled design of the small wards eliminates the need for long monotonous corridors, which are known to create negative psychological reactions in patients due to uncontrolled social interactions. 


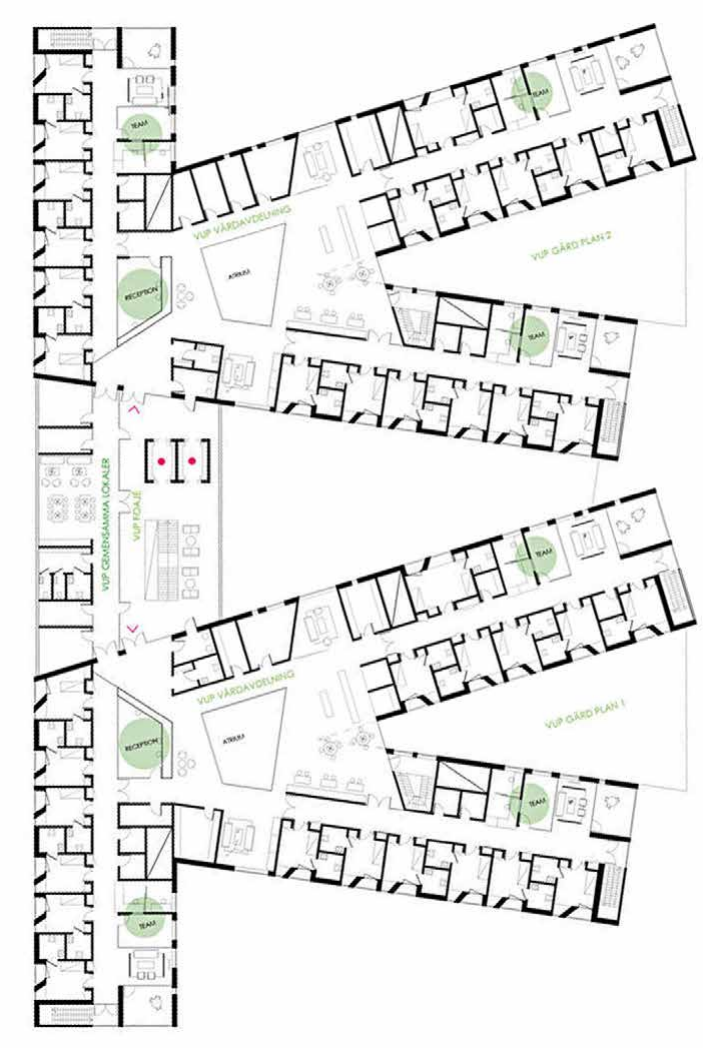

Figure 10: Psychiatric Unit of Boras third floor plan.

Figure 11: Psychiatric Unit of Boras interior rendering of patient room.
The design provides a range of spaces to accommodate private solitude and contemplation to large spaces for group events, "the patient is free to choose solitude or community, from sitting in the small living room to socializing in the ward's large dining room." Spaces for family members and staff are also incorporated into each ward since both staff and family attitudes and participation can directly affect wellbeing and behaviour.

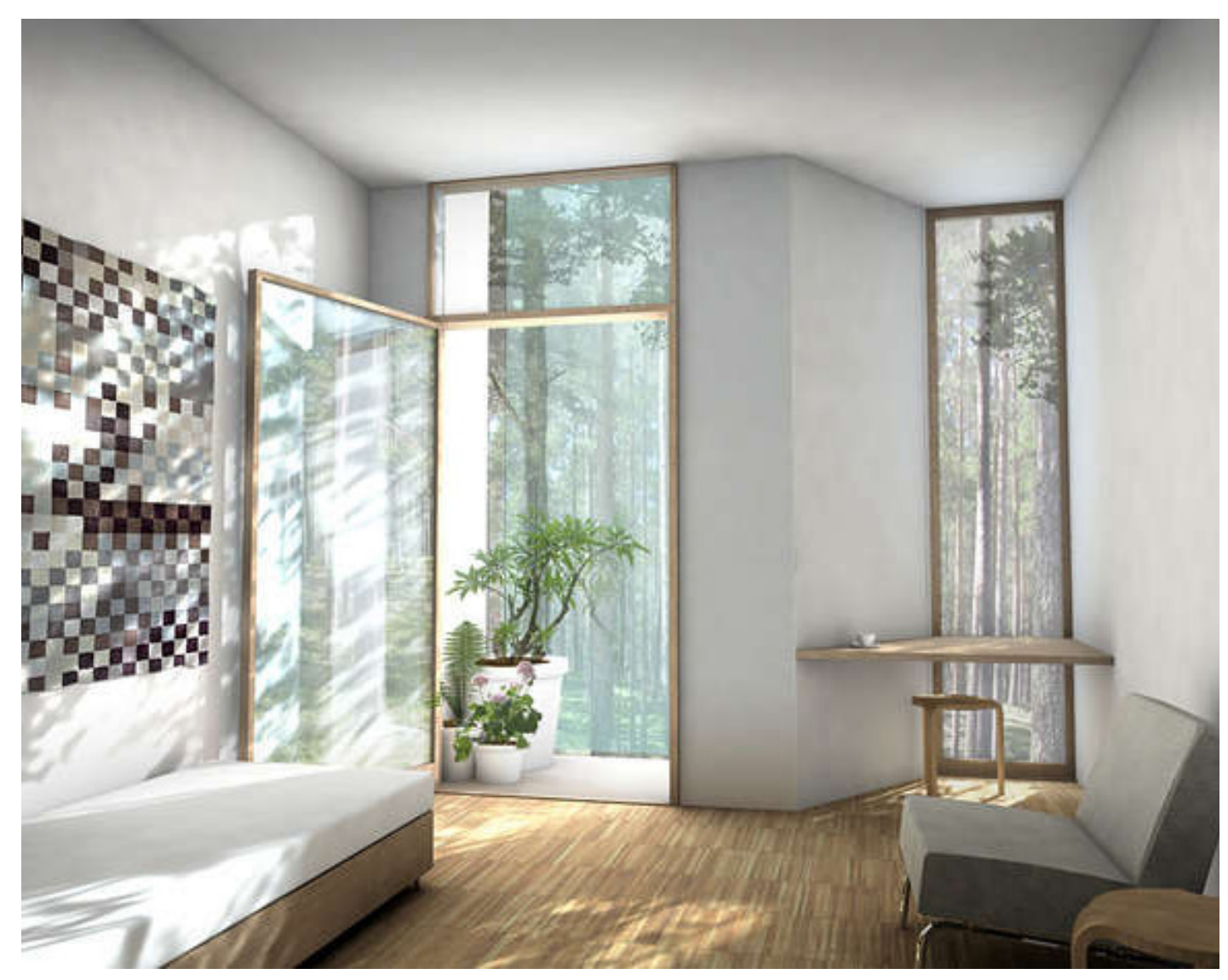


To enhance the positive healing effect of natural daylighting and nature within the interior spaces,

" the building is designed and orientated to take maximum advantage of this. The courtyards are directed toward the east: here the morning sun filtrates through the silent and calm pine forest" (Fig.12). ${ }^{63}$

Although the building is still in the design progress, the approach and ideas presented by White arkitekter $\mathrm{AB}$ advance the design of psychiatric facilities in a promising and contemporary way that are potentially beneficial to the physical and psychological needs of future patients. The proposed plan has already received positive attention within the design community and has won the WAN Healthcare Award for 2013. 


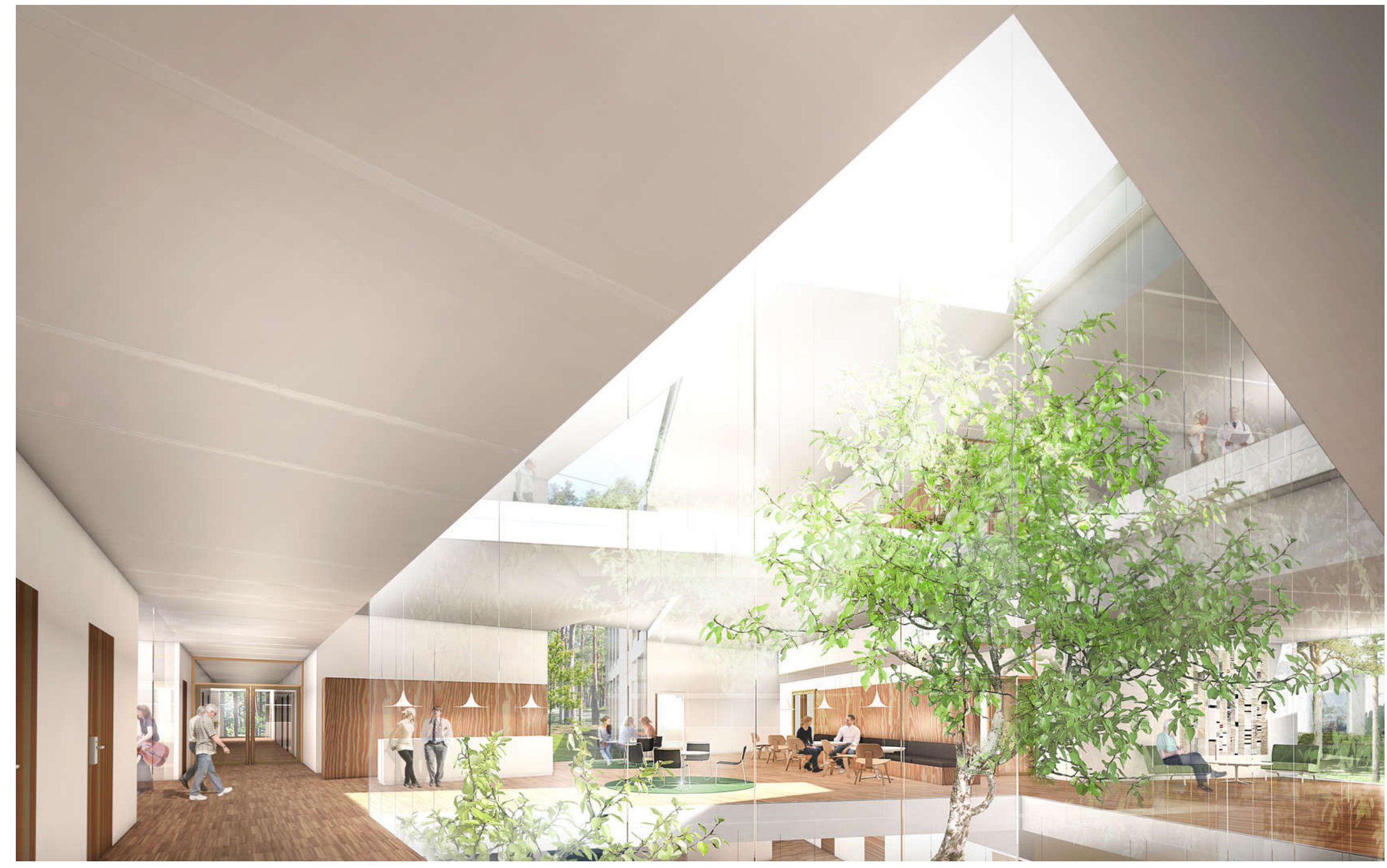

Figure 12: Psychiatric Unit of Boras rendering of interior courtyards. 


\section{YPARC Step-Up / Step-Down Facilities - Australia}

In Australia, The Youth Prevention and Recovery Care program (YPARC) represents a new type of community care called step-up / step down care. It provides a 'step up' option for young people at risk of an acute hospitalization, as well as a 'step down' option to assist the early and seamless transition of young people re-entering the community following a hospitalization. ${ }^{64}$ The YPARC program includes three separate facilities in Frankston, Bendigo, and Dandenong, with each catering to 10 transitional youth between the ages of 16-25 with a moderate mental illness, in a safe and secure environment. The programs operate on a 24-hour, 7 days a week, fully staffed, short stay residential and limited day care support program with the average length of stay approximately 28 days. As stated by the YPARC eligibility criteria for admission, an individual must:

- Have a significant mental health problem or be at high risk and vulnerable, with functional impairment associated with emotional and behavioural problems, \& significant psychological distress

- Be able to receive treatment and support safely and effectively within a community based residential setting; and have been assessed by staff as being able to benefit from this type of care

- Not be at significant risk of harming themselves or others

- Agree not to use illicit substances or alcohol during their stay

- Voluntarily agree to participate in the program (including people on Community Treatment Orders). ${ }^{65}$ 


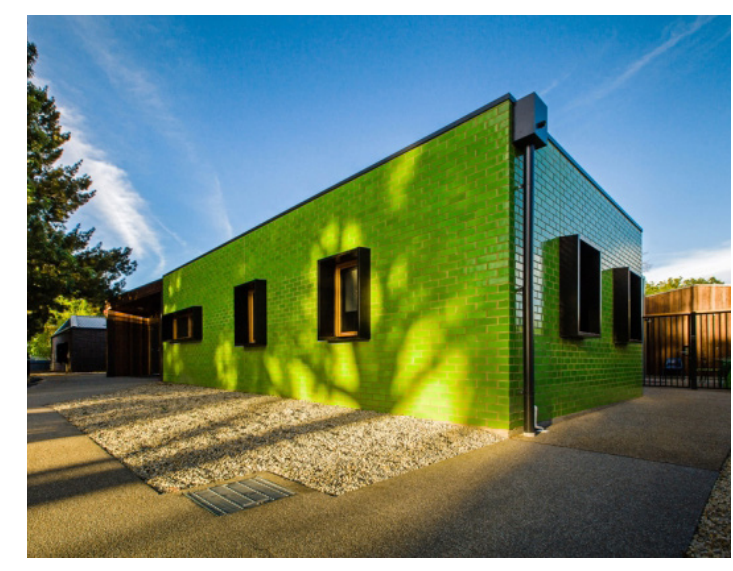

Figure 13: YPARC Bendigo, view of front facade and main patient entrance.
The following case study will examine one of the three facilities, the YPARC Bendigo Facility in Greater Bendigo, Victoria, Australia. ${ }^{66}$ In Bendigo, The YPARC Bendigo facility is located in Kennington, a residential suburb. This was the first of the three proposed facilities to be built. The facility is situated within a suburban area in a residential context to help integrate patients back into the community, by encouraging them to participate in social and community events. Surrounding the facility, the main type of building is residential and there are multiple parks and green spaces within close proximity. The building is well connected to existing public infrastructure including several major bus routes, the Bendigo airport, the Bendigo railway station, and several educational institutions including high schools and colleges. The Architects, Group GSA, utilize the term 'house' to describe buildings on the complex, which are broken into a number of elements to reduce its scale and mass alike to a series of houses. As described by Group GSA:

The key principle to its design is breaking down the notion of an "institutional facility" and promoting a sense of continuity with everyday life within the community. The design adopts the domestic home in form, scale and environment, to provide a reassuring and pleasant atmosphere, while maintaining, as a secondary function, the requirements for treatment and support - effectively becoming a large house and not a 10-bed mental health facility. The program is divided into four main clusters, three bedroom wings and administration staff wing, connected by the spine of the house which accommodates the circulation and communal living, dining and kitchen spaces. The clusters are reinforced through materiality with the use of different brick finish and colours. This presents as a series of smaller buildings along the streetscape and provides a common domestic language amongst the neighbouring residential properties. ${ }^{67}$ 


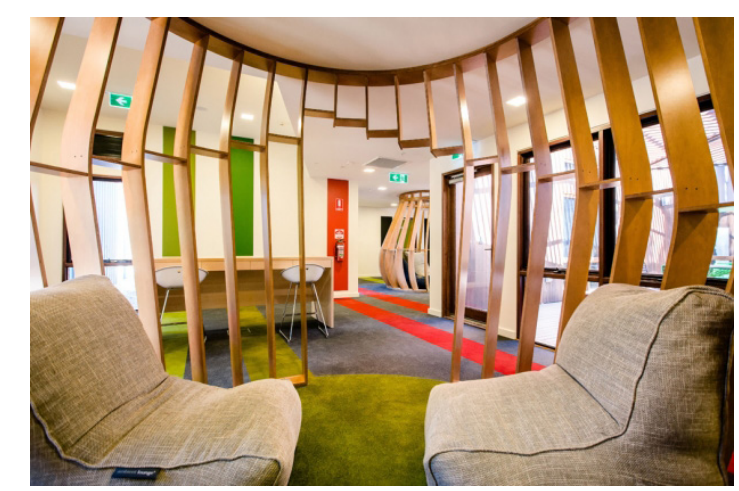

Figure 14: YPARC Bendigo, view of interior common areas.

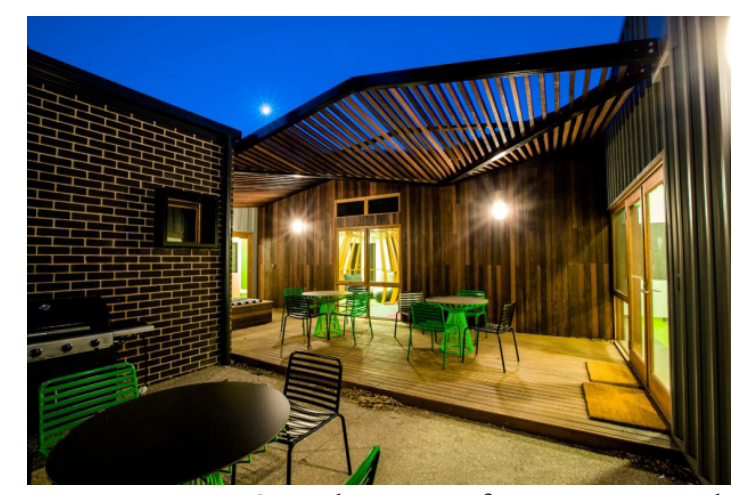

Figure 15: YPARC Bendigo, view of exterior courtyard.
The building provides two types of access from the street, one for patients and one for staff. The door for residents is recessed within the building façade to further reinforce the environment of the domestic house, empowering patients with the ability and independence to come and go as they please (Fig. 13).

The interiors were focused on the age of the residents and were designed to be youthful creating a vibrant and active atmosphere to encourage social activities and interactions. A mixture of spaces gives patients the choice to participate in social and communal activities or seek solitude. A quiet semi-private / semi-public zone was designed as a transition between each of the bedroom wings and common areas, allowing patients to remain within their comfort zone while being able to observe activities within the house (Fig. 14). Large windows allow for daylight to penetrate within the interior spaces and give patients access to exterior view, promoting well-being. An exterior communal courtyard provides access to nature and social spaces (Fig. 15). Aesthetically breaking the typical institutional stereotypes of mental health, a mixture of bright colors were used in all areas including each cluster of bedrooms to create a sense of identity and recognition of an individual's space. ${ }^{69}$ To further avoid an institutional setting they have avoided using handrails to ramps, signage, and other 'government' signals.

The YPARC Facility in Bendigo, represents a new type of community care that Canada is lacking for transitional youth suffering from mental illnesses. The non-institutional character of the exterior and interior promotes a positive image of mental illness that does not contribute to the negative stigmatization of those suffering from mental illness. The subsequent YPARC buildings in Franskton and Dandenong were then built upon the same principles promoted by YPARC Bendigo. 


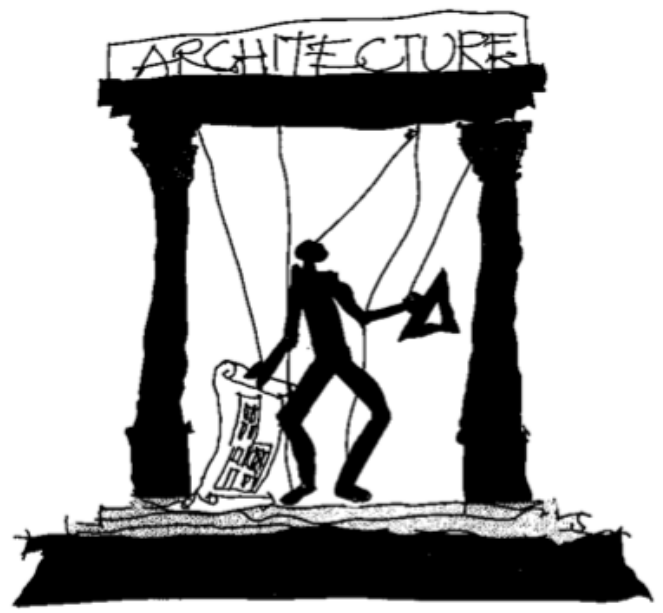

Figure 16: "We Make Architecture, But Architecture Makes Us." Marco Frascari (Eleven Exercises in the Art of Architectural Drawing)

\section{[ Part Two ]}

Architecture \& Neuroscience

The built environment in which we live sets an important backdrop to what we are and what we do, because we build architecture, but in return architecture builds us. ${ }^{70}$

- Marco Frascari (Eleven Exercises in the Art of Architectural Drawing)

Since we spend approximately ninety percent of our lives inside buildings, it is surprising that most people severely underrate the effect of architectural spaces on our emotional and physical well-being. Although social and behavioural research can provide evidence as to how humans react to certain environmental stimuli, it does not suggest why. We know that the built environment can change the way we feel and behave, but how does it generate these changes? Accumulating scientific research is beginning to reveal the science behind the relationship between the built environment and our bodies. With this knowledge starting to permeate through the field of architecture, how is it going to affect the discipline?

The following section examines neuroscience and architecture, including the emerging field of neuroarchitecture, recent developments and discoveries, and a concept explored by both neuroscience and neuroarchitecture: enriched environments. 


\section{The Emerging Field of Neuroarchitecture}

Historically, the disciple of architecture has heavily relied on theories and findings of other areas of research and knowledge. ${ }^{71}$ Unlike other disciplines such as philosophy, sociology, and psychology, when it comes to exploring and collaborating with neuroscience, the discipline of architecture has been much slower to take note of the dramatic scientific discoveries. Recently in 2003, San Diego architect Alison Whitelaw conceived The Academy of Neuroscience for Architecture (ANFA) which was founded by the San Diego Chapter of the American Institute for Architects to establish a connection between architecture and neuroscience. The beginnings of ANFA started with Jonas Salk, an immunologist and virologist, when he decided to take a sabbatical from his search for a polio vaccine due to frustration. He traveled to Italy and stayed in the famous St. Francis Abbey, where he claimed to be so greatly inspired by the beauty of the architecture that he experienced a moment of clarity that lead to the development of the polio vaccine. Salk then returned and advocated for collaboration between architects and neuroscientists to explore the power of architecture to enrich the human experience. ${ }^{72} \mathrm{~A}$ decade later ANFA was formed and over the past ten years they have initiated numerous research projects and collaborations contributing to the beginnings of neuroarchitecture.

The emerging field has not been without criticism as John Eberhard, a founding president of ANFA, wrote in his book Brain Landscape: The Co-Existence of Neuroscience and Architecture (2008), "It is not easy, in fact almost impossible, to introduce new knowledge into a large institutional setting that is seen by its leaders as already well suited to its goals". ${ }^{73}$ As an up- 
and-coming area of study, neuroarchitecture is subject to criticism due to all the failed 'ism's' of recent architecture. Yet, is the collaboration of architecture and neuroscience truly another ism? An objective of neuroarchitecture is to better understand whom the architect is designing for - who we are as humans, our biological workings - and designing for human needs, desires, and imagination.

Although the study of neurological reactions within the built environment is new, the creation of spaces to deliberately elicit specific feelings and behaviours from its inhabitants is not a new concept. Retail stores, churches, and government buildings have all utilized principles to orchestrate spaces that produce feelings of class, power, or inferiority, or to even disorient and reorient visitors. ${ }^{75}$

Understanding the relationship between the built environment and neuroscience, although in its infancy, is anticipated to one-day help architects design buildings that support both body and mind. Incorporating this knowledge into design has already proved to be useful in fields such as education, work environments, and healthcare. Changes to design based on a better understanding of our body and mind are producing beneficial effects, such as improvements in healing in health care facilities, learning capabilities in schools, and productivity in offices. ${ }^{76}$ As Marco Frascari said, "The neurological union of body and mind within the built environment is the real project of architecture." 77 The influence of neuroscience on architecture, which some believe will reduce architecture to a set of standards and guidelines, is in fact helping us better understand the complexity of our psychological and physical needs, as Harry Mallgrave pointed out in his book The Architect's Brain: Neuroscience, Creativity, and Architecture (2010): 
None of this is not to suggest a formulaic system for design or an attempt to narrow the field of technological innovation or design invention. In fact, the opposite is the case, because the brain, as science is now demonstrating, demands both novelty and highly varied environments. But if we accept the brain's propensity toward ambiguity and metaphors of life, and indeed the sensory-emotive grounding for these phenomena, then there remains for the architect a wide field of play - values that, in recent years, have been shunted aside by high minded abstractions and abject formalism. ${ }^{78}$

As Mallgrave suggests, the recent emphasis on form is prohibiting a beneficial environment that fosters mental health. Frequently, architects striving for originality, increasing efficiencies in building technology, commodification, and materialism, have produced bizarre forms resulting in obscured spatial, physical, and psychological needs. On the other hand, spaces designed with a deeper knowledge of our biological and neurological workings, could produce a beneficial environment that takes into account the meaningful relationship and interactions between humans and the environment. Neuroarchitecture offers a theoretical approach to the application of the emerging scientific data from neuroscience to the discipline of architecture. 


\section{ii. Developments and Discoveries in Neuroscience}

Within the past seventy years, giant strides in neuroscientific research brought major insight into the central nervous system making it possible to explain phenomena previously not understood, as well as completely new phenomena unknown until their discovery. Insight into the human brain has also opened up exploration of issues such as memory, consciousness, emotions, and perceptions, which have been questioned and theorized over thousands of years. The discipline is anticipated to make even more discoveries with the evolving use of sophisticated imaging and recording devices such as the functional magnetic resonance imaging (fMRI), computed tomography (CT scans), positron emission tomography, electroencephalography (EEG), magnetoencephalography (MEG), and near infrared spectroscopy (NIRS). Of the numerous discoveries and explanations, some have emerged concerning the relationship between the mind, body, and built environment. These include the science behind qualities of healing spaces, the discovery of place and grid cells, neuroplasticity, and enriched environments.

\section{Place Cells and Grid Cells}

In 2014, the Noble Prize of Physiology for Medicine went to John O'Keefe, and the team of May-Britt Moser and Edvard I Moser for "their discoveries of cells that constitute a positioning system in the brain". In 1971, O'Keefe first discovered the first component to this "internal GPS" system within our brains in a study involving rats. Using electrodes placed on the hippocampus he was able to see certain groups of nerve cells that would be activated when the rat was in one position of the room, and following a change in position other nerve cells were activated (Fig. 


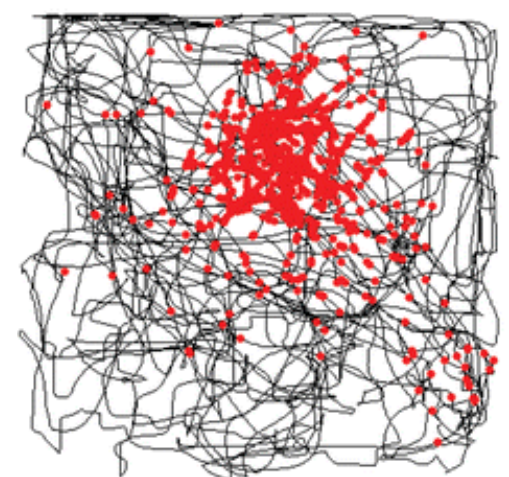

Figure 17: A place cell fires in one place in a square box

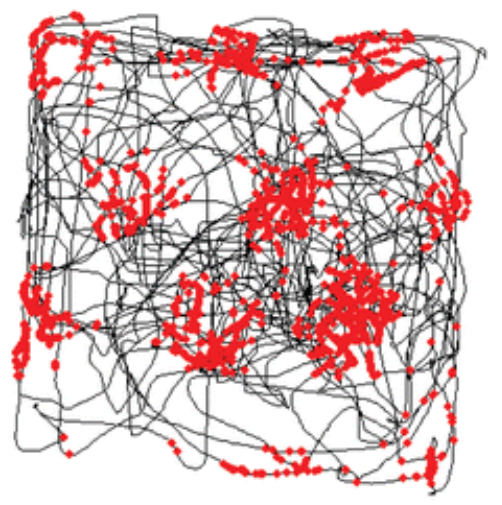

Figure 18: A grid cell fires in evenly spaced peaks all over a box.
17). O'Keefe concluded that these parahippocampal place cells made it possible to assemble information and create a multisensory image of where you are in space. ${ }^{79}$

To build upon John O'Keefe's discovery, in 2005, May-Britt Moser and Edvard I Moser discovered another crucial component to the internal GPS system. Grid Cells - nerve cells located in the entorhinal cortex - allow for spatial navigation. The study involving rats and other mammalian animals showed that as an animal navigated through space certain nerve cells would activate. The resulting pattern of activated nerve cells formed a hexagonal grid (Fig. 18). In connection with place cells, the grid cells create a circuitry that forms a comprehensive positioning system. ${ }^{80}$ Their discoveries have helped answer troubling questions of how our brain is able to navigate and position us within a space giving a sense of place.

\section{Neuroplasticity}

Neuroplasticity in adults is one of the most notable discoveries in the history of neuroscience. It was previously established that the brain underwent significant changes during childhood development. At birth, our brains have approximately one hundred billion neurons with approximately fifty trillion connections called synapses. As the brain develops, neurons mature and neural connections are created, strengthened, or even discarded. By the time a child reaches the age of three, they will have produced approximately one thousand trillion synapses, however only five hundred of the connections will survive due to the normal developmental process called synaptic pruning. The survival of synapses is use-dependent. As explained by John Eberhard, "synapses depend on external stimuli and synaptic firing under the influence of new types of 


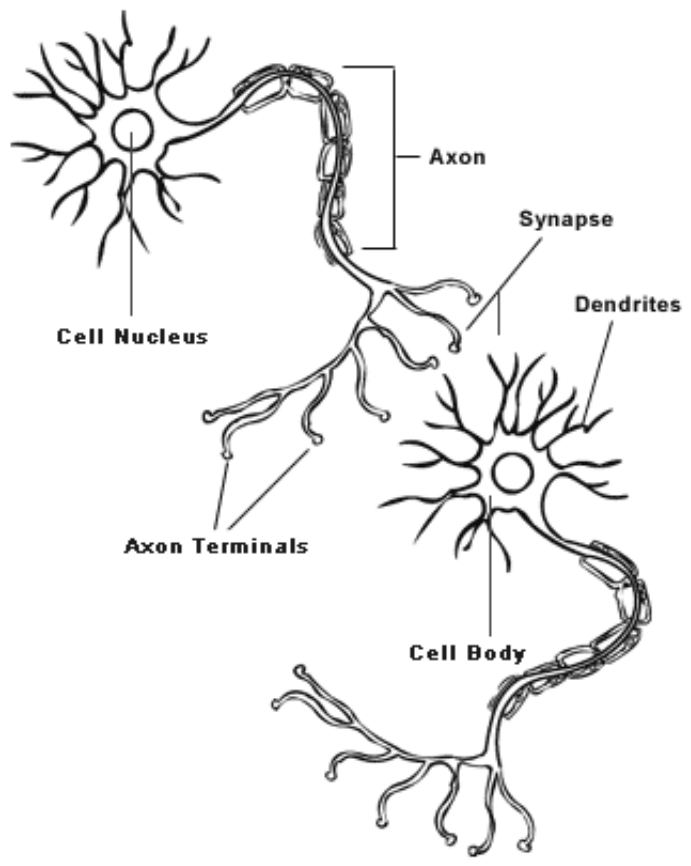

Figure 19: Diagram of neuron structure and connection. stimuli lead to synapse formation and neuronal survival", meaning that connections that are infrequently used will be terminated. ${ }^{81}$

This principle was then proven within adults and shattered the previous belief that the brain was an immutable organ incapable of change in adulthood. American psychologist and philosopher William James was the first to use the term plasticity in his book Principles of Psychology (1890). He was the first to theorize the brains capability of reorganizing itself. Neuroplasticity is now defined as, "changes in neural organization which may account for various forms of behavioral modifiability, either short-lasting or enduring, including maturation, adaptation to a mutable environment, specific and unspecific kinds of learning, and compensatory adjustments in response to functional losses from aging or brain damage." $\$ 2$

Since then, studies have proven not only is the brain capable of structural change in adulthood, but also that these changes can be stimulated by the environment. A study in 1960 by neurochemist Edward L. Bennett, neuroanatomist Marian C. Diamond, biological psychologists David Krech and Mark R. Rosenzweig, revealed that certain environments lead to measurable changes in the brain's neurochemistry and neuroanatomy, such as the size and density of neurons, and dendritic branching and spine density. ${ }^{83}$ However, it wasn't until 1989 that a study by York, Breedlove, Diamond, discovered that enriched environments stimulated the process of neurogenesis, the formation of new neurons. ${ }^{84}$ A neuron is the primary working cell of the brain that uses electric and chemical signals to transmit information to one another governing everything that we do from breathing to sleeping, feeling and thinking (Fig. 19). 


\section{Enriched Environments}

A concept explored by both neuroarchitecture and neuroscience are enriched environments. Since the unique languages from each discipline often distance the two fields, the concept of an "enriched environment" embrace slightly different meanings, yet explore and question the built environments influence on an individual. The following section examines the definition of the term from the understanding of each discipline.

\section{i. Explained by Neuroscience}

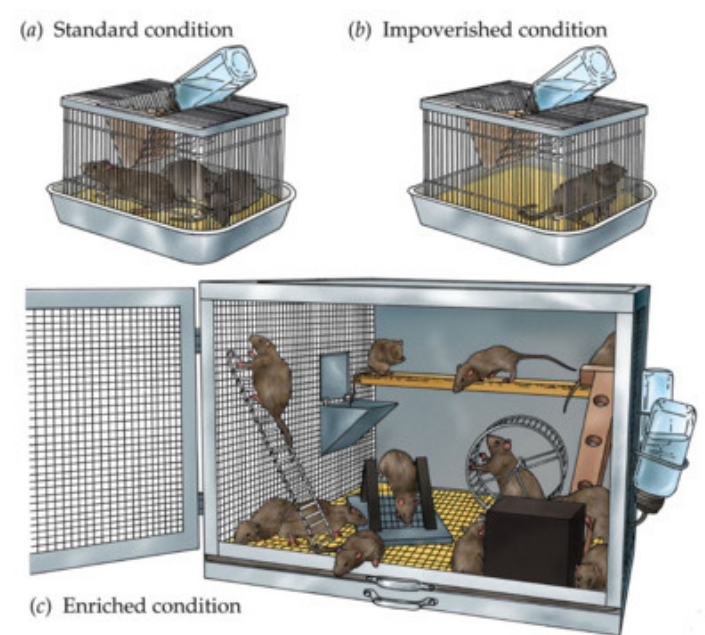

Figure 20: Diagram of typical Standard (a), Impoverished (b), and Enriched (c) housings for research studies.
In neuroscience, an enriched environment is the stimulation of the brain by a combination of complex social and inanimate interaction. As mentioned earlier, initial studies on mice and rats determined that certain environments could lead to measurable changes in the brain such as changes in nerve cells and neurotransmitters, with further studies confirming evidence of neurogenesis. Additional studies explored varying critical variables such as age, length of exposure, and type of animal. The basic principle of structural change within the brain through enriched environments has not only been proven in animals such as mice, rats, cats, monkeys, but also in a few experiments using human brain tissue (Jacobs et al. 1993 and Eriksson et al. 1998). ${ }^{85}$

The premise of enriched environment studies involve the examination and comparison of the brain structure of an impoverished test group(s) versus, standard test group(s) and enriched test group $(s)$ - some studies include additional categories such as social test group(s), and exercise 
test group(s) (Fig. 20). In the original experiment by Krech et al., (1960), all test groups were given free access food and water, and had the same lighting conditions. The impoverished test group placed the animal alone within a small cage $(20 \times 20 \times 32 \mathrm{~cm})$. The standard test group placed three animals within a small cage $(20 \times 20 \times 32 \mathrm{~cm})$. The enriched test group placed twelve animals within a large cage $(70 \times 70 \times 46 \mathrm{~cm})$ and were given 5-6 objects to explore and climb, which were changed two to three times a week. Following a thirty-day period the animal's brains were dissected analyzed, the enriched test group had a larger cortex and heavier brain weight than the standard group, whereas the size of the cortex and weight of the impoverished group decreased in comparison to the standard test group. ${ }^{86}$ The study concluded that the main features of an enriched environment were friends (social interaction), and toys (play). The frequent replacement of toys provided newness and challenge to the animals and was also deemed a critical component to an enriched environment.

Generally, in subsequent experiments, an enriched environment provides animals with larger cages and the opportunity for complex social interaction. The environment houses complex and varied objects such as tunnels, nesting material, toys, and running wheels that are changed frequently. No single contributing factor has been isolated for causing these neural changes from an enriched environment- is it rather the complex interaction of all essential elements. ${ }^{87}$ Effects of enriched environments have included improvement in learning and memory capabilities, and motor skills. ${ }^{88}$ Additional effects that remain under debate include the reduction and prevention of stress. ${ }^{89}$ 


\section{Neurogenesis \& Mental Disorders}

\section{Enriched Environments}

The stimulation of the brain by complex social and inanimate interaction.

1

1

\section{Neurogenesis}

The formation of new neurons within the hippocampus.

$\downarrow$

\section{Improved Mental}

\section{Health \& Well-being}

Normalize dysregulated hippocampal structure and function.

Figure 21: Diagram showing the potential connection between enriched environments and mental disorders.
It is quite possible that a connection between the built environment and mental health / illness lies within these studies on neuroplasticity and neurogenesis since, "mental health is a precarious state that may easily be altered in the direction of illness by a great variety of experiences many of which are influenced by structured space." ${ }^{\text {90 }}$ Research by the Department of Psychiatry, University of Texas Southwestern Medical Center (UTSMC), has recognized hippocampal neurogenesis playing potential role within the complex treatment of psychiatric and neurological disorders such as addiction, depression, epilepsy, and schizophrenia.

Hippocampal structure and function are often dysregulated in the brains of patients with schizophrenia, addiction, epilepsy, and mood disorders. Studies have shown that hippocampal neurogenesis often normalize these hippocampal functions within animal models. ${ }^{91}$ Additionally, the hippocampus is greatly involved in mood regulation, memory, and can have great influence over the reward pathway of the brain. However it is noted within a 2008 study by UTSMC entitled Adult Neurogenesis, Mental Health, and Mental Illness: Hope or Hype? that, "although current findings in the field suggest that adult hippocampal neurogenesis is not a sole cause of these illnesses or the sole mechanism of treatment efficacy, it is likely an important contributor to these complex disorders." ${ }^{\prime 2}$ It is wise to acknowledge the ever growing and changing knowledge and literature on the central system and mental disorders - what may be proven today could be disproved tomorrow. However, it is constant testing, criticizing, and theorizing such as this that has lead to some of the most notable discoveries in science. 


\section{ii. Explained by Neuroarchitecture}

While the brain controls our behavior and genes control the blueprint for the design and structure of the brain, the environment can modulate the function of genes and, ultimately, the structure of our brain, and therefore they change our behavior. In planning the environments in which we live, architectural design changes our brain and behavior. ${ }^{93}$

- Fred Gage, Neuroscientist

Despite similarities between the brain's of animals and humans, what constitutes an enriched environment that produces neural changes may be harder to discern for humans. The current impossibility of creating controlled experimental environments for ethical and plausible reasons - the diversity and complexity of human experience - prohibits researchers from designing experiences comparable to those used with animals. ${ }^{94}$ Yet in neuroscience, models are often proven with animals and cannot be fully tested on humans. This leads researchers to theorize the implications on humans. Although the scientific term "enriched environment" is not specifically used, proponents in neuroarchitecture, including John Eberhard, Harry Mallgrave, Juhani Pallasmaa, and Marco Frascari, all theorize the implications of the built environment on the mind and body in relation to emerging neuroscientific research, and explore the need for an architecture that enriches the human condition - an architecture that supports the mental realm.

As Frascari explores in De Beata Architectura, Places for Thinking (2012), "Contemporary architecture has generated an incredible number of places for activities such as entertaining, 


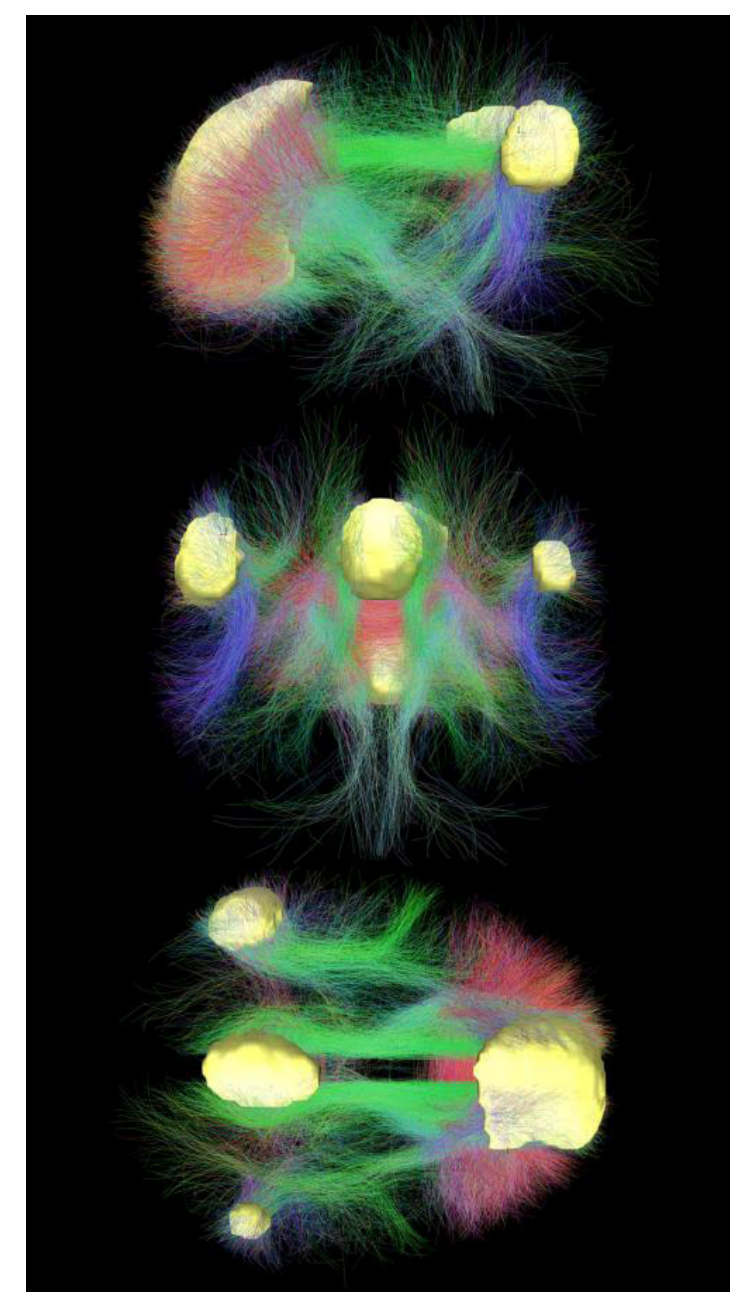

Figure 22: A daydreaming brain: the yellow areas depict the default mode network from three different perspectives; the coloured fibers show the connections amongst each other and with the remainder of the brain. preparing and serving food, sleeping, working, shopping, and playing sports. However, just a few places are dedicated to "thinking." Only the presence of places, which allow thinking can make a vita beata (a good life) possible. In such places, the quest for happiness and wonder take place."95 The built environment is not only a place to house thinking, but it can stimulate and arouse our minds - it can generate thinking, imagining, and daydreaming.

Daydreaming, metaphorically known as having one's head in the clouds, has recently been identified as an essential cognitive tool, one that facilitates creativity. Neuroscientists at the Max Planck Institute for Human Development in collaboration with the Free University of Berlin and the University Hospital Freiburg have recorded through brain imaging the specific brain structures that are activated during daydreaming known as the "default network". When active this network, consisting of the frontal cortex, limbic, system, and several cortical areas associated with sensory experiences, can generate its own stimulation called "stimulus independent thought" - a thought about something other than events that originate from the outside environment. ${ }^{96}$ This allows the mind to explore our unconscious, our own associations, contemplating counterfactuals and fictive scenarios that only exist within the head. ${ }^{97}$ Like conscious thinking, the built environment is a crucial tool to generate unconscious thinking. As Gaston Bachelard wrote within The Poetics of Space (1996), “... if I were asked to name the chief benefit of the house, I should say: the house shelters day-dreaming, the house protects the dreamer, the house allows one to dream in peace," and goes on to say, "And always, in our daydreams, the house is a large cradle."

The following section examines qualities that support the mental realm of thinking, imagining, and daydreaming: perceptual richness, ambiguity, metaphor and story telling. 


\section{Perceptual Richness}

In built space, our bodies undergo continuous reactions between input - sensing the space around us, processing - relaying the information to our brain, and output - a reaction. These reactions can be short-term such as an emotion or behaviour, or eventually become long lasting effects such as influencing well-being or personality formation. ${ }^{99}$ Space itself can only be sensed that is perceived. Everything that forms a space including materials, textures, smells, structures, sounds, and spatial arrangements, creates information that is captured by the body through our skin, eyes, ears, nose, and mouth, and then travels to the brain to be processed. On the contrary to previous belief that the brain worked in a linear fashion, - analogous to a computer - incoming information is processed in parallel networks. Each perception (an interpretation of sensory information), "is constructed through the "parallel processing" of assemblies of neurons in distinct cortical areas, that is, along highly selective neural pathways that relay information in a fraction of a second." ${ }^{100}$ Each circuit is highly specialized to which stimulation they respond to; meaning that certain circuits respond only to specific colors, forms, smells, sounds, and even types of lines. ${ }^{101}$ As discussed earlier, depending on how often they are utilized, neural circuits and synaptic networks will either become strengthened and form new connections, or weakened and dissolve - this plasticity through experience allows us to enrich our cortical maps with knowledge, memories, and creative associations, and enhance the brain's neural complexity. ${ }^{102}$ A space that engages multiple senses could therefore strengthen multiple neural circuits and cortical maps. 
Yet, the world around us, including built space, is dominated by the visual sense over all other senses. This has been deemed the ocularcentrism of our culture. As Pallasmaa points out, "The inhumanity of contemporary architecture and cities can be understood as a consequence of the neglect of the body and the senses, and an imbalance in our sensory system." ${ }^{103}$ Complex, highly varied and perceptually rich architecture places the whole body within the space at the locus of experience. It offers the ability for the body to move through a physical space and create relationships through touching, smelling, hearing, tasting, and seeing, creating a multi-sensory, highly varied and complex experience. This can be made possible through the tectonic play of materiality, hapticity, texture, shape, light, shadow, acoustics, and movement.

An architecture that is complex, highly varied, and engages all the senses "...strengthens the existential experience, one's sense of being in this world, and this is essentially a strengthened experience of self." ${ }^{104}$ As Harry Mallgrave explains, "If neurological research says anything about this issue it suggests the need for a discrete and highly varied environment: culturally, materially, and expressively. When faced with habituation (the replication of the same stimuli or materials over and over), the brain simply shuts down." ${ }^{105}$ He goes on to also state that a monotone environment will degrade the human condition. Yet, in contradiction to this, many psychiatric facilities emphasize safety over perceptual richness and sensory experience resulting in baron monotone environments. 


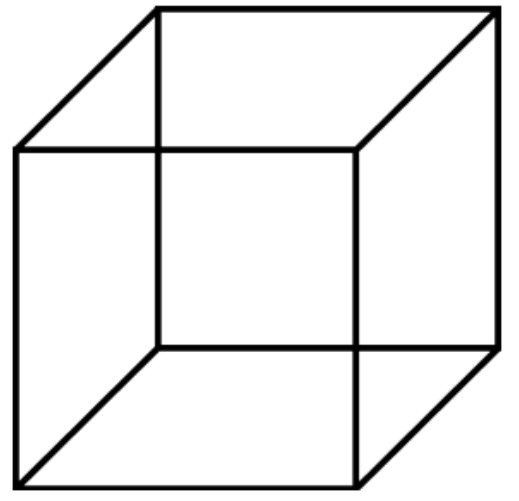

Figure 23: Simple cube diagram demonstrating the ability to have multiple truths. All the lines could be in the same plane, or the viewer could be looking at the top or bottom face of a three dimensional cube.

\section{Ambiguity}

Semir Zeki, a neuroscientist and professor of neuroesthetics, has shown the brain's propensity towards ambiguity. Zeki neurobiologically defines ambiguity as, "the opposite of the dictionary definition; it is not uncertainty, but certainty-the certainty of many, equally plausible interpretations, each one of which is sovereign when it occupies the conscious stage". ${ }^{106}$ Ambiguity therefore challenges the brain to interpret multiple meanings (Fig.23). As Harry Mallgrave explains:

What Zeki seems to be touching upon here is the fact that the brain, in its everyday activities, canvases the world, rapidly constructs and organizes its images, and with its highly organized propensity for structural patterns, expends little or no cognitive energy on easily categorized or familiar events. Such viewing, as we often complain, is tedious. Yet art, in exploiting the brain's biological quest for knowledge about the world, offers something different. It invokes something less familiar, something that forces the brain to pause, engage multiple areas, and reflect upon the new phenomenon it encounters... This psychological need is in fact grounded in the brain's biological necessity to enrich or enhance its neural efficiency - new trains of thought are in fact the formation of new synaptic growth. ${ }^{107}$

Complex ambiguity is when the brain is presented with several plausible meanings. One of the examples used by Zeki in his paper, The Neurology of Ambiguity, to demonstrate such ambiguity is the Girl with the Pearl Earing (1632-75), "she is at once inviting, yet distant, erotically charged but chaste, resentful and yet pleased. These interpretations must all involve memory and experience, 
of what a face that is expressing these sentiments would look like." 108 Therefore, when challenged by complex ambiguity, multiple parts of the brain including the memory systems are engaged, and can influence what is perceived at any given moment.

Just like our perceptions of art, our perceptions of built space are connected to our consciousness and unconsciousness, where memory systems - the hippocampus, amygdala, thalamus, hypothalamus, peripheral cortex and temporal cortex - are linked to incoming sensory information and produce emotions, feelings, and meanings. Each individual's past experiences will influence the perceptual experience at the moment, and therefore since no one has the exact same memories the experience, response, and meaning will be unique to the individual. In architecture, complex ambiguity is possible when a building can generate multiple interpretations according to which it symbolizes or refers to different things. Juhani Pallasmaa implies a visual ambiguity in architecture within his notion of focused and unfocused (peripheral) vision. The current emphasis on vision and conscious intentionality gives us architecture with clear, fixed, and static meanings. Peripheral vision, forms a painterly image with a multiplicity of meanings and perspectives, and engages the mental realm of imagination. ${ }^{109}$ 


\title{
Metaphor \& Story Telling
}

\author{
The timeless task of architecture is to create embodied and lived existential \\ metaphors that concretise and structure our being in the world. ${ }^{110}$ \\ - Juhani Pallasmaa (The Eyes of The Skin)
}

Just like ambiguity, the metaphor allows us to express two truths at the same time, for instance the human body as a metaphor for architecture, and architecture as a metaphor for the human body. ${ }^{111}$ The metaphor, commonly associated with language and literary use, is a multimodal tool that can evoke deep and unconscious cognition. "Metaphor is primarily a form of cognition rather than a trope or figure of speech. Further, metaphor as a cognitive tool can operate unconsciously, so that a metaphoric process is one aspect of the unconscious mind." ${ }^{112}$ In the built environment, the embodied metaphor is a method of non-verbal story telling, which is the neurological core of consciousness. ${ }^{113}$ Marco Frascari believes that in order to make real places for thinking, architects must rediscover the lost art of story telling, "architectural storytelling is not a unitary project, but rather a plurality of understandings, probably contradictory, but it is a free-for-all source of contesting interpretations. It is a cosmopoiesis, a world-making where this is no neutral space between interpretations within which a confrontation can be conducted. There are no impartial criteria to arbitrate interpretations." ${ }^{114}$

This need for storytelling is supported by the theory of dual modes of cognitive processing. Neuroscientists and psychologists alike have revealed that our brain has two modes of thought. 
As explained by psychologist Jerome Bruner in Actual Minds, Possible Worlds (1986), "One mode, the paradigmatic or logico-scientific one, attempts to fulfill the ideal of a formal, mathematical system of description and explanation. It employs categorization or conceptualization and the operation by which categories are established, instantiated, idealized, and related one to the other to form a system." 115 This mode searches for general causes and for empirical truth. The narrative mode on the other hand understands "good stories, gripping drama, believable (though not necessarily "true") historical accounts. It deals in human or human-like intention and action and the vicissitudes and consequences that mark their course. It strives to put its timeless miracles into the particulars of experience, and to locate the experience in time and place." ${ }^{116}$ Therefore, one mode searches for factual sensible information, whereas another part searches for narrative and sensorial meaning. ${ }^{117}$

The age of technology is producing dramatic biological discoveries, but are we in fact neglecting this information and hindering ourselves by producing a commodity, not architecture? What does this mean for the human condition? Perhaps today we can see ourselves among an impoverished test group - isolated and disconnected from each other and our own senses. An enriched architecture places the human at the centre of design and utilizes neuroarchitectural theory supported by biological evidence and understanding to enhance the human condition. 


\section{[ Part Three ]}

The Project: A Treatment Centre for Transitional Youth

This thesis has explored the design of healing and enriched environments and their effects on well-being both physically and psychologically. To apply this research, the following part focuses on the design proposal for a step-up step-down residential facility for the growing number of transitional youth with mental illness in Ottawa. This emerging type of facility can provide an intermediate step between outpatient community care and inpatient acute care hospitalization.

Currently, step-up/step-down facilities do not exist within Ottawa. Various long-term residential programs - length of stay on average three years - for transitional youth with mental illness exist, such as Ottawa Salus, the Ottawa Mental Housing Association, and the Housing First Project. However, only two facilities are specifically dedicated to transitional youth. The Royal Ottawa also offers a Residential Recovery Program for "people with functional deficits caused by prolonged illness and long hospitalizations" for persons of all ages, with the average length of stay of six months. ${ }^{118}$

The design approach will be based upon four guiding principles to offer an architectural approach towards the design of an enriched place for living and thinking - an architecture that enriches the quality of life and wellbeing for residents, and places the resident at the centre of design: 
Principle 1. Embed the facility within the existing urban fabric to promote awareness of mental illness, attempt to minimize stigmatization, and encourage residents to engage with people and activities within the community.

Principle 2. Provide a program that supports a seamless transition between phases of mental states - from mental illness to mental health.

Principle 3. Incorporate known features of healing environments that contribute positively to a resident's well-being, both physically and psychologically.

Principle 4. Incorporate features of enriched environments from both the perspective of neuroscience and neuroarchitecture.

As explored in Part Two, there are two modes of thought: the logico-scientific mode, and the narrative mode. The two modes are complementary - used together they form a rich diversity of thought. For this reason the following part provides both pragmatic details of the project, while also capturing the narrative mode of thought through a multiple perspective narrative in a section called A Storytelling: A Walk in Their Shoes. The story is not concerned with facts or truths, but rather experience. 


\section{Site Analysis}

Principle 1. Embed the facility within the existing urban fabric to promote awareness of mental illness, attempt to minimize stigmatization, and encourage residents to engage with people and activities within the community.

As mentioned earlier, the location of the site for a psychiatric facility influences its relationship and image to society and also the patients. Placing the proposed facility within a residential context will not only help in breaking down the notion of a stigmatized and isolated institutional facility, it will also help integrate patients back into the community. In turn, the facility becomes an integrated part of the neighborhood and society.

The selection of the site was based upon an analysis of the existing psychiatric services for youth within Ottawa including psychiatric hospitals, general hospitals with psychiatric wards, psychiatric services, and community centers offering outpatient services (Fig.24). Further analysis identified areas that lacked psychiatric services for youth that were also heavily populated with high schools, universities, and colleges. Selecting a site close to existing educational institutions for transitional youth is critical in order for the youth to access care within a familiar community. One residential area demonstrating such criteria contained the Adult High School, Carleton University, St. Pius X High School, and Brookfield High School, and thus became a starting point for site selection. 


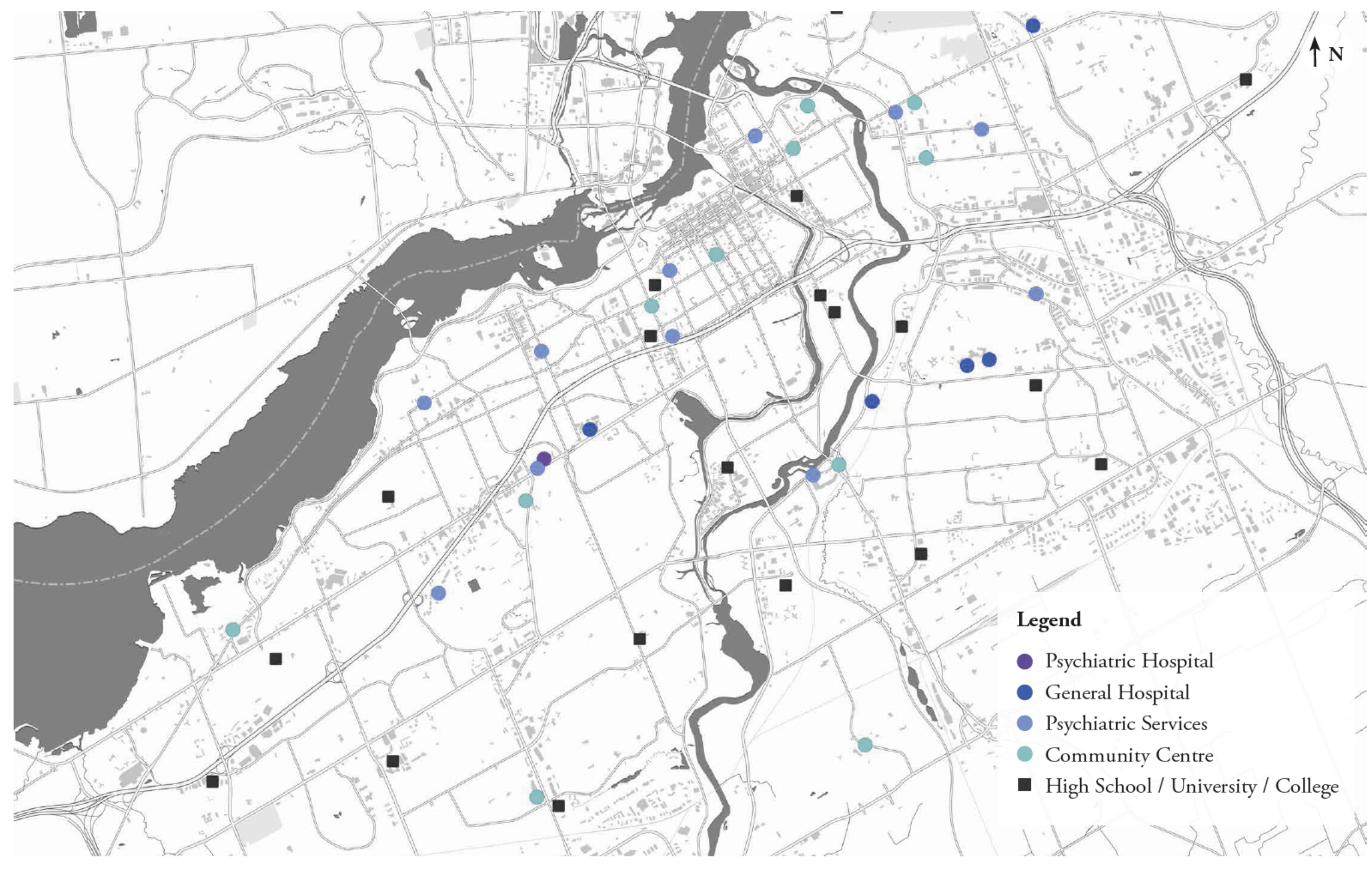

Figure 24: Map of existing psychiatric services and educational institutions for transitional youth in Ottawa. 


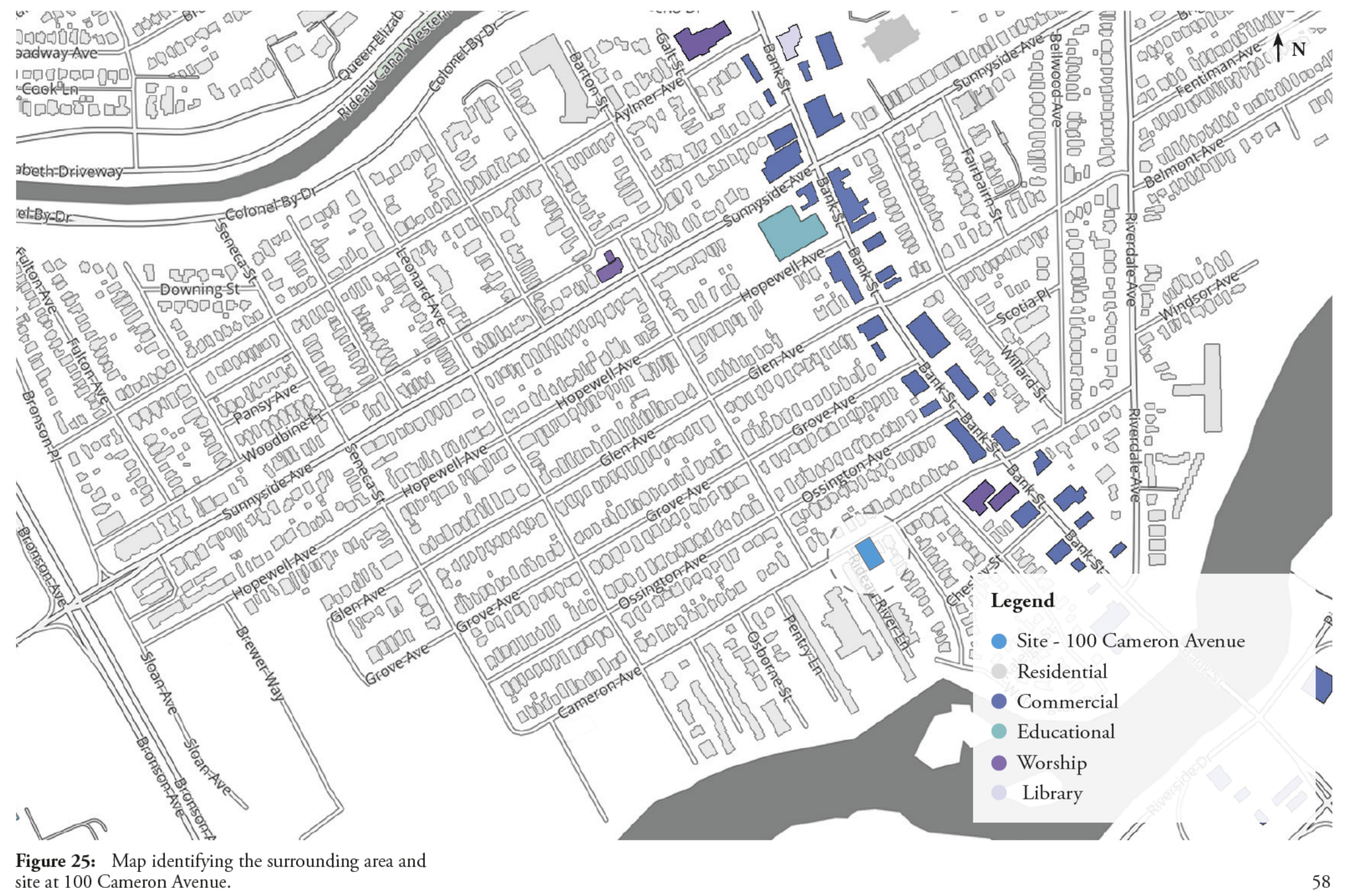




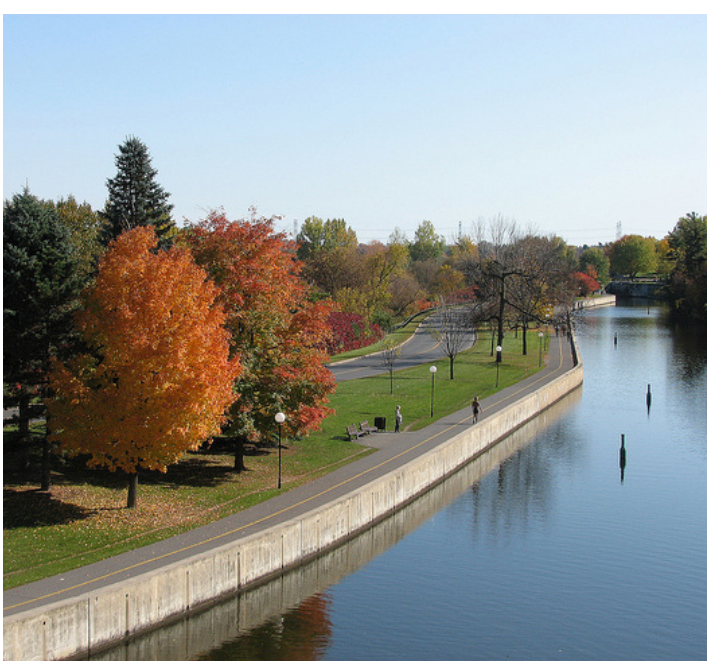

Figure 26: World Heritage Site: The Rideau Canal during the fall.
The area examined is the vibrant residential community of Old Ottawa South. The boundaries of the community are defined by The Rideau Canal, a World Heritage Site, to the North, the Rideau River to the East and South, and Bronson Avenue to the west. Old Ottawa South is a residential area that hosts a variety of housing types, from single-family dwellings to multi-unit housing in a mix of traditional and modern contemporary styles (Fig. 25).

Within and surrounding the area exists several beautiful parks and green spaces including Brewer Park, Windsor Park, and one of Ottawa's main attractions, Landsdowne Park. The newly redeveloped urban park offers mixed-use residential, commercial, public, and green space. The facility offers a skating court, water plaza, civic gardens, as well as the TD Place a major sporting arena and venue. To the north of the site, The Rideau Canal, a major recreation attraction, is flanked on either side by scenic parkways, gardens, and cycling paths that hosts various types physical activities including kayaking, canoeing, running, cycling, and ice-skating, as well as festivals such as the Tulip festival (Fig.26).

The building site selected is located at the intersection of Cameron Avenue and Rideau River Lane Private - 100 Cameron Avenue. Directly adjacent the site to the northwest is Cameron Avenue, with Rideau River Lane to the southwest (Fig.31). The northeast boundary of the site abuts a residential property, with the southeast boundary directly adjacent a parking lot for a multi-residential unit building (Fig.29). The zoning of the site holds an R3-P Residential Third Density zoning classification - with the permitted uses within this zone allowing for a group home with a maximum of ten residents. Existing residential care facilities within the area include the Hospice at May Court, a residential hospice care program with nine beds at 114 Cameron Avenue, and a four-bedroom Ottawa Salus Housing unit for residents with mental illness at 111 Grove Avenue. 


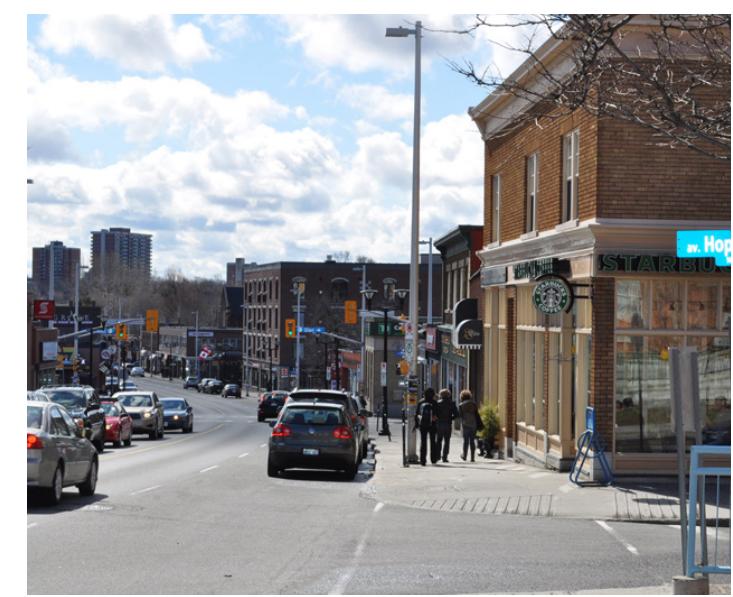

Figure 27: Bank Street, a main street running through Old Ottawa South.
The site is well connected to existing public infrastructure including Bank Street, an animated main street spine in Ottawa that runs northeast through the neighborhood. Bank Street offers a variety of services including retail stores, restaurants, grocery stores, coffee shops, laundromats, pubs, entertainment venues, and health and wellness facilities all within walking distance from the building site (Fig.27). Furthermore, various methods of public transportation are located within close proximity, such as the O-Train, and major bus routes (1, 4, 5, and 7). Accessibility to public transit is essential in the treatment for residents, since it affords access to additional mental health resources throughout the city.

The site offers for the opportunity to have two distinct entrances. One entrance, off Cameron Avenue, is for the residents of the inpatient component. As they approach the building, the form and language of a residential home evokes a warm and welcoming feel. Providing residents with their own separate entrance further promotes a non-institutional feeling and sense of independence, which could contribute positively to their psychological well-being. A second entrance, accessed from the existing parking lot to the south of the site, is for outpatients and staff. A stone pathway to the west of the site links the sidewalk to the outpatient entrance for patients who travel by foot or bike.

Engaging residents with the community can help minimize the stigma attached to mental illness and treatment facilities. A green space on the east of the site is dedicated to a small garden where residents can learn to garden and grow vegetables from community members. Gardening and growing food is also a beneficial therapy for residents and has been proven to reduce stress, and promote positive self worth. 


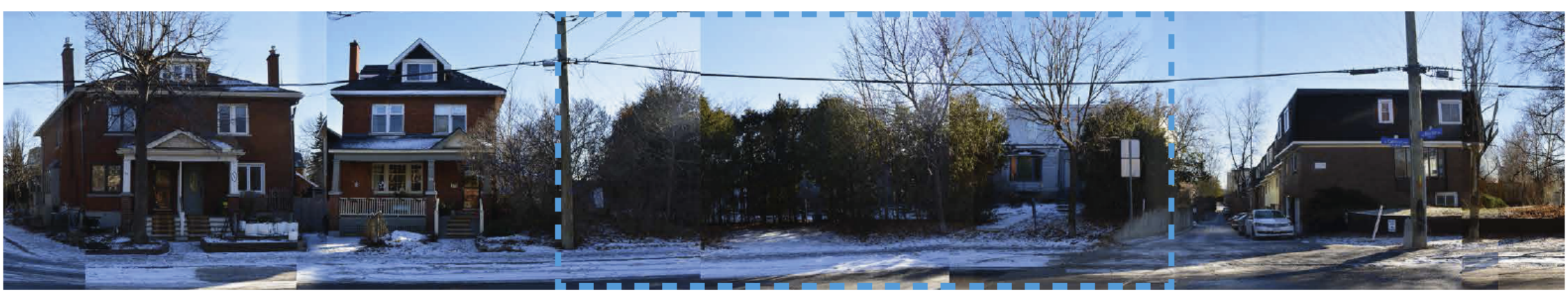

90-92 Cameron Ave. 94 Cameron Ave.

100 Cameron Ave.

2 Rideau River Ln.

Figure 28: Streetscape of Cameron Avenue.

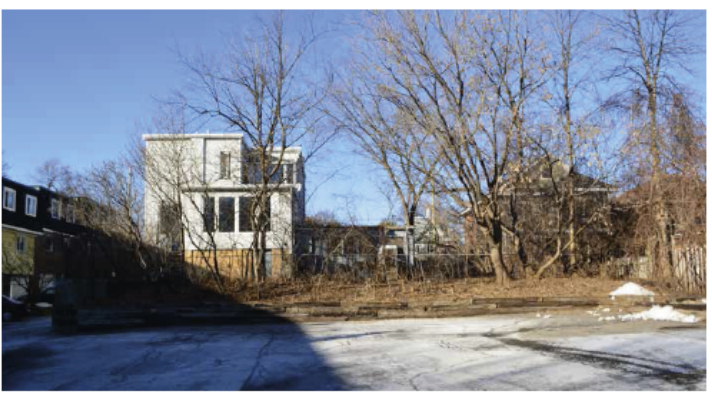

Figure 29: Southeast view of site showing adjacent existing parking lot for multi-unit residential housing.

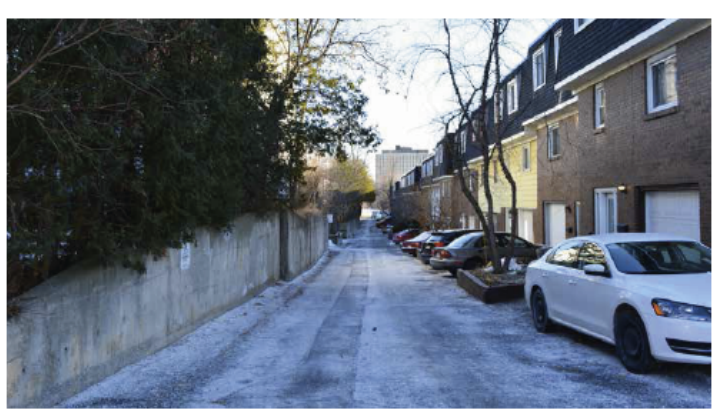

Figure 30: View of Rideau River Lane, southwest of site.

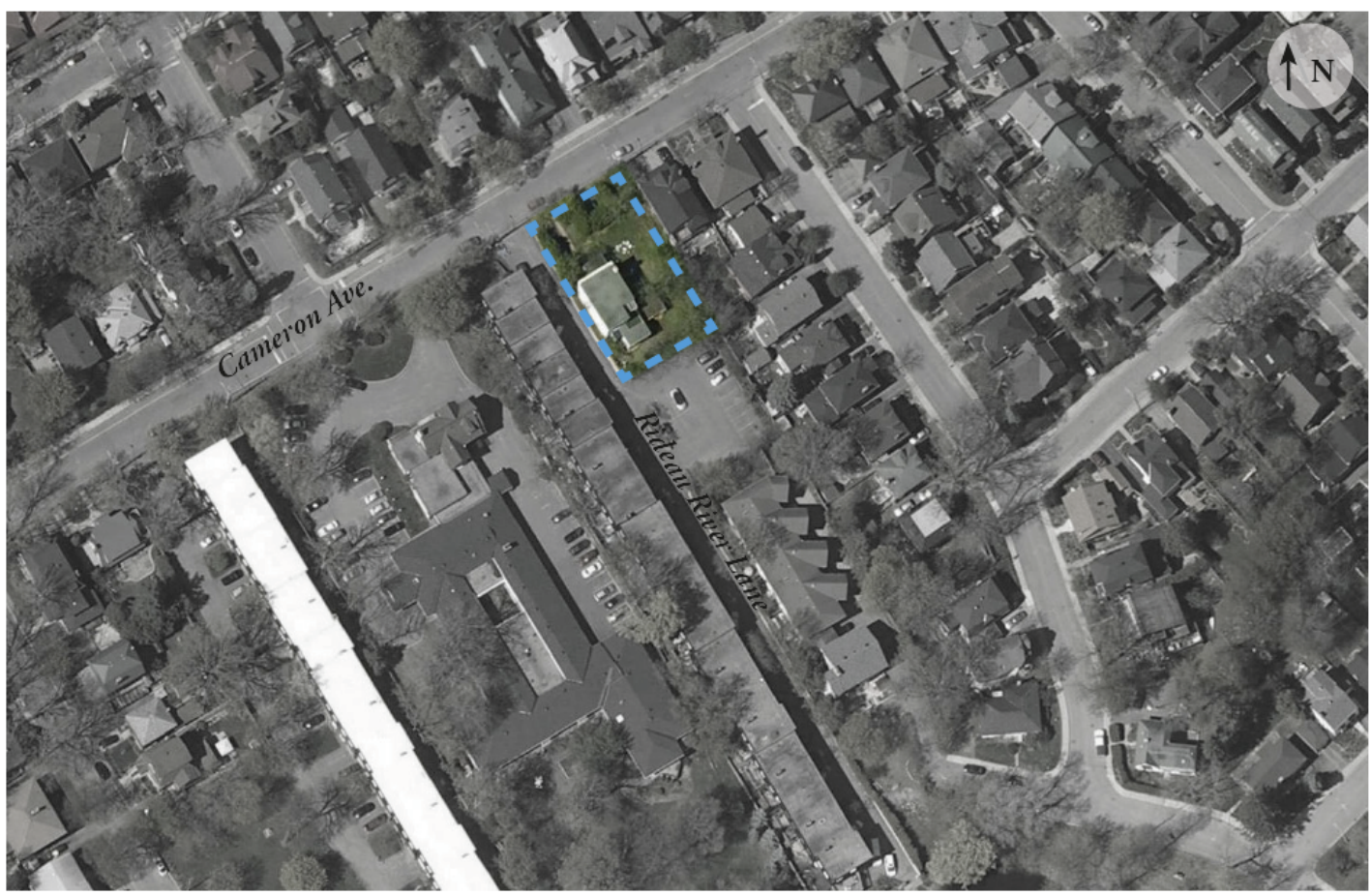

Figure 31: Map identifying site at 100 Cameron Avenue. 

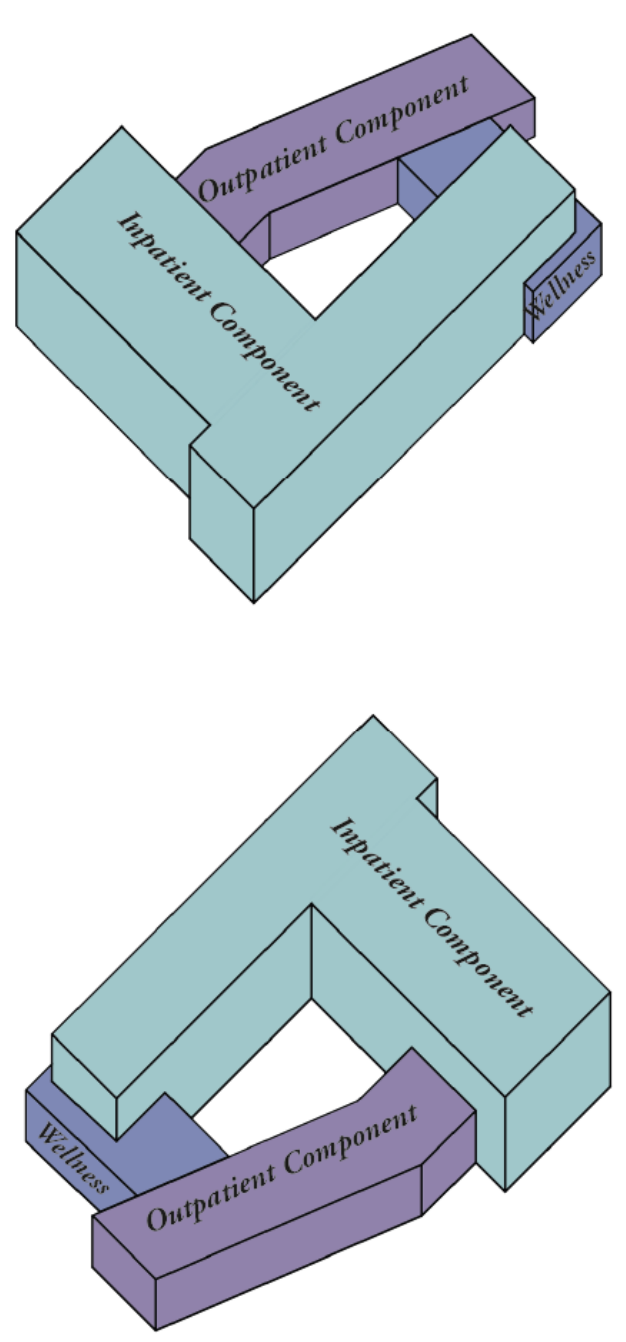

Figure 32: Conceptual massing and programming models.

\section{Programming}

Principle 2. Provide a program that supports a seamless transition between phases of mental states - from mental illness to mental health.

The facility is comprised of an inpatient, outpatient, and wellness program. Combined, the three programs aim to support the cyclical nature of mental illness to mental health. As mentioned before mental health can be a fluctuating lifelong process and often patients will transition between inpatient to outpatient care. Ensuring that patients remain in a familiar environment with mental health care practitioners that they trust can aid them in recovery.

\section{Inpatient}

The focus of the inpatient component is on rehabilitation and reintegration. The guidelines of the inpatient program will look to the transition program behind the YPARC facilities within Australia: headspace. Globally, headspace is considered as the best-known transition program for CAMHS/AMHS. ${ }^{119}$ As per the YPARC program and admission guidelines, the inpatient component will serve youth with moderate mental health issues who are in need of supported living, with the average length of stay approximately thirty days. The house will accommodate six residents, as well as one staff member that are on site twenty-four hours, seven days a week.

A major focus of the inpatient program is on reintegrating residents back into community and teaching them skills that can help them transition to independent living. Learning to cook, budget, and plan, can help ease the transition from living within a supportive home to living on their own. 


$\begin{array}{lc}\text { Inpatient } & 75 \text { sq. } \mathrm{ft} \\ \text { Entrance Vestibule } & 400 \text { sq. ft } \\ \text { Kitchen and Dining } & 325 \text { sq. ft } \\ \text { Family Room } & 55 \text { sq. ft } \\ \text { Escape Space \#1 } & 40 \text { sq. ft } \\ \text { Escape Space \#2 } & 350 \text { sq. ft } \\ \text { Day Dreaming Space } & 615 \text { sq. ft } \\ \text { Creative Space } & 155 \text { sq. ft } \\ \text { Patient (6) } & 165 \text { sq. ft } \\ \text { Staff Room (1) } & 100 \text { sq. ft } \\ \text { Bathroom (2) } & 85 \text { sq. ft } \\ \text { Storage } & 935 \text { sq. ft } \\ \text { Circulation } & 4,175 \mathrm{sq} . \mathrm{ft}\end{array}$

\section{Outpatient}

$\begin{array}{ll}\text { Private Therapy Rooms (2) } & 145 \text { sq. } \mathrm{ft} \\ \text { Sensory Modulation Room } & 145 \text { sq. } \mathrm{ft} \\ \text { Group Therapy Room } & 320 \text { sq. } \mathrm{ft} \\ \text { Administration Area } & 190 \text { sq. } \mathrm{ft} \\ \text { Washroom } & 60 \text { sq. } \mathrm{ft} \\ \text { Circulation } & 375 \text { sq. } \mathrm{ft} \\ \text { Total } & 1,380 \text { sq.ft }\end{array}$

\section{Wellness}

\begin{tabular}{ll} 
Yoga Studio / Fitness Room & 300 sq. $\mathrm{ft}$ \\
Courtyard & 875 sq. $\mathrm{ft}$ \\
\hline Total & 1,175 sq. $\mathrm{ft}$
\end{tabular}

Total Program

6,730 sq. $\mathrm{ft}$

\section{Outpatient}

The focus of the outpatient component is on rehabilitation. Providing outpatient services allows the youth to continue treatment with the same health care professionals that they trust within a familiar setting. Also, since forming friendships and establishing trust plays an important role in the treatment of youth with mental illnesses, providing outpatient services allows the youth who have completed inpatient treatment to befriend and help mentor patients entering the inpatient program, or to maintain established friendships formed during the inpatient stay.

The private therapy rooms provide a calming and safe feeling for patients to express their thoughts one on one with a therapist, while the group therapy room is suited to verbal and non-verbal therapies such as art and music. Incorporating non-verbal therapies allow youth who are unable to fully express their emotions through words to express and articulate their feelings indirectly.

Sensory modulation rooms, commonly known as Snoezelen Rooms, use fixtures and objects within the room to stimulate and sooth by delivering sensory stimuli through light, colour, sound, aromas, and textures. Although sensory modulation rooms are typically used for children with development disabilities, studies are now revealing the benefits of sensory modulation therapy for patients with psychiatric illnesses. One study by Department of Behavioral Health at Cooley-Dickinson Hospital revealed that ninety-eight percent of patients who participated in multi-sensory room therapy experienced positive effects such as a decrease in self perceived stress. In addition the use of restraints within the inpatient wards was dramatically decreased. ${ }^{120}$ 


\section{Wellness}

The focus of the wellness component is on prevention and mental health promotion. This is a relatively new concept in the mental health care system. Instead of waiting for an illness to appear or worsen, enhancing factors known to help protect people and diminishing factors that put them at risk can reduce the onset of some mental health problems and illnesses, reduce symptoms and disabilities, and support people in their journey to recovery. ${ }^{121}$

One factor known to improve mental health and prevent mental illness is physical activity and exercise. Psychological well-being has been directly linked to physical activity in several studies and include benefits such as improved positive mood, reduced fatigue, reduced stress, increased self esteem, increased cognitive functioning, and higher quality of life. In recent studies, meditation has also been proven to increase well-being both physically and psychologically. On a physical level, meditation can increase energy levels, increase serotonin, relieve insomnia, and improve the immune system. Mental health benefits include decreased anxiety and stress, and increased emotional stability, memory, and attention. Recent neuroscientific studies are also revealing structural changes to the brain associated with meditation such as increased grey matter (Luders et al, 2009), increased volume in areas related to emotion regulation (Davidson et al, 2003), and increased cortical thickness in areas related to paying attention (Lazar et. al 2005).

The yoga studio and courtyard provide tranquil space for physical activity, meditation, and relaxation. 

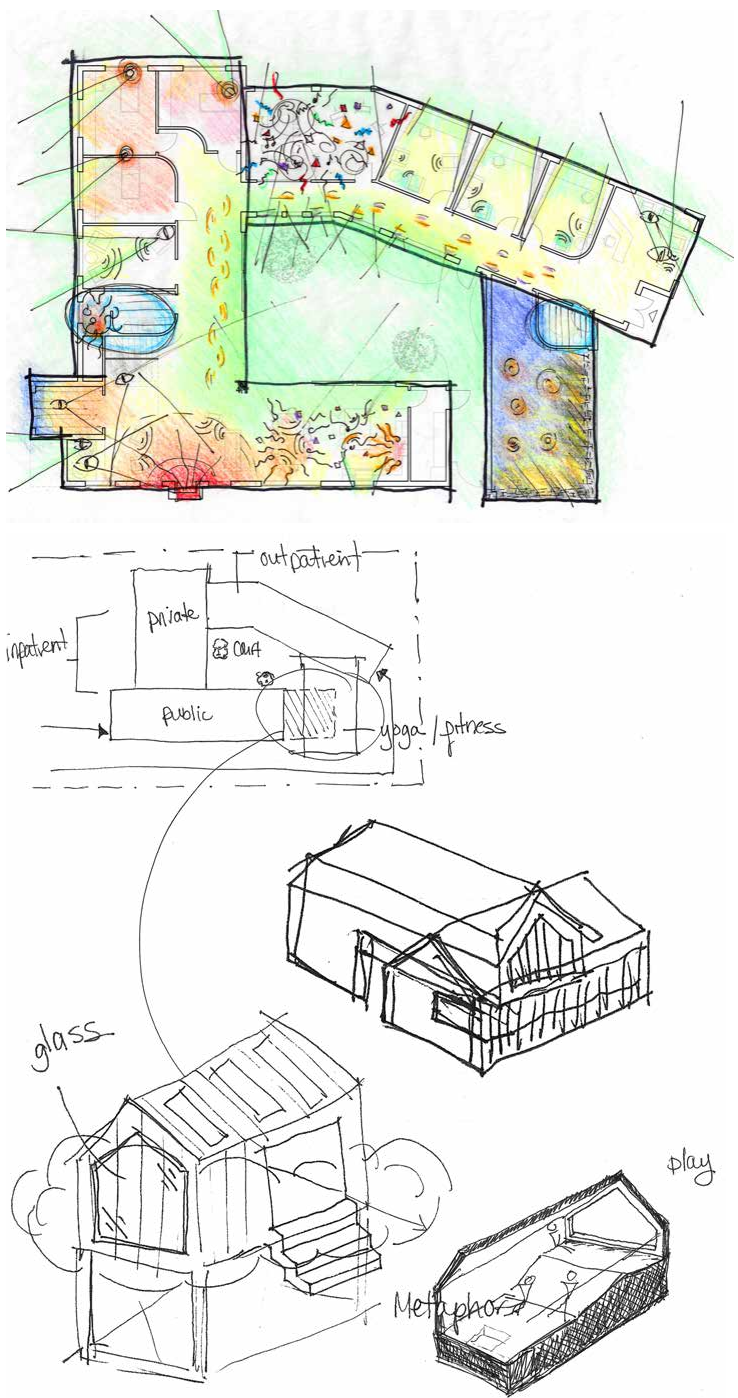

Figure 33: Conceptual sketches for enriched environments

\section{Enriched Environment}

Principle 3. Incorporate known features of healing environments that contributes positively to a resident's well-being, both physically and psychologically.

Principle 4. Incorporate features of enriched environments from both the perspective of neuroscience and neuroarchitecture.

A physical environment has the ability to heal the body and mind, change behaviour, and how inhabitants feel. It also has the incredible ability to change the structure of the brain. The following part explores the qualities of healing and enriched environments embedded within the building. Since qualities of healing spaces and enriched environments rely so heavily on our senses and perceptions they often overlap creating a layering of healing and enriched qualities. The resulting layering of qualities is an architecture that places the human at the center of design - attempting to create a union between body and mind.

Derived from an analysis of the existing research literature and scientific studies explored in Part One and Two, the following mapping identifies the factors directly contributing to healing spaces, as well as enriched environments from both the perspective of neuroscience and neuroarchitecture (Fig. 34). But, how do we use this research to propose an architectural solution? Table 2 and conceptual sketches identify the application of the principle factors of healing and enriched environment factors within specific areas of the proposed step-up / step-down facility. 


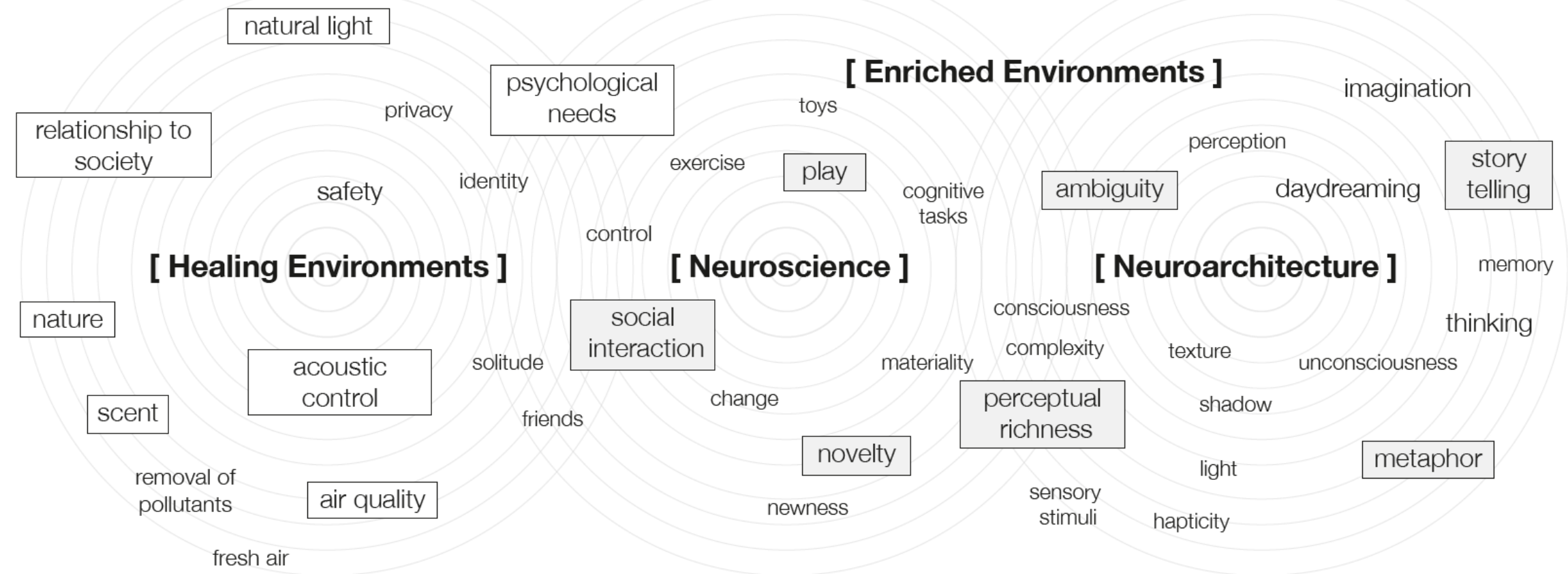




\begin{tabular}{|c|c|c|c|}
\hline Facility Program & $\begin{array}{c}\text { Healing } \\
\text { Environments }\end{array}$ & $\begin{array}{l}\text { Neuroscience: Enriched } \\
\text { Environments }\end{array}$ & $\begin{array}{l}\text { Neuroarchitecture: Enriched } \\
\text { Environments }\end{array}$ \\
\hline $\begin{array}{l}\text { Exterior / } \\
\text { Entrance }\end{array}$ & $\begin{array}{l}\text { Relationship to society: the exterior and } \\
\text { entrance to the facility should be residential } \\
\text { in appearance and non-institutional. } \\
\text { Psychological needs: the entrance should be } \\
\text { familiar and welcoming to patients. Light } \\
\text { / safety: the entrance should be well lit, } \\
\text { especially during the night. }\end{array}$ & $\begin{array}{l}\text { Social interaction: the non-institutional } \\
\text { feel of the facility can promote social } \\
\text { interaction and engagement between the } \\
\text { community and patients. }\end{array}$ & $\begin{array}{l}\text { Story telling. Perceptual richness: } \\
\text { materiality, texture, light, shadow. Focus } \\
\text { on touch and sight. }\end{array}$ \\
\hline Living Room & $\begin{array}{l}\text { Psychological needs: a mixture of seating will } \\
\text { promote interaction, but also allow a patient to } \\
\text { keep defendable personal space. Natural light } \\
\text { and air quality: windows and skylights. }\end{array}$ & $\begin{array}{l}\text { Social interaction: can be stimulated by a } \\
\text { sociopetal furniture placement. }\end{array}$ & $\begin{array}{l}\text { Perceptual richness: materiality, texture, } \\
\text { and color. Focus on touch, sight, hearing. }\end{array}$ \\
\hline Escape Spaces & $\begin{array}{l}\text { Psychological needs: defendable personal space, } \\
\text { while observing other activities within the } \\
\text { house. }\end{array}$ & Play. & $\begin{array}{l}\text { Ambiguity, metaphor and story telling: a } \\
\text { place for thinking and imagination. }\end{array}$ \\
\hline $\begin{array}{l}\text { Daydreaming } \\
\text { Space }\end{array}$ & $\begin{array}{l}\text { Psychological needs: for when a patient wants } \\
\text { to control their surroundings and seek solitude } \\
\text { or privacy. Acoustic control. Natural light: } \\
\text { large windows and skylights. }\end{array}$ & Play. & $\begin{array}{l}\text { Ambiguity, metaphor and story telling: } \\
\text { a place for thinking and imagination. } \\
\text { Perceptual richness. Focus on light and } \\
\text { Shadow. }\end{array}$ \\
\hline Creative Space & $\begin{array}{l}\text { Psychological needs: a mixture of seating will } \\
\text { promote interaction, but also allow a patient to } \\
\text { keep defendable personal space. Natural light } \\
\text { and air quality: windows and skylights. }\end{array}$ & Social interaction. Novelty. Play. Toys & Perceptual Richness. Story telling. \\
\hline Dinning Area & $\begin{array}{l}\text { Natural light and air quality: windows and } \\
\text { skylights. }\end{array}$ & Social interaction & $\begin{array}{l}\text { Perceptual richness: materiality, texture, } \\
\text { and color. Focus on touch, taste, smell, } \\
\text { and sight. }\end{array}$ \\
\hline
\end{tabular}




\begin{tabular}{|c|c|c|c|}
\hline Facility Program & $\begin{array}{c}\text { Healing } \\
\text { Environments }\end{array}$ & $\begin{array}{l}\text { Neuroscience: Enriched } \\
\text { Environments }\end{array}$ & $\begin{array}{l}\text { Neuroarchitecture: Enriched } \\
\text { Environments }\end{array}$ \\
\hline Staff Room & $\begin{array}{l}\text { Psychological needs: privacy, control. Safety. } \\
\text { Natural light and air quality: operable } \\
\text { windows. Acoustic control: staff should be } \\
\text { able to speak about clinical matters without } \\
\text { patients hearing. }\end{array}$ & $\begin{array}{l}\text { Novelty and change: the staff should be } \\
\text { able to bring and change personal items to } \\
\text { create a sense of identity and choice. }\end{array}$ & $\begin{array}{l}\text { Perceptual richness: materiality and } \\
\text { texture. Focus on touch and sight. }\end{array}$ \\
\hline $\begin{array}{l}\text { Sensory Modula- } \\
\text { tion Room }\end{array}$ & $\begin{array}{l}\text { Psychological needs: privacy, control. Safety. } \\
\text { Acoustic and light control: no windows. }\end{array}$ & Play. Novelty. & $\begin{array}{l}\text { Perceptual Richness. Focus on all of the } \\
\text { senses. }\end{array}$ \\
\hline $\begin{array}{l}\text { Private Therapy } \\
\text { Rooms (2) }\end{array}$ & $\begin{array}{l}\text { Psychological needs: privacy, control, safety. } \\
\text { Acoustic control: acoustic materials can } \\
\text { eliminate sound transfer, as it is important } \\
\text { for the patient to feel safe and comfortable } \\
\text { talking. Natural light. Scents. }\end{array}$ & & $\begin{array}{l}\text { Perceptual richness: materiality and } \\
\text { texture. Focus on hearing, smell, and } \\
\text { sight. }\end{array}$ \\
\hline $\begin{array}{l}\text { Group Therapy / } \\
\text { Activity Room (1) }\end{array}$ & $\begin{array}{l}\text { Psychological needs: control. Acoustic control. } \\
\text { Natural light and connection to nature: } \\
\text { windows. }\end{array}$ & $\begin{array}{l}\text { Social interaction. Play. Novelty: room } \\
\text { should be flexible to accommodate a range } \\
\text { of activities and therapy types. }\end{array}$ & $\begin{array}{l}\text { Perceptual richness: materiality and } \\
\text { texture. Focus on hearing, touch, and } \\
\text { sight. }\end{array}$ \\
\hline $\begin{array}{l}\text { Administration } \\
\text { Area }\end{array}$ & $\begin{array}{l}\text { Psychological needs: area should be } \\
\text { welcoming for both patients and family } \\
\text { members. Natural Lighting. }\end{array}$ & & $\begin{array}{l}\text { Perceptual richness: materiality and } \\
\text { texture. Focus on hearing and sight. }\end{array}$ \\
\hline $\begin{array}{l}\text { Yoga Studio / } \\
\text { Fitness Room }\end{array}$ & $\begin{array}{l}\text { Psychological needs: exercise helps reduce } \\
\text { stress. Natural lighting and connection to } \\
\text { nature: windows and skylights. }\end{array}$ & Social interaction. Play: exercise. & $\begin{array}{l}\text { Ambiguity, story telling, and metaphor: a } \\
\text { space for imagination and thinking. } \\
\text { Perceptual richness: light, shadow. Focus } \\
\text { on hearing and touch. }\end{array}$ \\
\hline Washrooms (2) & $\begin{array}{l}\text { Psychological needs: privacy, control. Safety. } \\
\text { Natural light and connection to nature: } \\
\text { windows. }\end{array}$ & & $\begin{array}{l}\text { Perceptual richness: materiality and } \\
\text { texture. Focus on touch, sight, smell, and } \\
\text { sound. }\end{array}$ \\
\hline
\end{tabular}

Table 2 cont'd: The principle healing and enriched environment factors within specific spaces of the facility. 


\begin{tabular}{|c|c|c|c|}
\hline Facility Program & $\begin{array}{c}\text { Healing } \\
\text { Environments }\end{array}$ & $\begin{array}{c}\text { Neuroscience: Enriched } \\
\text { Environments }\end{array}$ & $\begin{array}{c}\text { Neuroarchitecture: Enriched } \\
\text { Environments }\end{array}$ \\
\hline Circulation & $\begin{array}{l}\text { Psychological needs: avoid long narrow dead } \\
\text { end hallways. Lighting: should be brightly } \\
\text { lit with natural lighting. At night artificial } \\
\text { lighting should be bright enough to light } \\
\text { area, but not disturb the sleep cycle of } \\
\text { patients. Way-finding: easy to navigate using } \\
\text { landmarks. }\end{array}$ & Social interaction. Play. & $\begin{array}{l}\text { Perceptual richness: materiality and } \\
\text { texture. Focus on hearing, touch, and } \\
\text { sight. }\end{array}$ \\
\hline Courtyard & $\begin{array}{l}\text { Psychological: therapeutic design to reduce } \\
\text { stress. Way-finding: visual and physical } \\
\text { connection. Air quality: fresh air. Natural } \\
\text { light. Connection to nature. }\end{array}$ & Social interaction. Play. & $\begin{array}{l}\text { Perceptual richness: materiality, hapticity, } \\
\text { and texture. Focus on hearing, touch, } \\
\text { sight, smell. }\end{array}$ \\
\hline
\end{tabular}




\section{i. Plans, Sections, \& Axonometrics}

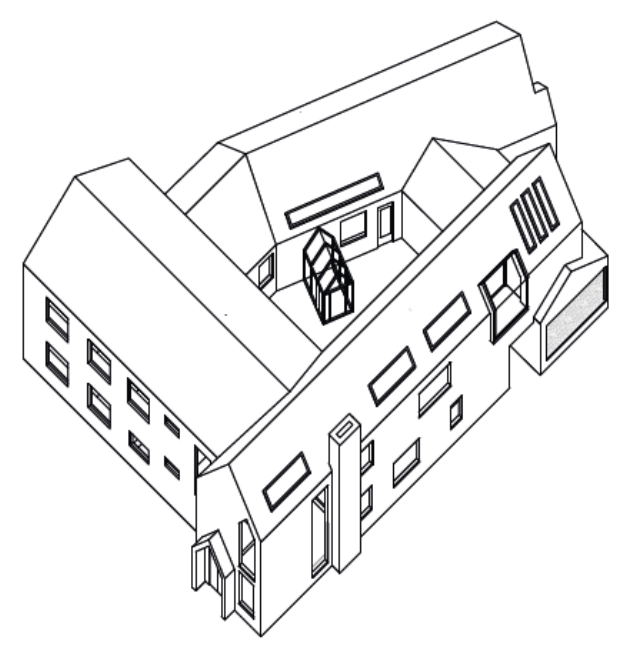

The following section provides the architectural drawings and diagrams to provide a comprehensive understanding of the step-up/step-down facility and the enrichment factors embedded within.

The form of the Centre is an exploration of the archetypal form of a house. The house reduced to its simplest form, a square base and sloping triangle roof, is manipulated by pulling, rotating, and shifting to create the overall massing for the Centre. This creates a non-institutional feel while also maintaining a residential appearance alike to the surrounding buildings.
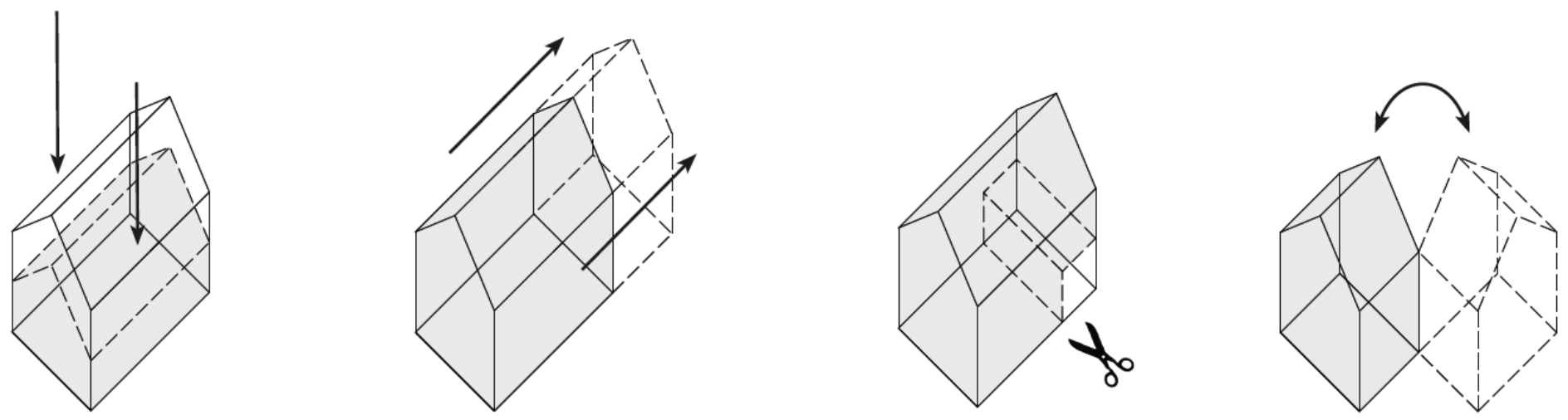

Figure 35 : Design strategy for the form and massing 
A small community garden is located to the northeast of the site where residents can learn to grow and produce vegetables and flowers from residents within the community.

The program is organized to form an enclosed central courtyard that can be accessed by both residents and outpatients.

The site offers for the opportunity to have two distinct entrances. One for the patients of the residential component facing Cameron Avenue, and a second entrance, accessed from the existing parking lot to the south of the site, for outpatients and staff. A small path to the south west of the site allows for patients arriving by foot or bike to access the outpatient entrance.

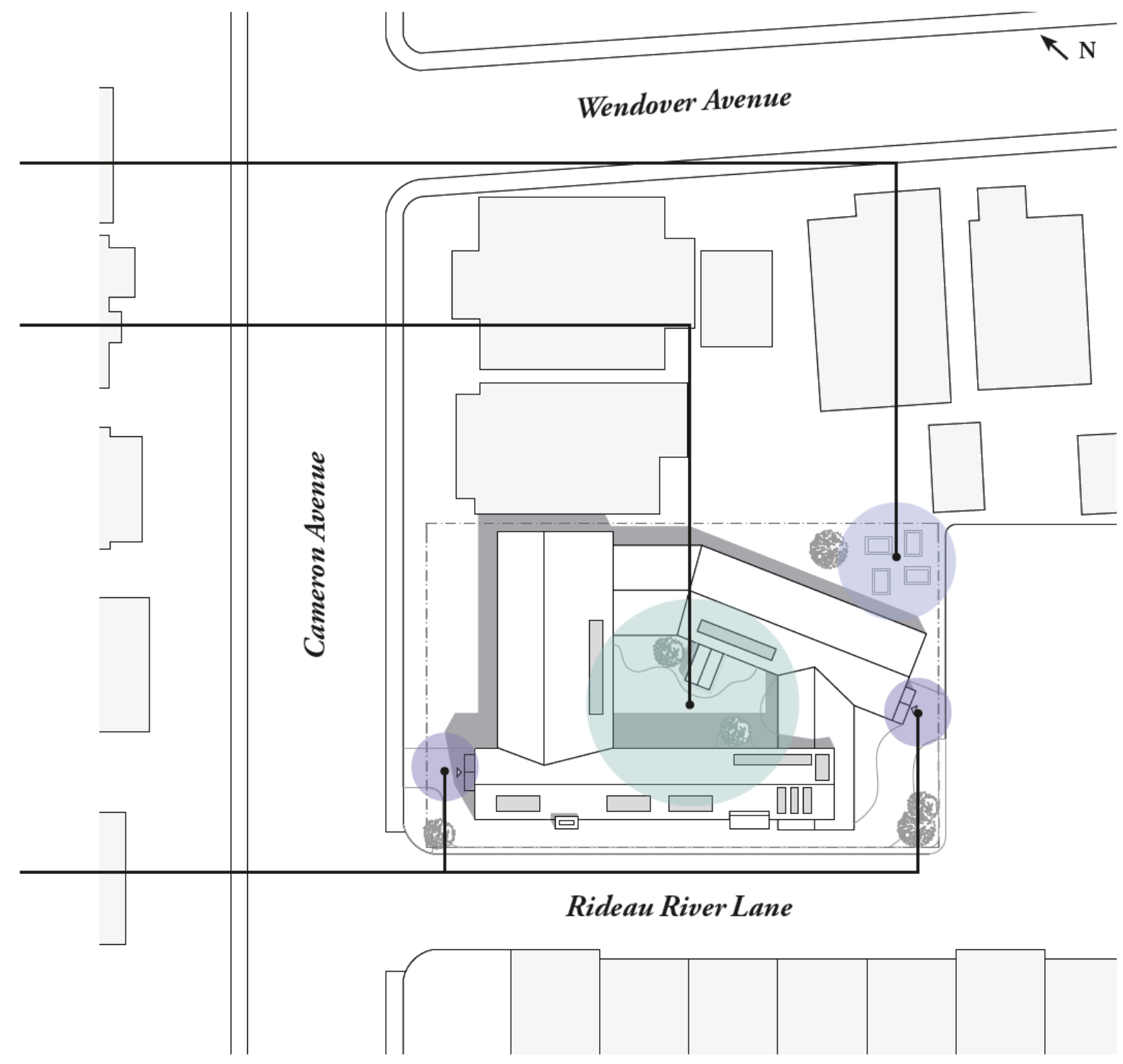

Figure 36: Site Plan 1:500 


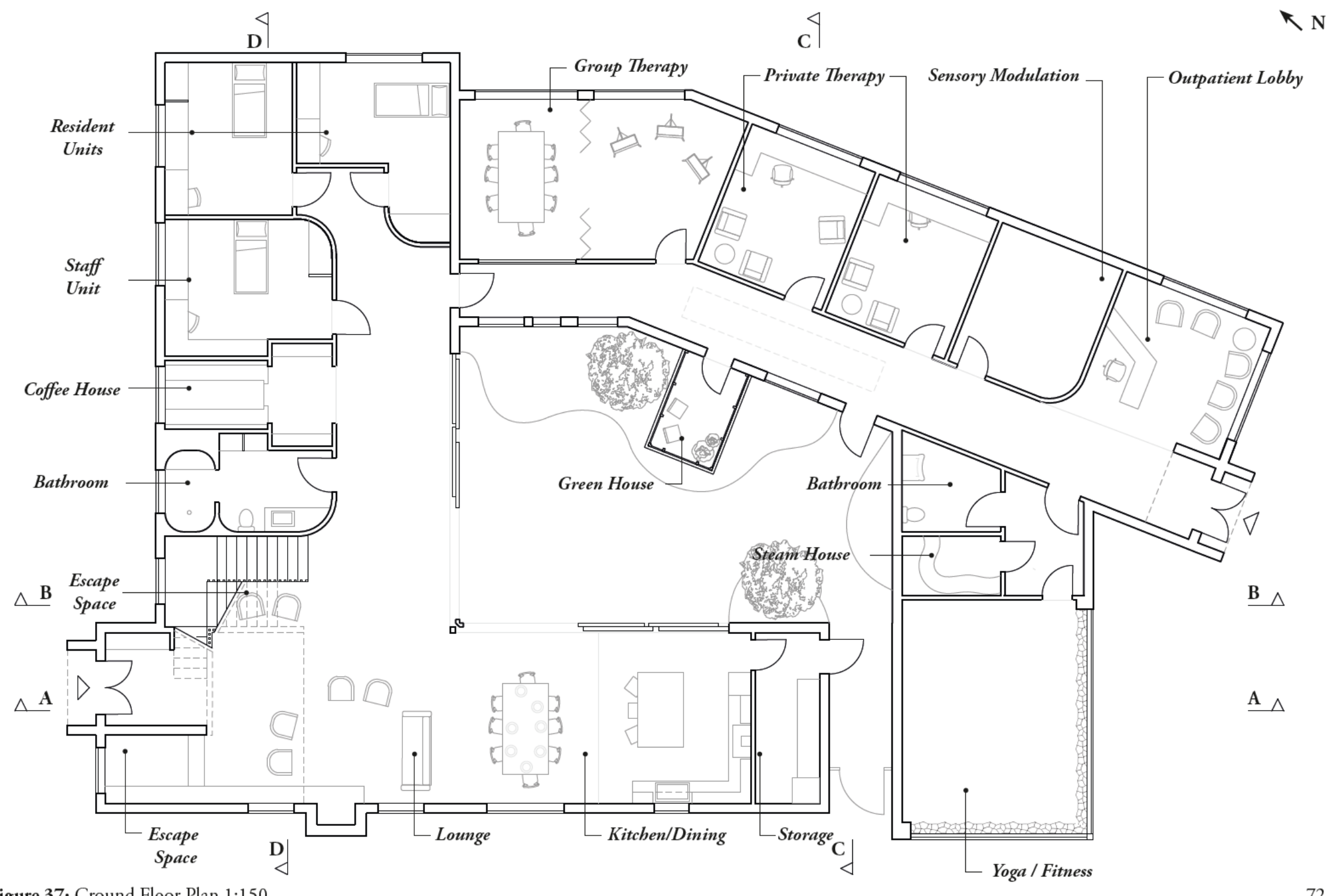

Figure 37: Ground Floor Plan 1:150 


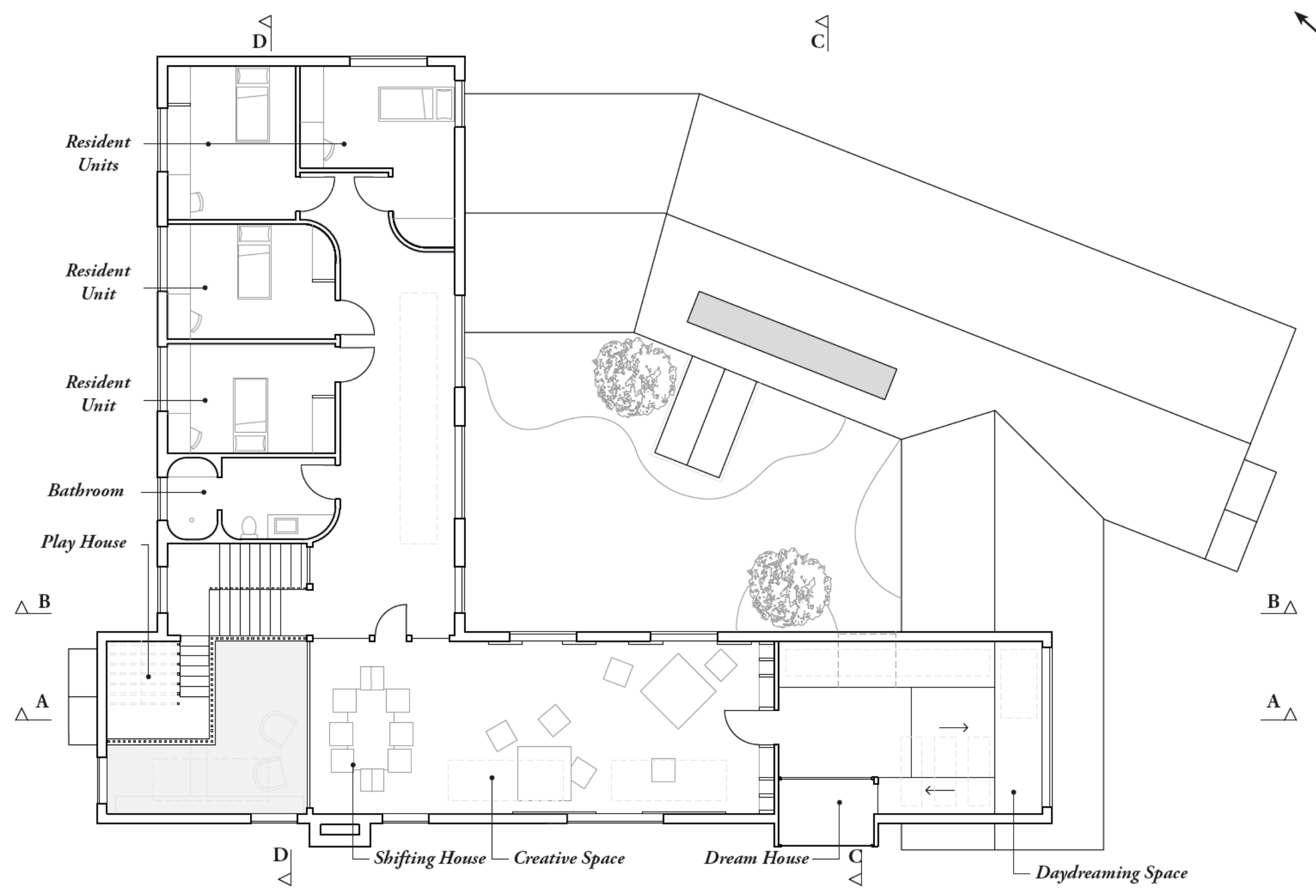

Figure 38: Second Floor Plan 1:150 


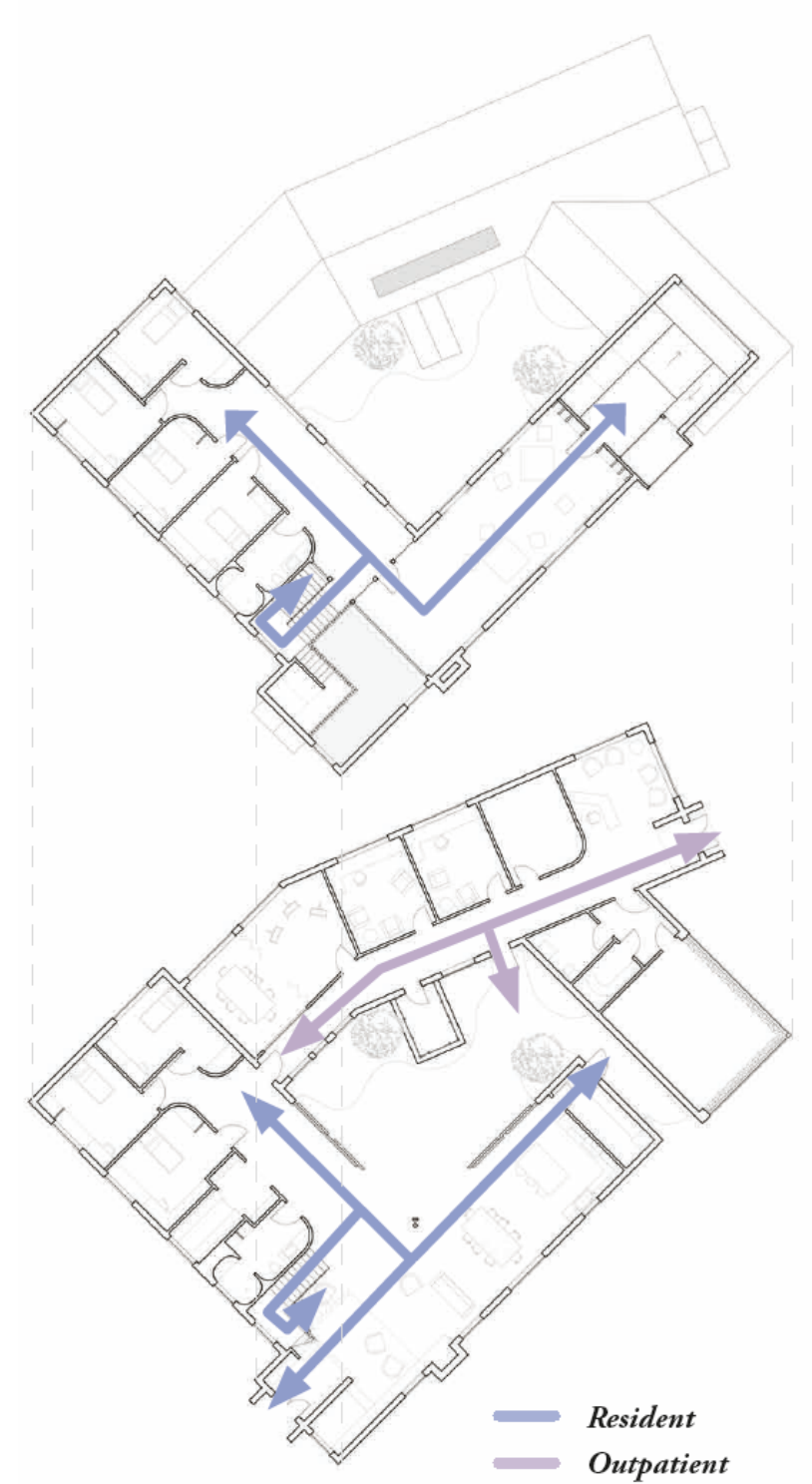

Figure 39: Circulation Diagram.

\section{Circulation}

As mentioned earlier, courtyards can also serve as a landmark and way-finding tool. Organizing the main circulation paths around the courtyard can provide ease of navigation for residents and outpatients, while also providing exterior views and a visual connection to nature. The design attempts to minimize narrow and long dead end corridors. The hallways within the residential component are $10 \mathrm{ft}$ wide and can also serve as informal gathering spaces. In contrast, the hallways of the outpatient component are narrower to minimize activities taking place outside of the therapy rooms - minimizing noise and ensuring patient privacy.

While circulating throughout the centre, it is important for there to be clear transitions and boundaries between spaces. Various flooring materials are used to maintain an open layout and minimize the need for walls to define programs. To further promote a home-like feel in the residential component, hardwood flooring was selected within the main circulation spaces, and tile for the kitchen and bathrooms. Carpet tiles are used within the resident's rooms, since the soft material minimizes noises and creates a warm and calming atmosphere. They are also durable and can be easily replaced in isolated areas. Wooden beams on the ground floor ceiling between the lounge and dining area, and the lounge and resident unit area, are also used to indicate boundaries between spaces without the use of walls. Within the outpatient component, durable vinyl tiles are used in the main circulation spaces, carpet tiles within the private therapy rooms, and hardwood flooring in the yoga studio and sauna. 


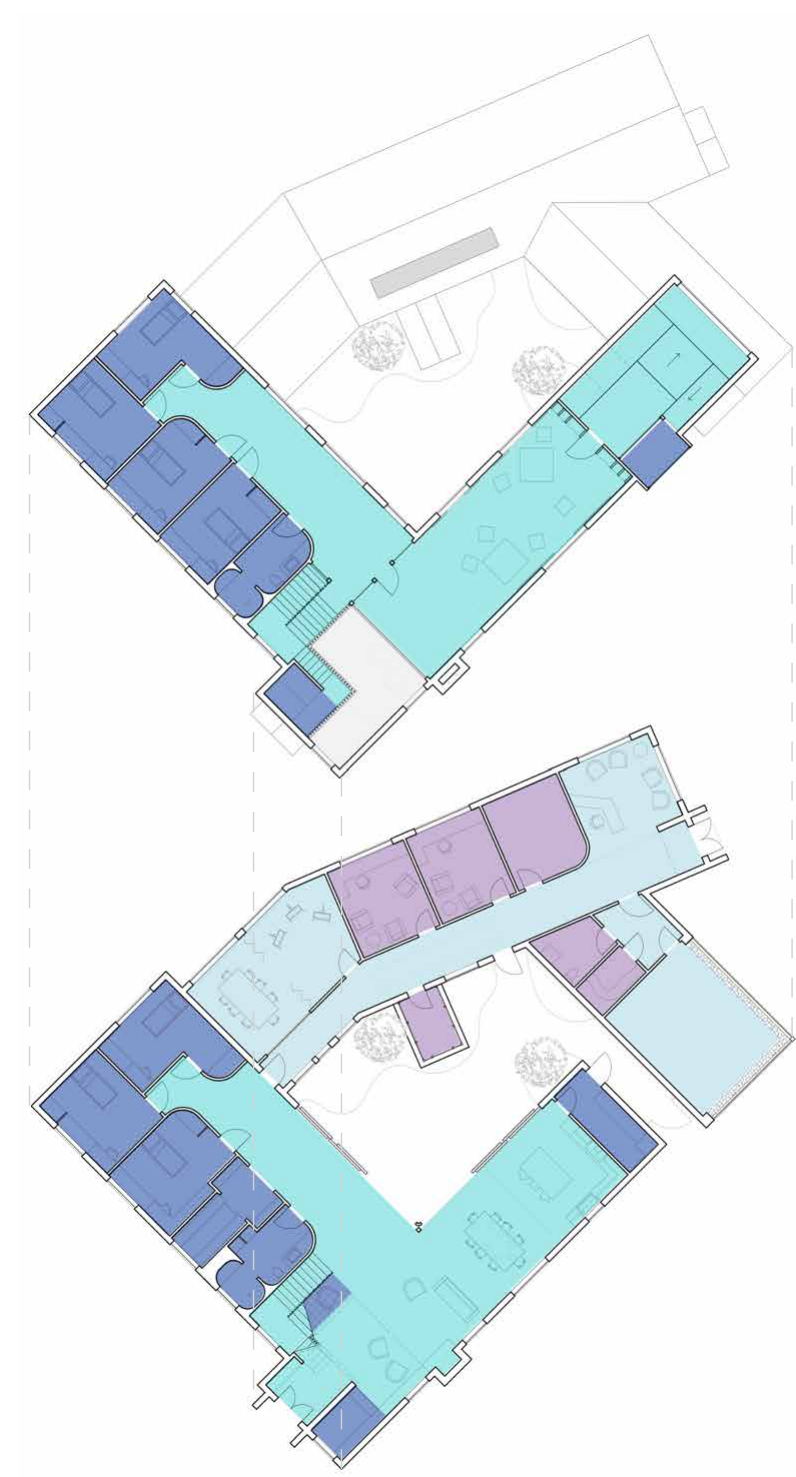

Figure 40: Communal vs. Private Spaces Diagram.

\section{Communal / Private / Semi-Private Spaces}

Providing residents and outpatients the opportunity to control their social environment can help eliminate stress, anxiety, and depression due to uncontrollable social interactions. The design offers varying spaces that facilitate a range of social interactions from large spaces for public or group activities, such as the group therapy room and creative room, to small intimate spaces for solitude and privacy, such as the coffee house or escape spaces. The escape spaces provided within the larger communal area of the residential component allow residents to stay within their comfort zone and observe activities within the house without the need to participate.

Organizing private / semi-private and therapy spaces around the courtyard may lead to the feeling of discomfort and paranoia for residents and visitors due to the invasion of visual and acoustic privacy. For this reason, the communal and circulation spaces are organized around the central courtyard.

Residence - Communal

Residence - Private / Semi-Private

Outpatient - Communal

Outpatient - Private / Semi-Private 


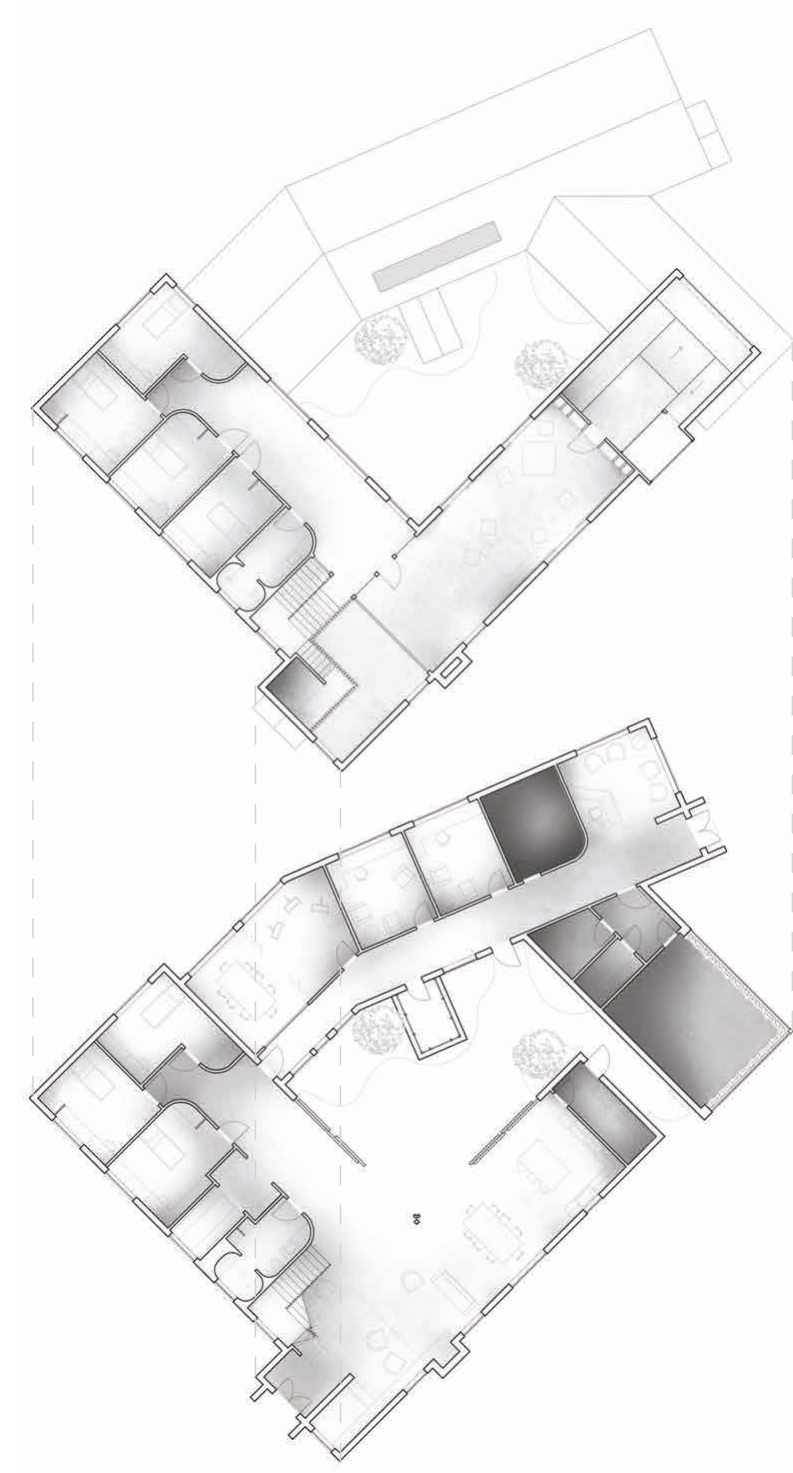

Light Study

The design of the centre maximizes natural lighting to create well-illuminated interior spaces. The main circulation and communal spaces are organized around the central courtyard to maximize natural lighting. On the ground floor of the residence large sliding doors facing east and south allow morning and afternoon sun to penetrate into the circulation space. During the warmer months these sliding doors can be opened to create a connection between interior and exterior space. On the second floor of the residence large windows with sliding sunshades allow residents to control their environment - for activities requiring bright lighting such as reading or working, to activities requiring dim light such as watching movies. Multiple skylights are also used to allow natural lighting to penetrate the second floor of the residence and circulation of the outpatient component.

Spaces requiring dim to no lighting such as the sensory modulation room and the bathhouse have no access to natural lighting.

Additionally, the single story outpatient component is located on the south of the site maximizing sunlight into the residential component and courtyard - especially during the winter months.

Figure 41: Light Study Diagram. 


\section{Additional Design Considerations}

Curved Walls: Wherever possible, curved walls were introduced into the circulation spaces. Numerous studies have documented a human bias for curves over straight or sharp lines. Sharp angled objects tend to evoke feelings of pain and sadness, while curvilinear forms elicit feelings of happiness and elation. This bias was recently proven in a study by neuroscientists Moshe Bar and Maital Neta in 2007, entitled Visual elements of subjective preference modulate amygdala reaction, where participants observed over 200 different shapes. It revealed that sharp visual objects triggered a significant reaction in the amygdala (part of the brain that is link to fear responses) in comparison to curvilinear shapes. ${ }^{123}$

Ceiling Heights: Emerging research is linking ceiling height to creativity and detail-oriented thinking. A study by Joan Meyers Levy and Rui Zhu entitled The influence of ceiling height: the effect of priming on the type of processing that people use, revealed that people tend to think more abstractly and freely in rooms with ten feet high ceilings in comparison to eight feet high ceilings. However, rooms with lower ceilings (8ft) were better suited to detail-oriented tasks. ${ }^{124}$ For this reason, programs that require creative thinking such as the group therapy room, creative space, and daydreaming space have higher ceilings. Spaces that require more focus for tasks such as the patient units (where they may retreat to do homework), yoga studio, and kitchen have lower ceilings. 
Enclosed Courtyard: It has been observed that humans tend to prefer outdoor spaces that have buildings surrounding them on several sides creating a room-like condition, in contrast to large open spaces. This can be referred to as thigmotaxis, and explains why humans have a bias to avoid centers (which causes anxiety) and seek safety by sticking to walls. ${ }^{125}$ The design of the courtyard is enclosed on all sides, except for a covered exit to the southwest of the site, to give the feeling of a room-like condition and reduce the possibility of anxiety.

Chalkboards: To promote a sense of individual identity within the centre, each resident will have a chalkboard on their bedroom door that they can personalize.

Open Shelving: For patient safety, storage and closet space within the resident units are comprised of open shelving.

Bathrooms: Often bathrooms carry negative associations in psychiatric facilities. The layout of the bathroom uses curved walls, warm materials, a large shower with seating, and natural lighting to create a space of revitalization and cleansing.

Art Walls: Walls throughout the interior and exterior of the outpatient component are dedicated as mural walls. The group therapy program invites patients to express their creativity through painting or leave their mark on the wall once they complete residential treatment. 


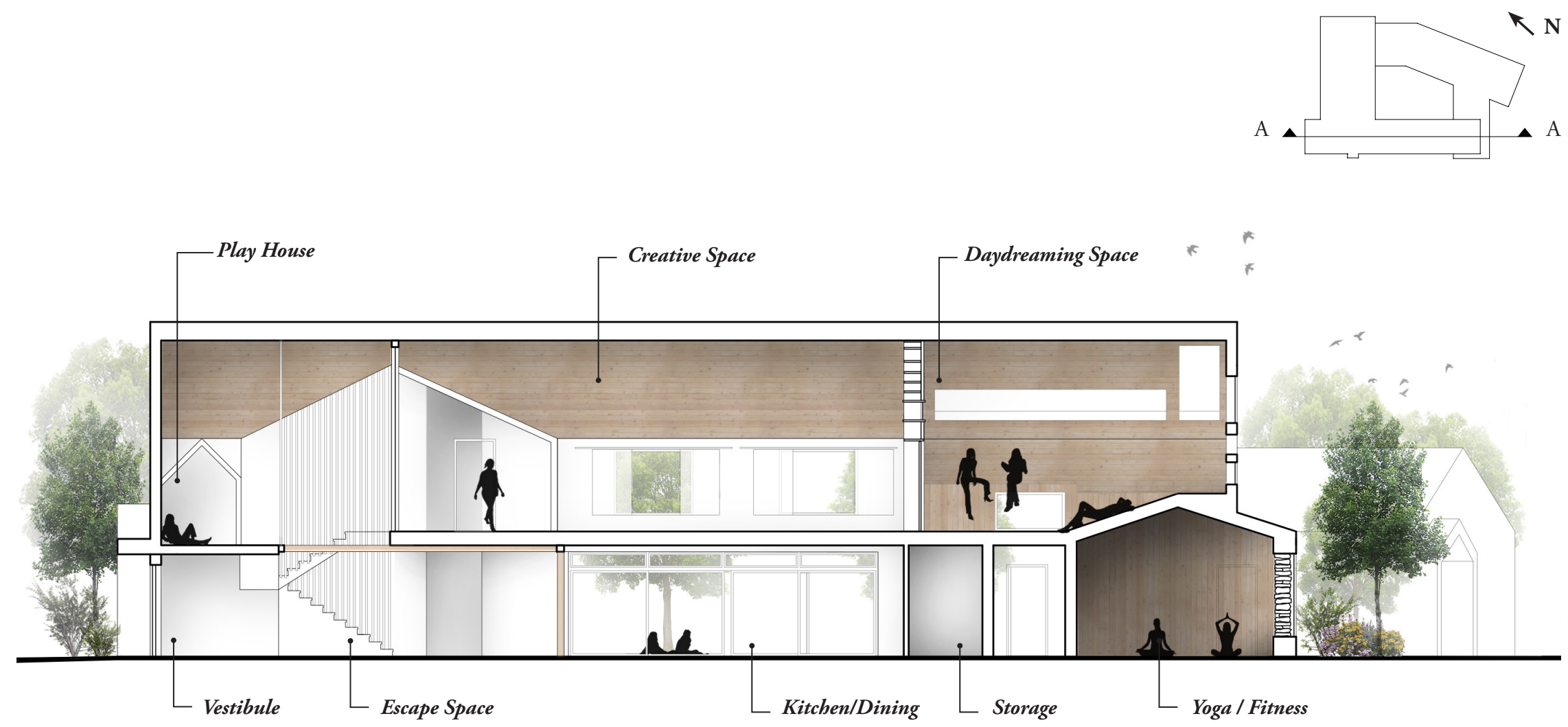

Figure 42: Section A-A 1:150 

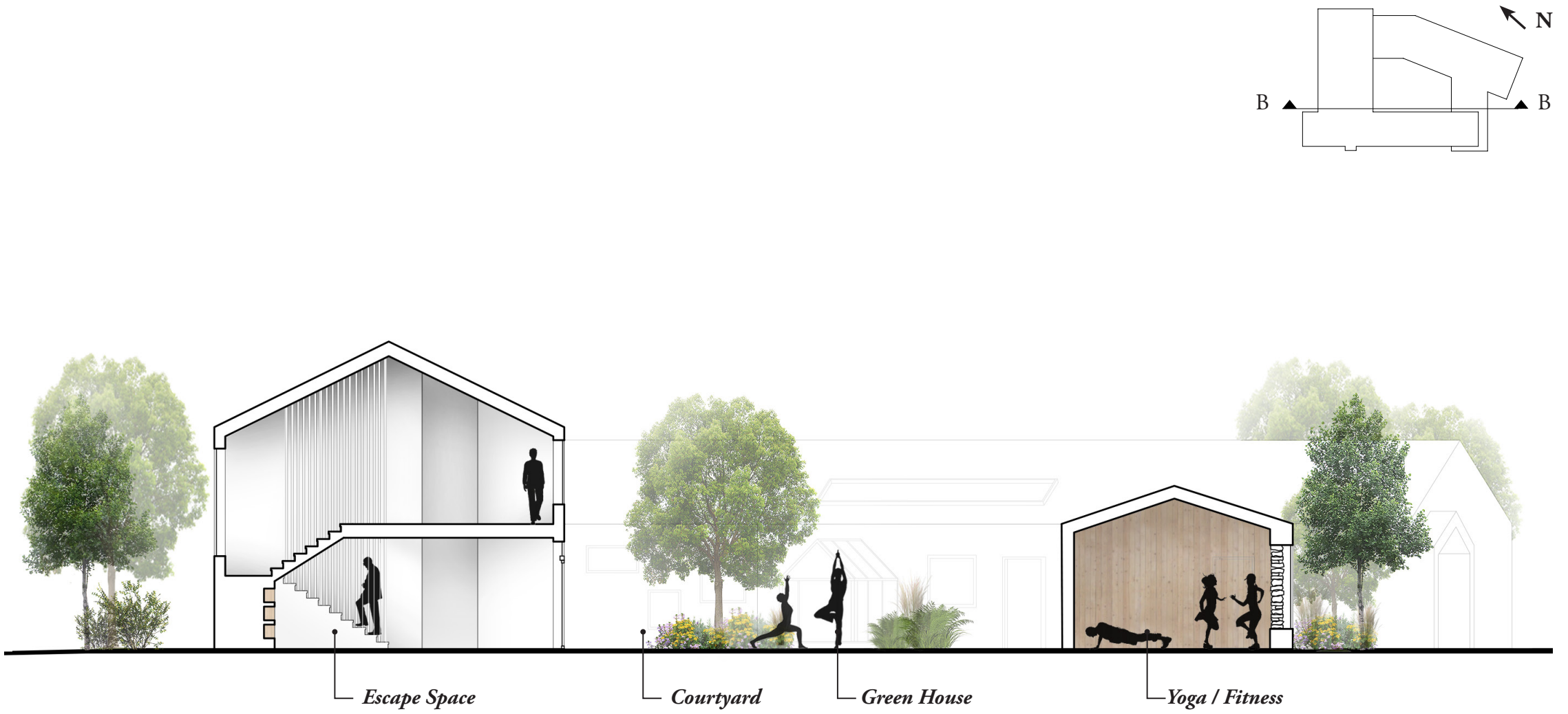

Figure 43: Section B-B 1:150 

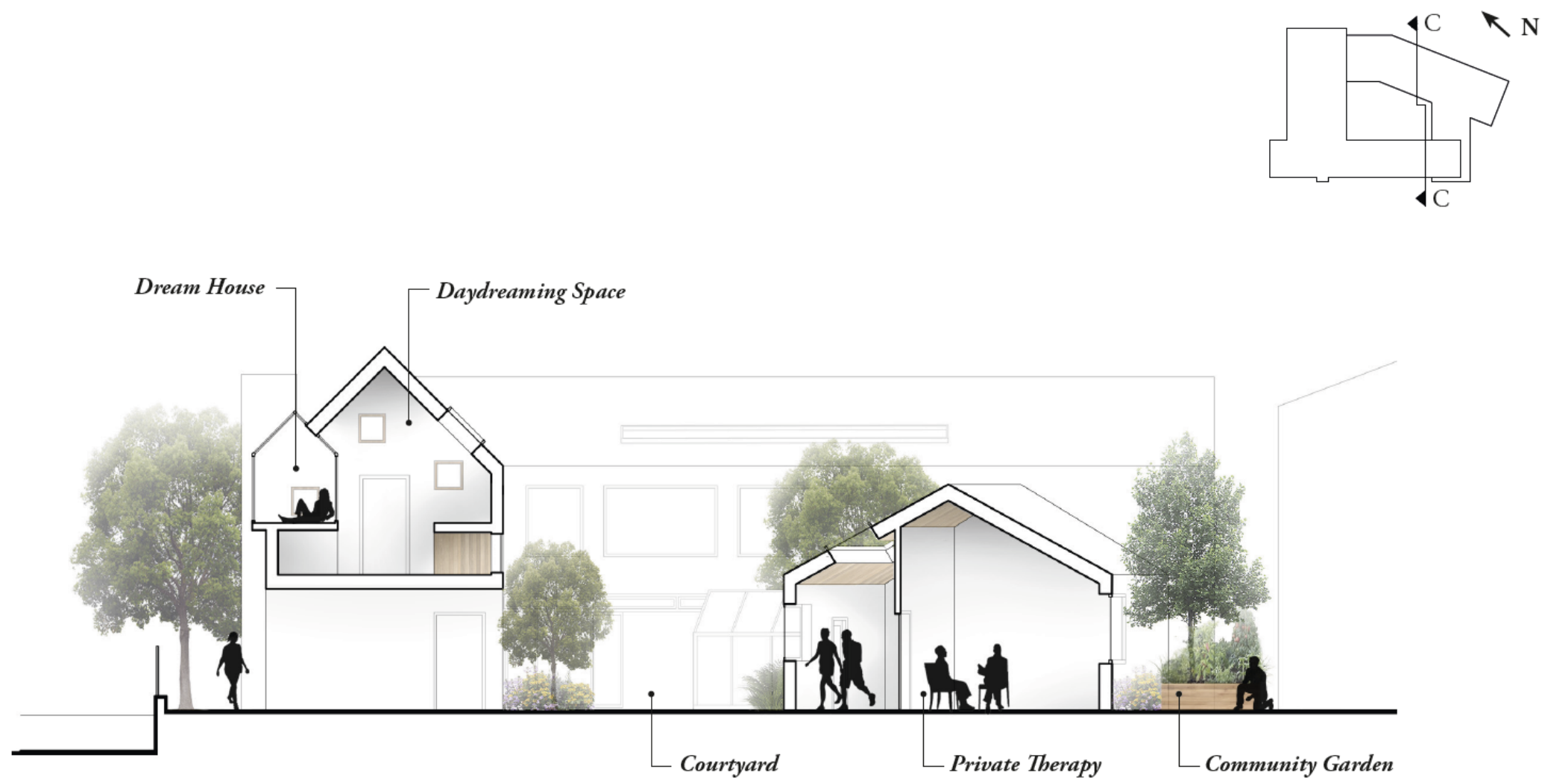

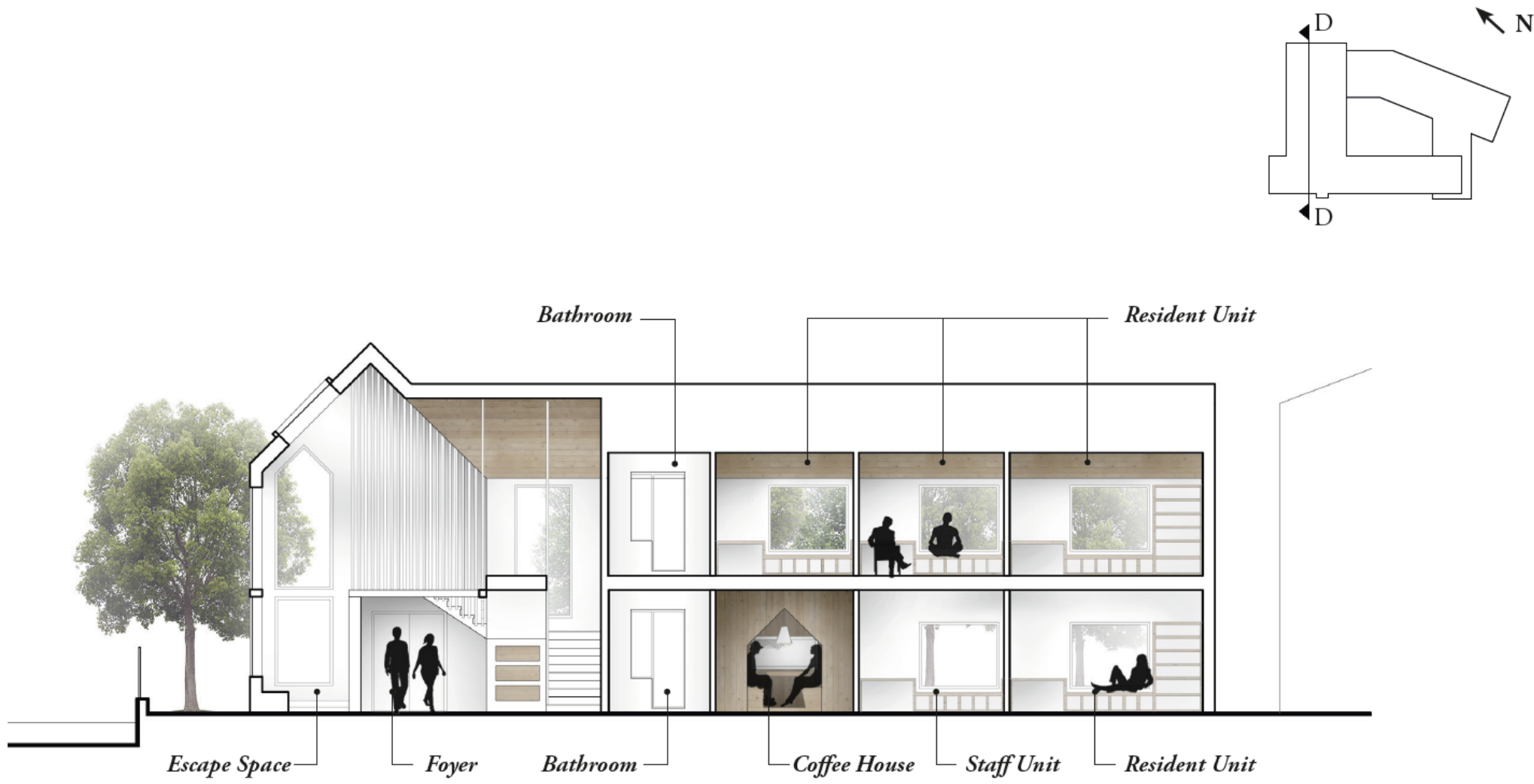


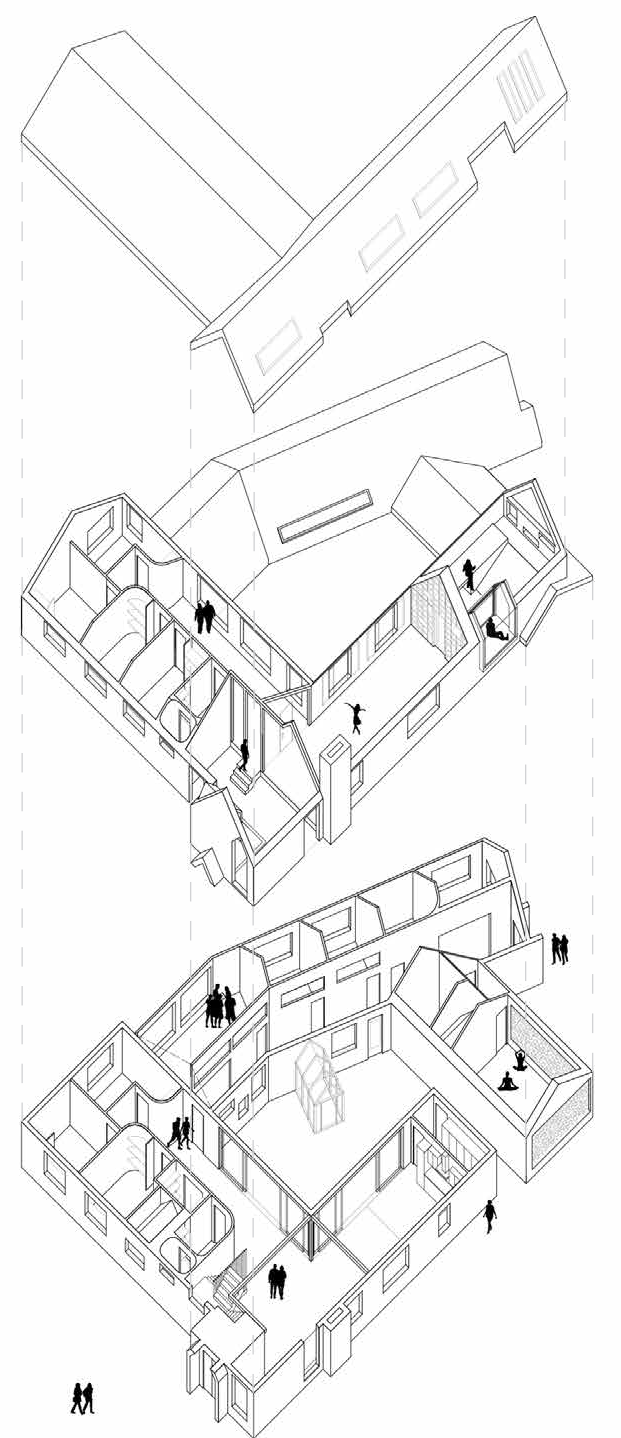

Figure 46: Exploded axonometric diagram.

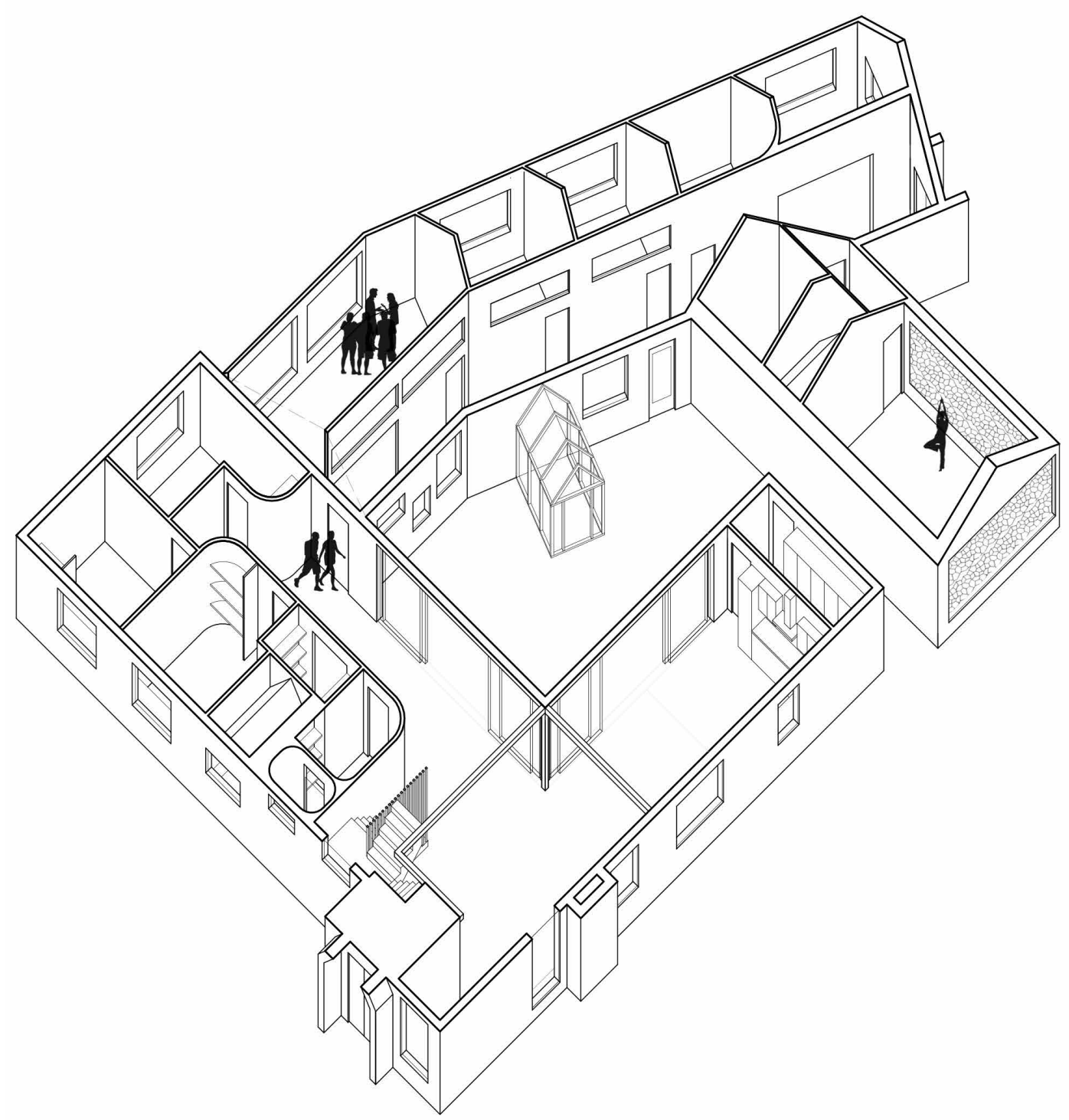

Figure 47: Ground floor axonometric diagram. 


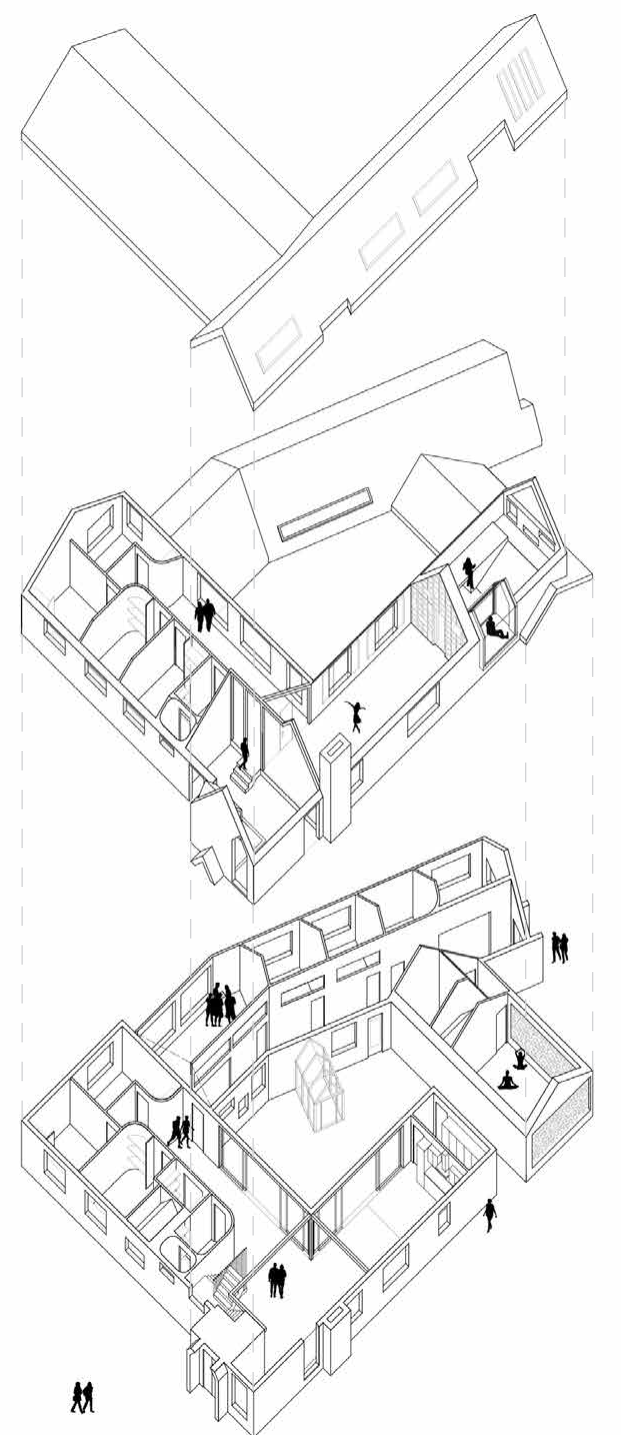

Figure 48: Exploded axonometric diagram.

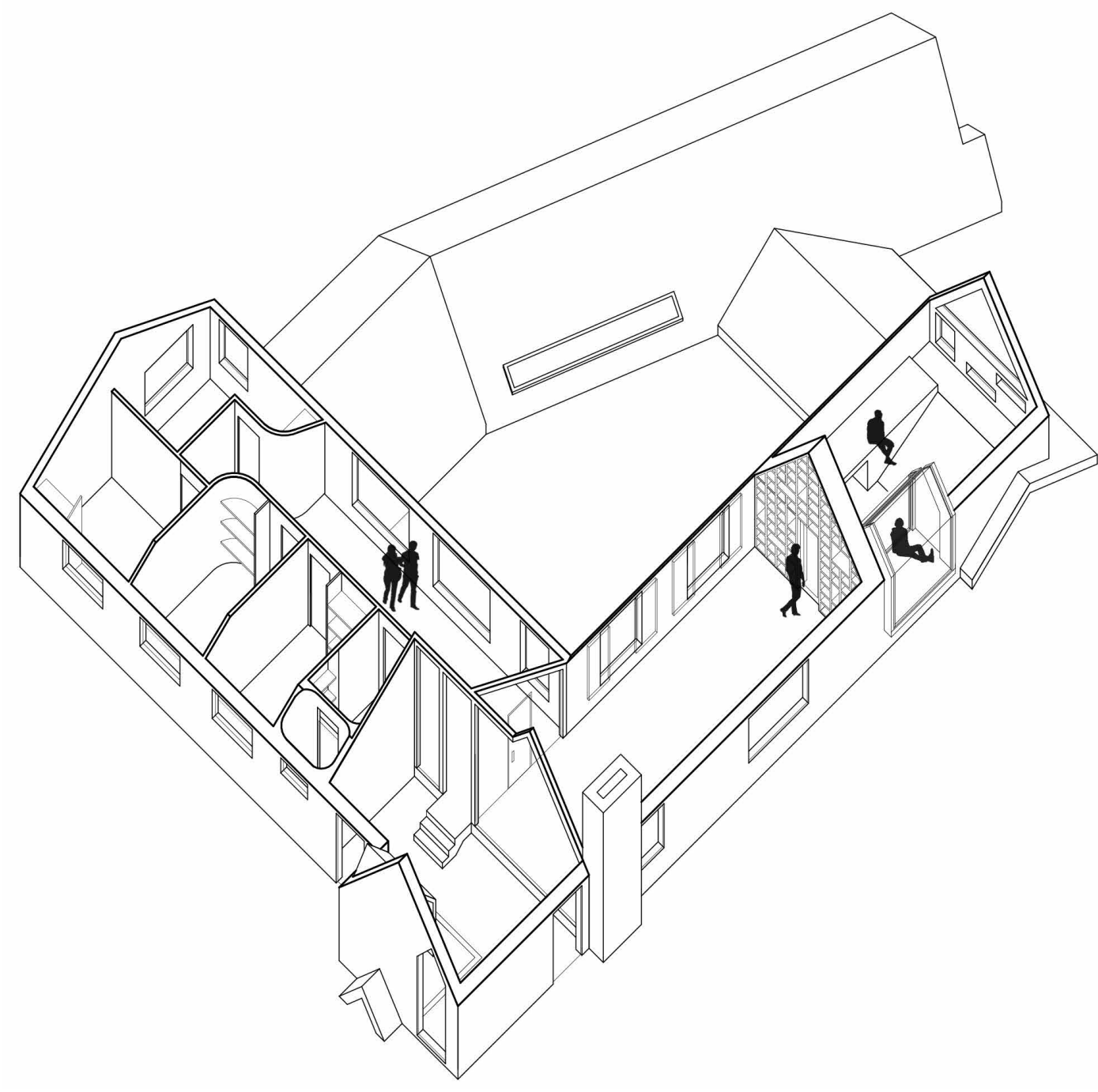

Figure 49: Second floor axonometric diagram. 


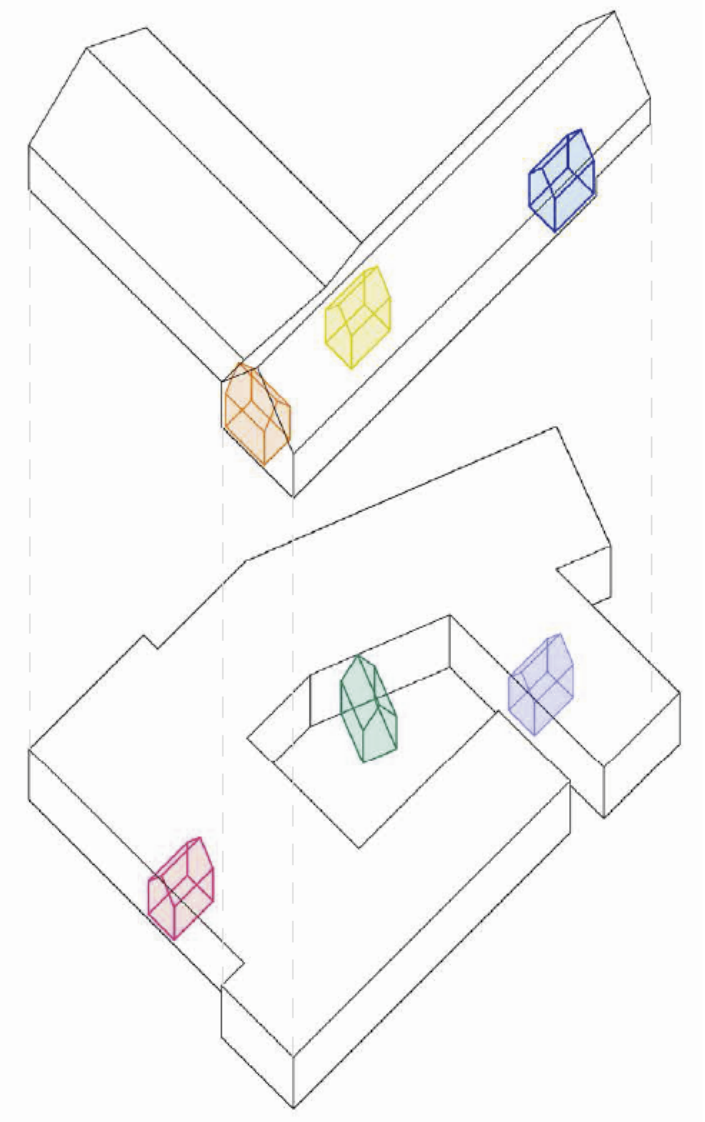

Figure 50: Massing model with enriched houses placed within.

\section{ii. A House Within A House}

...if I were asked to name the chief benefit of the house, I should say: the house shelters day-dreaming, the house protects the dreamer, the house allows one to dream in peace. ${ }^{122}$

- Gaston Bachelard (The Poetics of Space)

To further the idea of enrichment, six small archetypal houses - each emphasizing one of the qualities of enrichment determined in Part Two - are placed within the program to further support the mental realm. Each space serves as a private or semi-private space within the larger communal spaces for when an individual or small group wants to think, imagine, or daydream in solitude and peace.

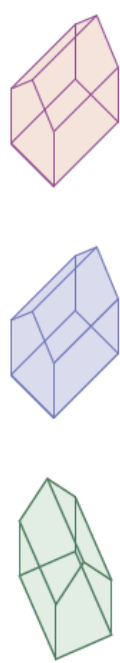

Social Interaction

The Coffee House

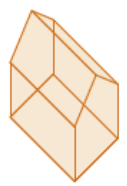

Play

The Play House

\section{Storytelling}

The Steam House

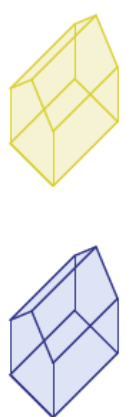

\section{Novelty \& Ambiguity}

The Bath House

\section{Perceptual Richness}

The Green House

\section{Metaphor}

The Dream House 


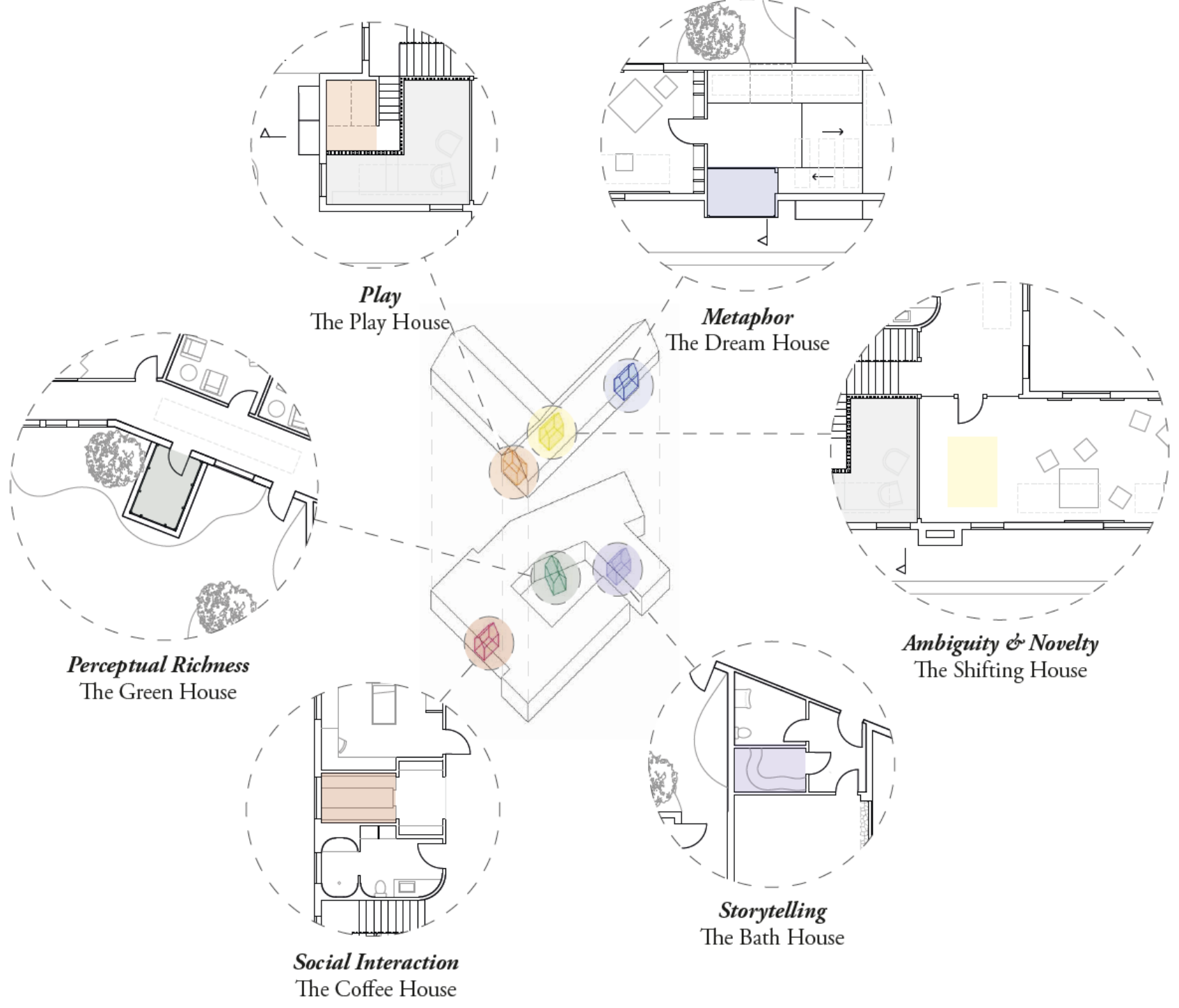

Figure 51: Location of enriched houses placed within. 


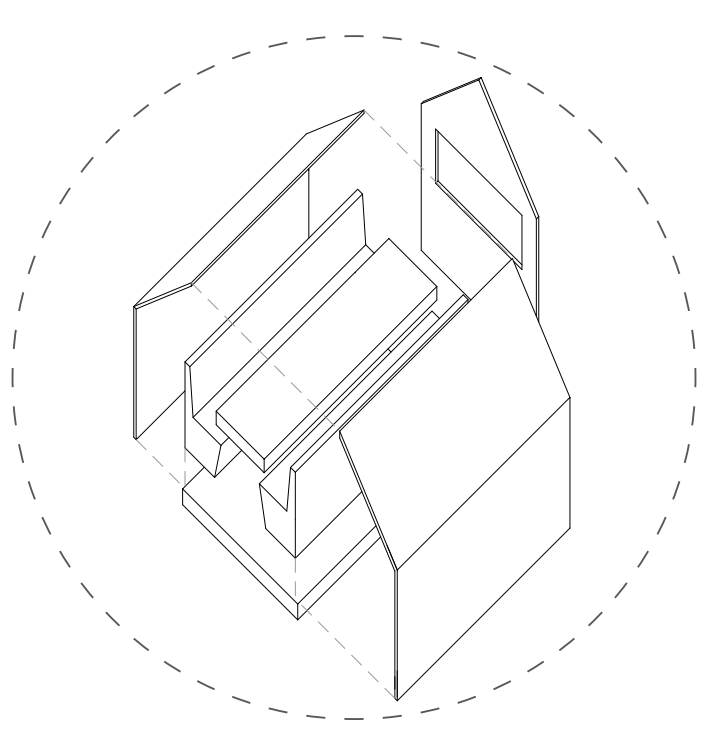

Social Interaction - The Coffee House

The coffee house has a long history of creating a sense of community and being a place where people meet and discuss ideas or enjoy face-toface social interaction. They are also places to escape, work, or quietly read a book. Inspired by a restaurant booth, the coffee house is located on the ground floor where residents can interact in small groups.

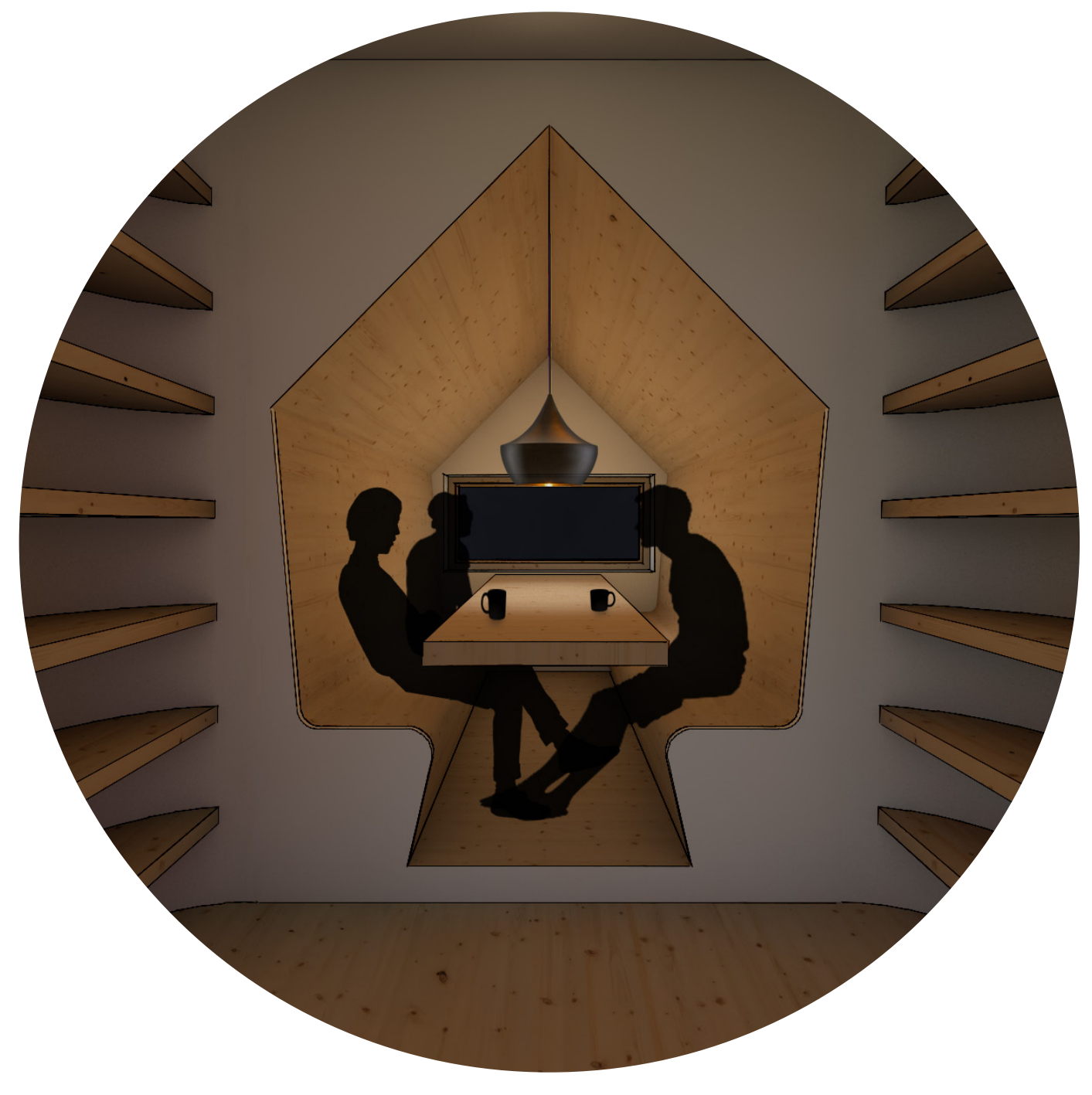

Figure 52: Interior view of the Coffee House. 


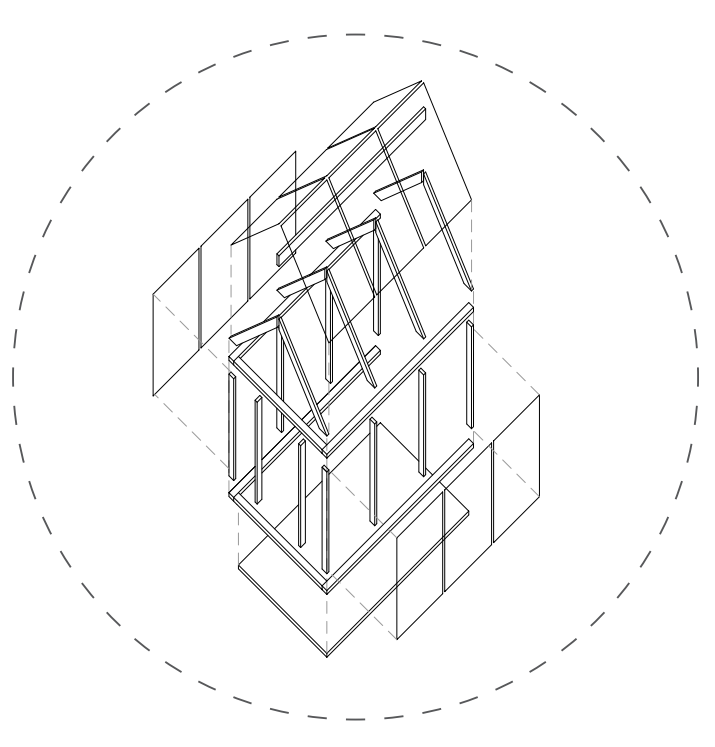

Perceptual Richness - The Green House

A layering of materiality and texture entice the senses of touch and taste, the eyes are drawn to the encompassing nature, the nose is attracted to the rich aromatic atmosphere created by small garden planters of lavender and herbs, and the ears are lured by the water trickling down a water feature. Through nature and natural materials the greenhouse engages all the inhabitants senses, creating a perceptually rich environment.

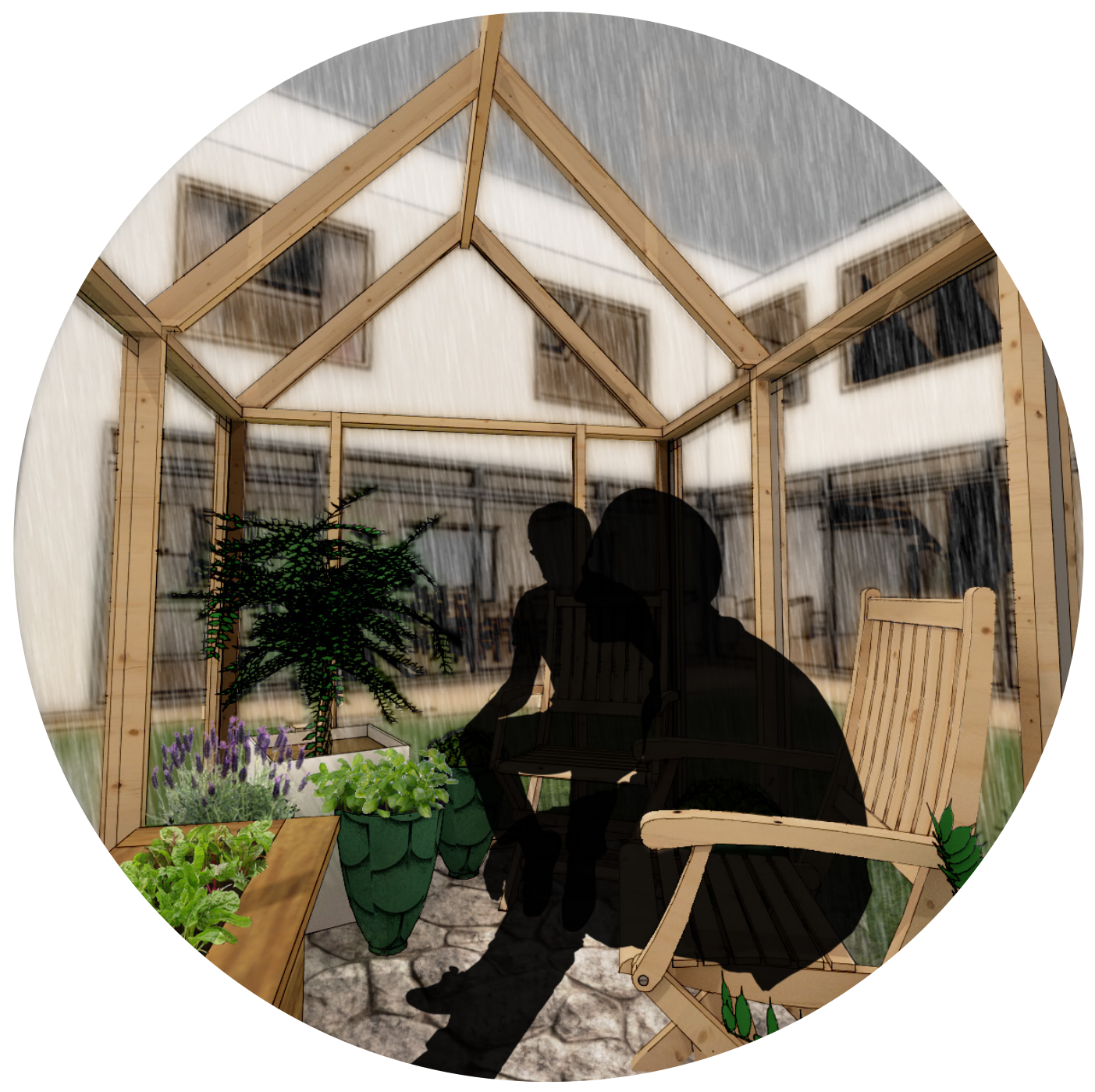

Figure 53: Interior view of the Green House. 


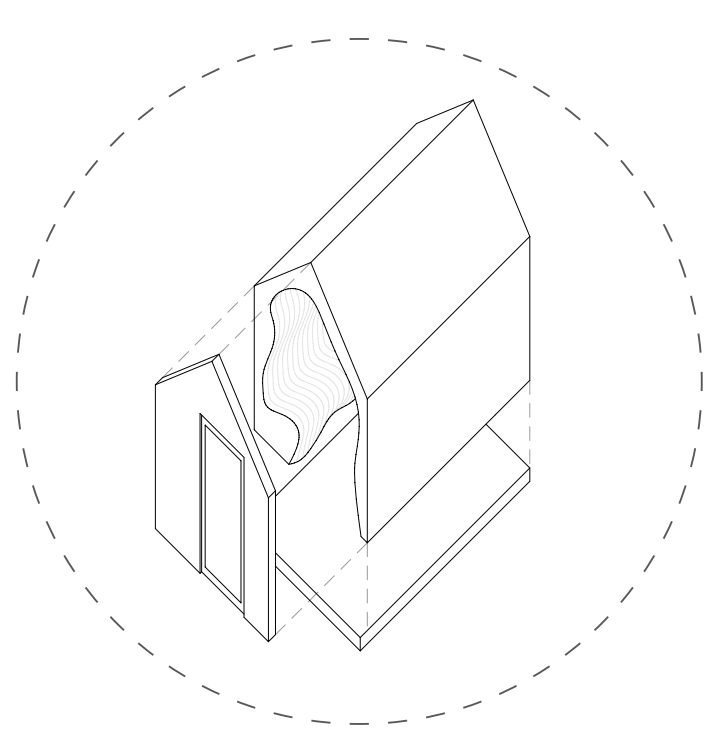

Storytelling - The Bath House

Saunas, also known as bathhouses, are places of experience that not only provide physical benefits but also strengthen social bonds. Located within the wellness component, the bath house, becomes an intimate space for residents, outpatients, and staff to share stories and form social bonds. The curved interior cedar walls and benches are sculpted out of the archetypal form of the house, creating a cave like space.

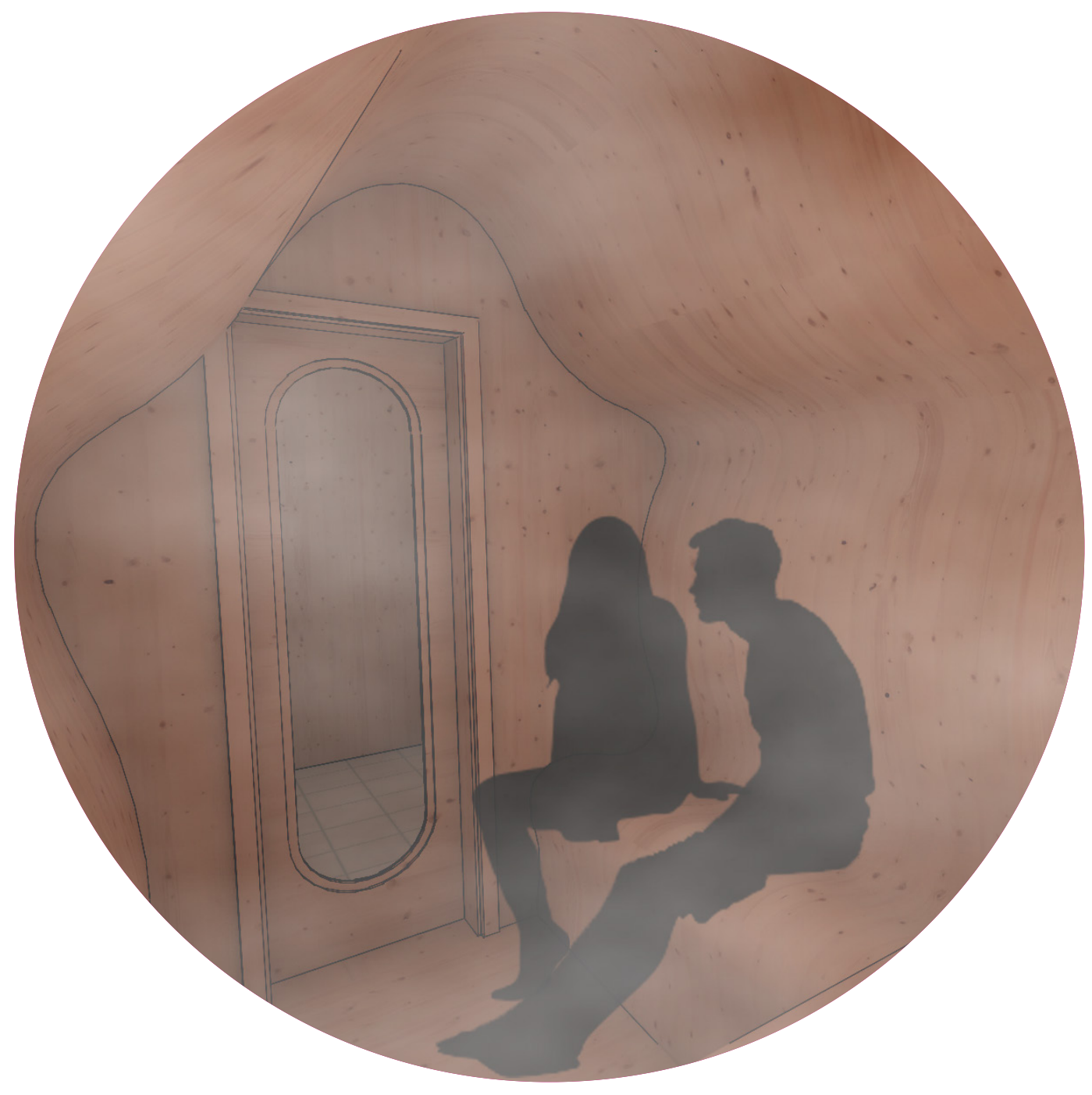

Figure 54: Interior view of the Bath House. 


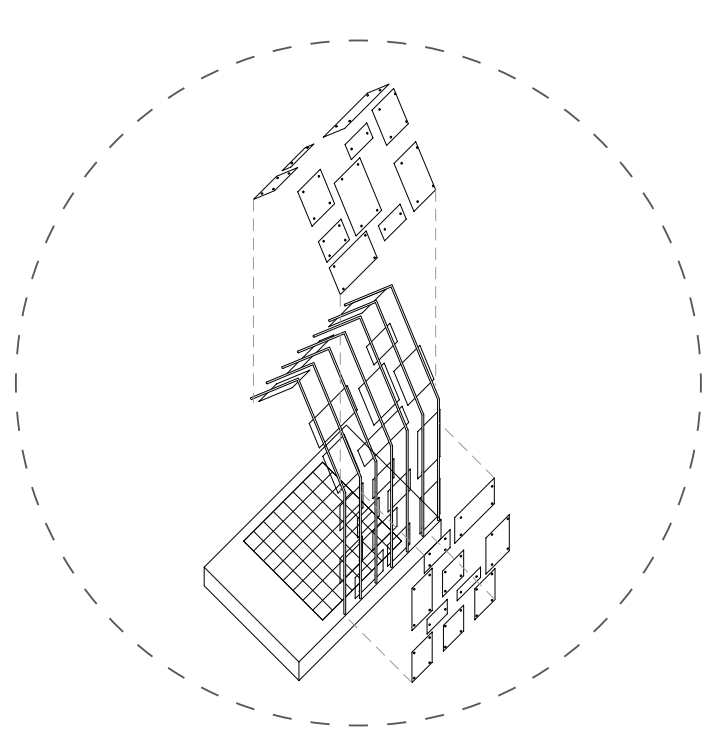

Play - The Play House

A small set of stairs leads residents up to the playhouse and looks down upon the communal areas on the ground floor - letting residents observe the activities with the house. Light shining through the bright colored plexiglass panels create a dance of color on the checkerboard floor. The wood checkerboard floor can be used as a large game board to stimulate play and social interaction between residents.

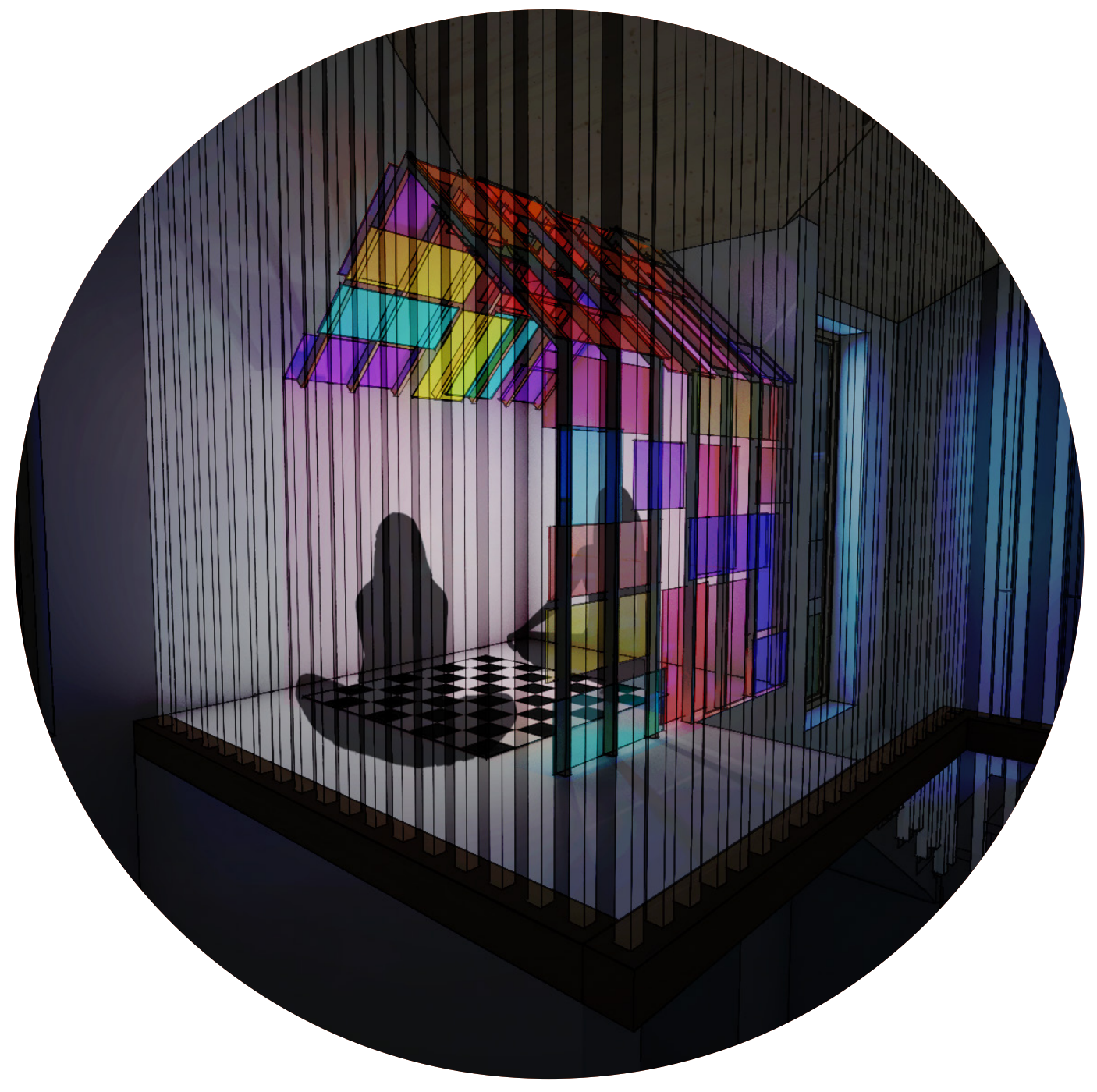

Figure 55: Interior view of the Play House. 


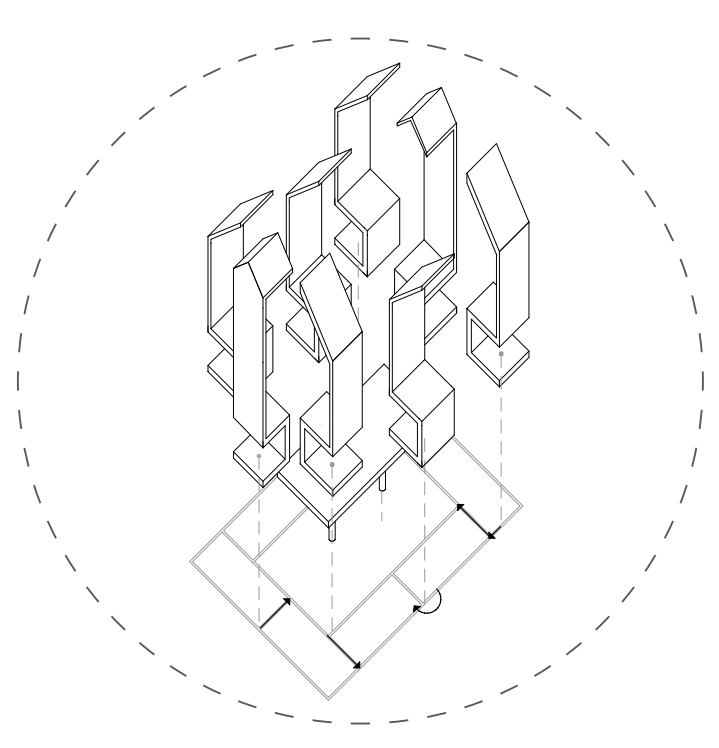

Ambiguity \& Novelty - The Shifting House

Moving elements change the space, allowing residents to play with the boundaries and void space of the archetypal form of a house. Together the seating area creates the outline of a house, once residents start to move and change the structure it becomes a house broken in space. It becomes multiple truths; a house, a broken house, a sculpture, and a seating area.

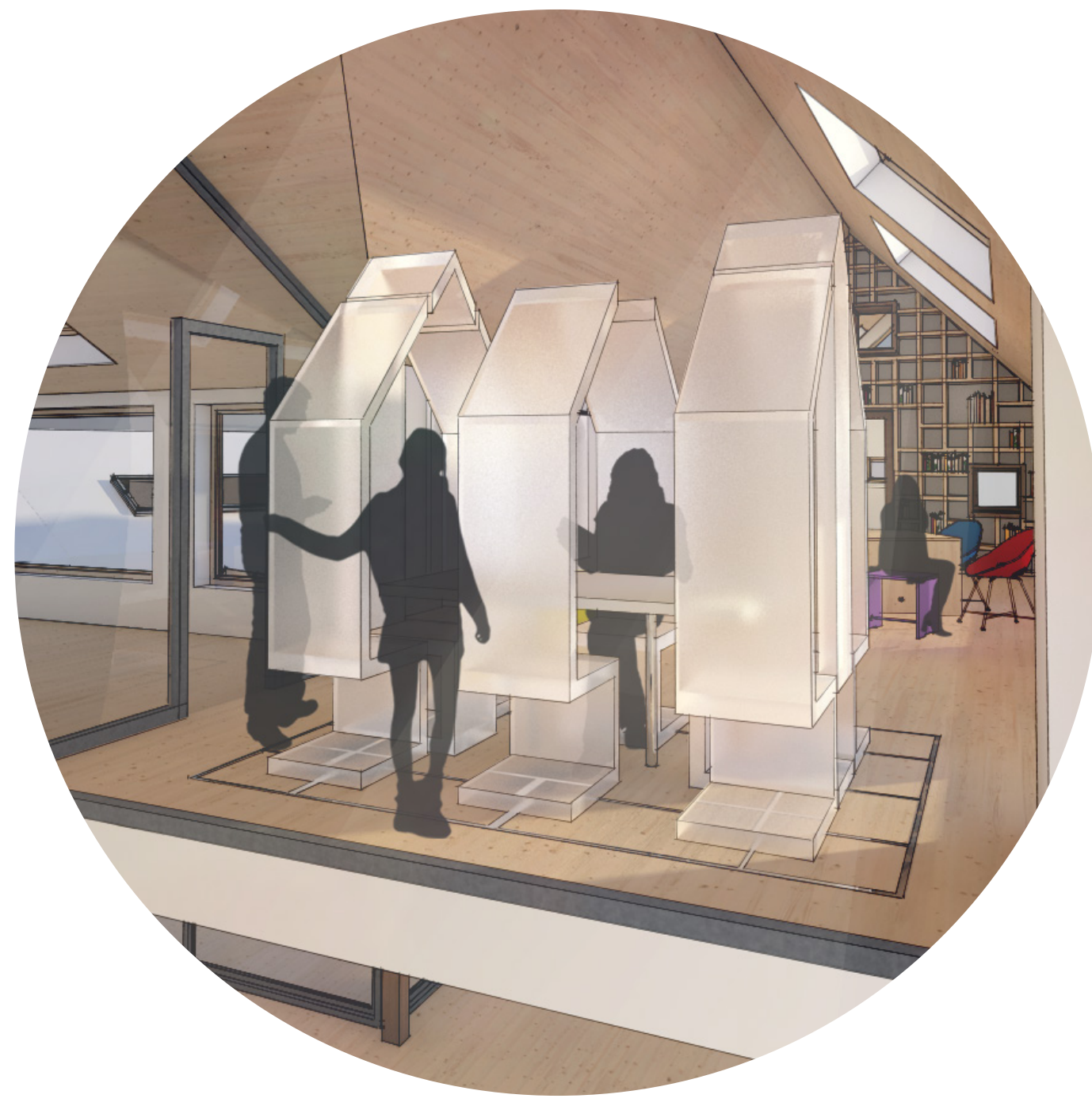

Figure 56: Interior view of the Shifting House. 


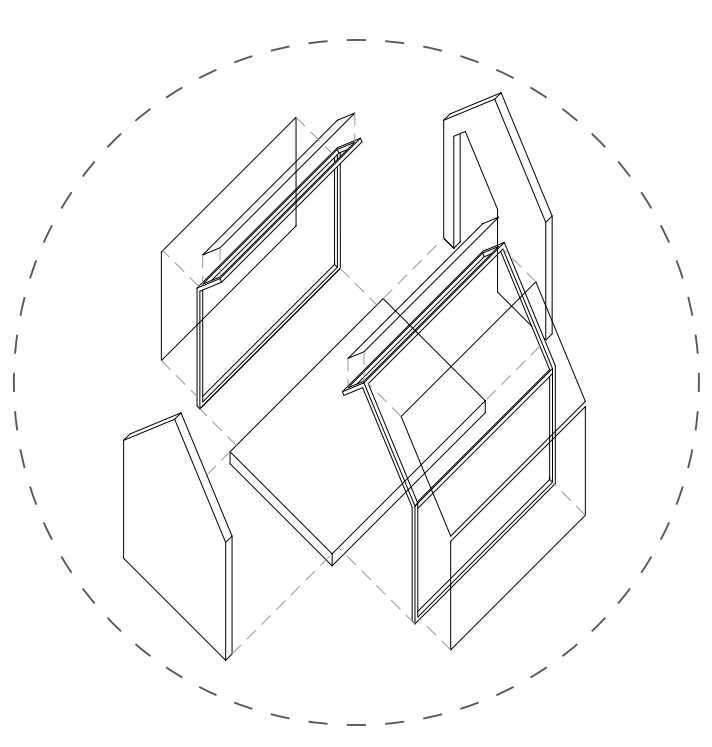

Metaphor - The Dream House

The glass and steel structure of the dream house gives the feeling of weightlessness. A place for residents to escape and daydream, the metaphor of floating among the clouds is embedded within the design of the dream house. The thin steel structure appears to be floating within the daydream space, and the interior uses soft and warm materials to allow one to dream in peace.

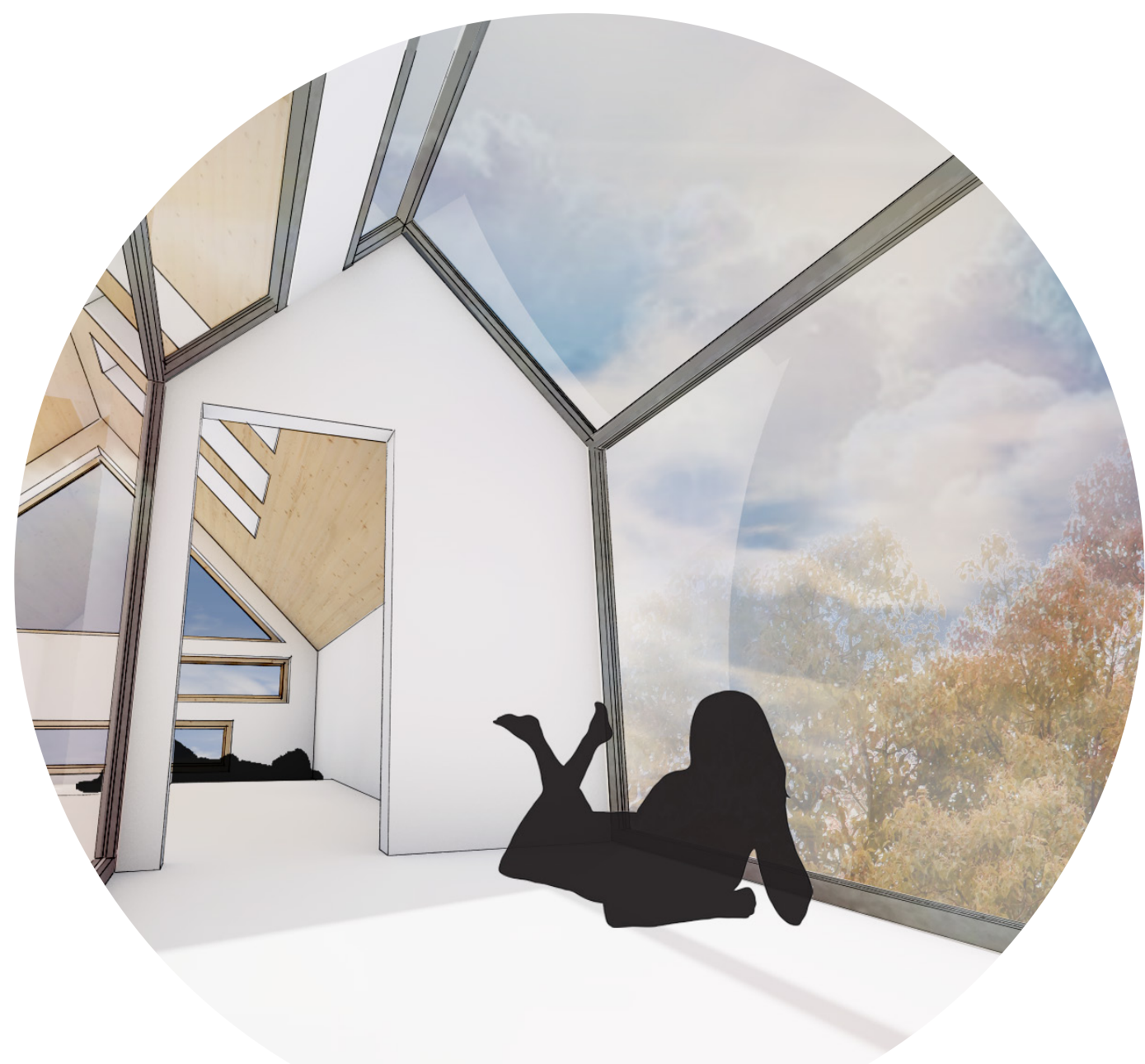

Figure 57: Interior view of the Dream House. 


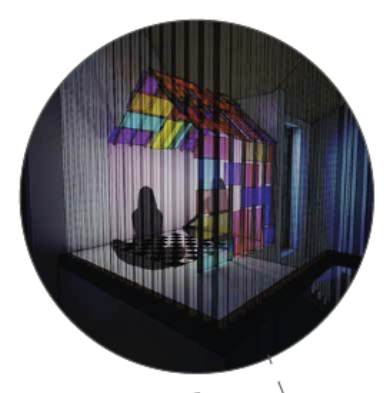

Play

The Play House

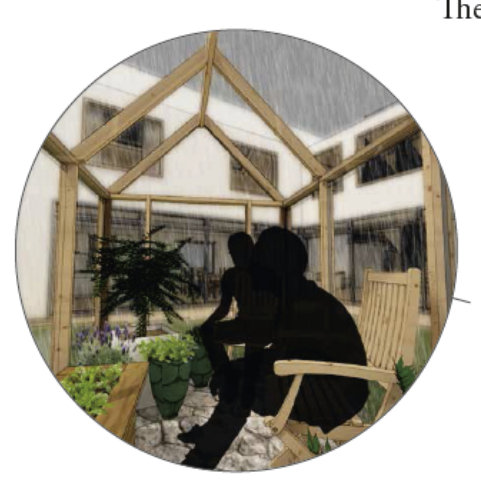

Perceptual Richness The Green House

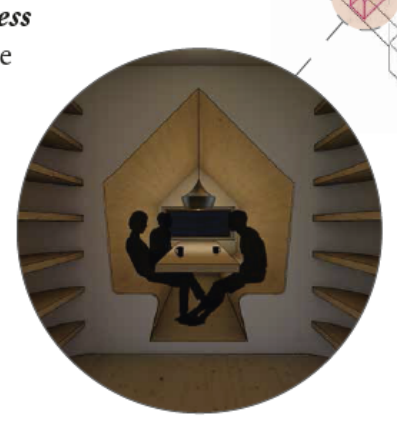

Social Interaction The Coffee House

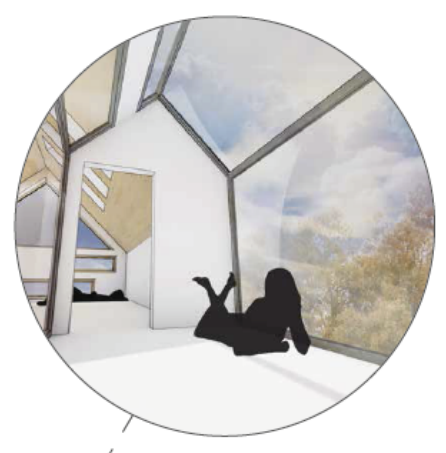

Metaphor The Dream House

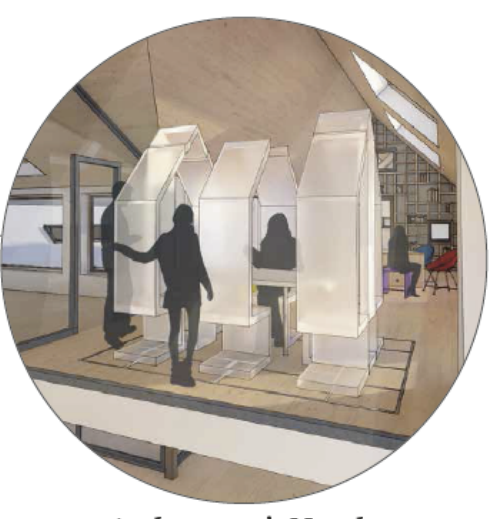

Ambiguity \& Novelty The Shifting House 


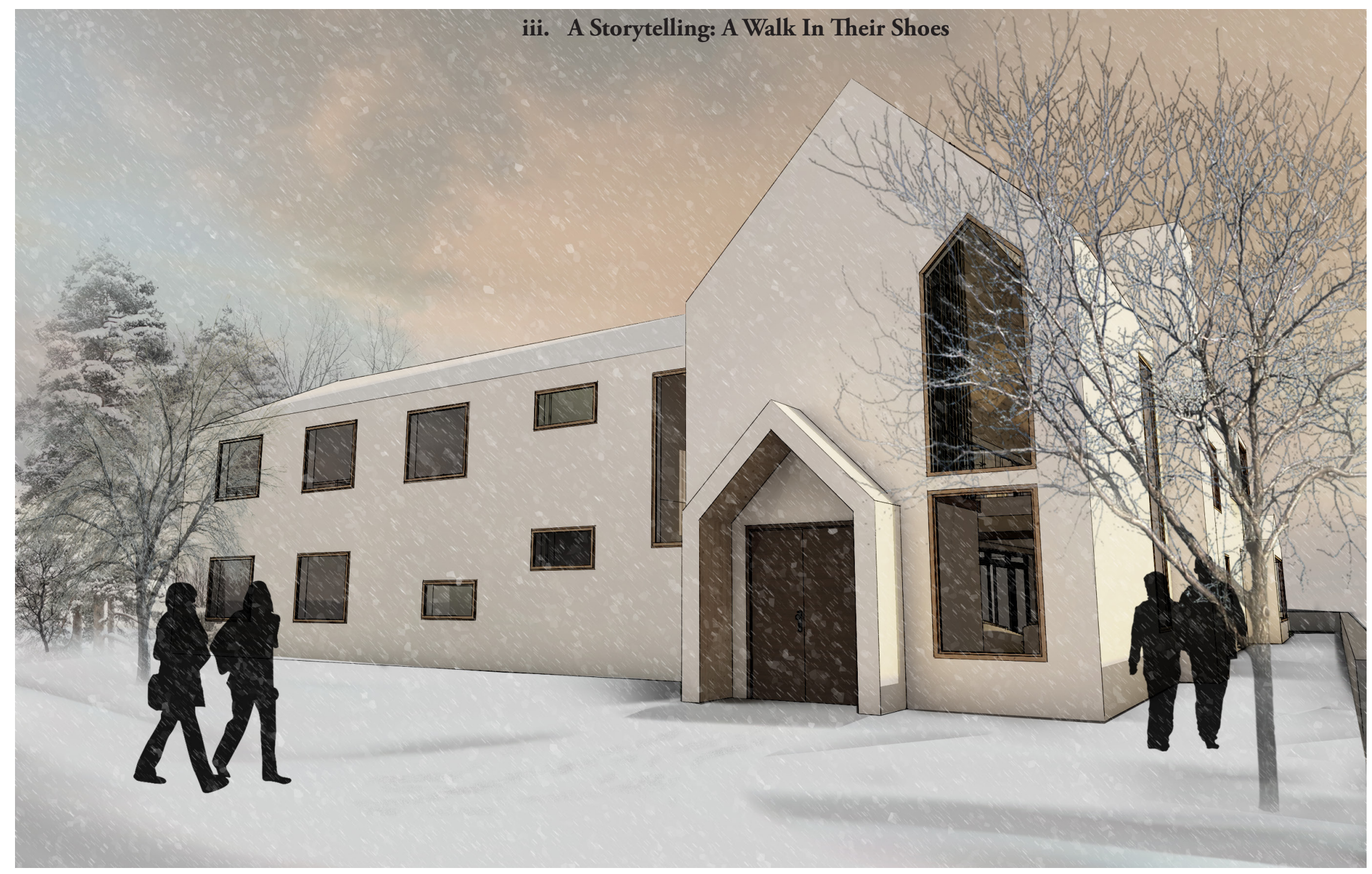

Figure 59: Exterior view of resident entrance 


\section{Emma}

The cold from the winter's air began to turn Emma's cheeks red. She stood outside the large wooden door of a white brick building that resembled her first home. She was scared for what waited inside. She looked down at her purple duffle bag and clenched the handles tight before ringing the doorbell. The door opened and a rush of warm air escaping from the inside brushed against her face. A young man appeared and greeted her with a large smile. The young man, named John, had met Emma last Saturday at the hospital. He was one of the live-in care specialists at the home. John helped Emma with her purple duffle bag and asked her to follow him. She stepped inside the small wooden foyer. She could smell something, something she recognized but couldn't quite figure out. As she entered into the space an encompassing warmth hugged her body, and she could see four people circled around a stone fireplace talking. It was the smell of a fire. "Meet Emma everyone", said John. They all looked over with inviting smiles, but she could only manage to give off a shy wave. She followed John up the stairs to the second floor, where a wooden plank cathedral ceiling covered the space. They stopped just outside the second door to the left. John needed to get back to making dinner with Jenna and Mark, his footsteps slowly faded away as he walked down wooden hallway. Emma opened up the door, and walked into the space. She could feel beneath her toes the carpet floor, took a big breath in, and dropped her bag. She didn't want to go back downstairs; there were so many people to meet. She started to feel overwhelmed, but felt comfort in the privacy of her room. She opened up her purple duffle bag and unpacked a photo of her mom and placed it on one of the wooden shelves. 


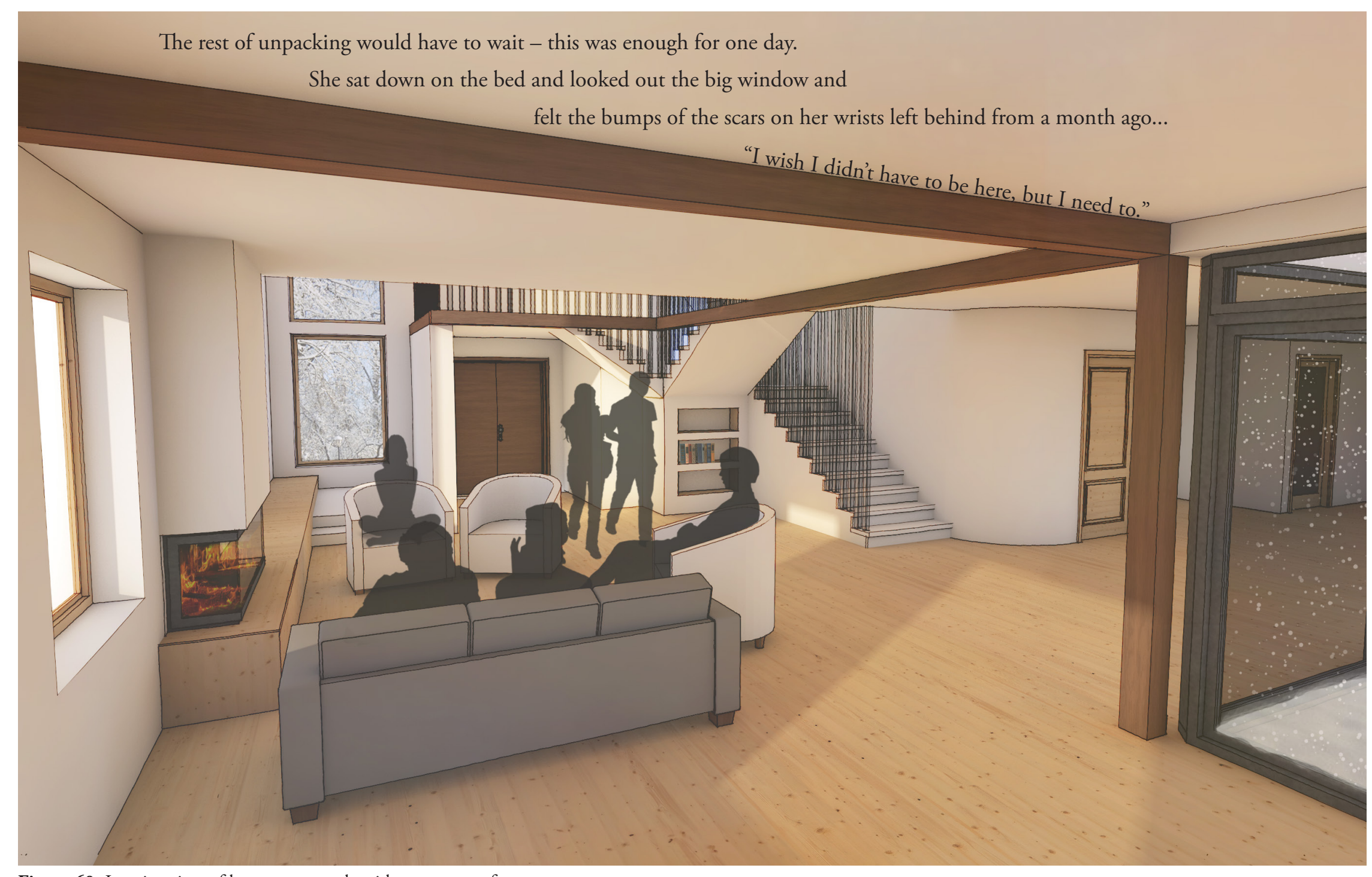

Figure 60: Interior view of lounge area and resident entrance from

Cameron Avenue. 


\section{Julie}

A soft repetitive knock

knock... $\quad$ knock... knock .. .knock ..

knock... knock... knock...

came from the daydreaming room. Julie, a young student from Carleton, was frustrated with her day and was tapping her index finger against the window. The small-suspended steel and glass room in the daydreaming space, known to the residents as the metaphor, was where she came to be alone - a place where she let her thoughts slowly drift away. She didn't like any of the other residents, she saw herself alone, the one friend she made, Rebecca, had been discharged a week ago.

Emma, attracted by the repetitive sound, could see Julie's bright red hair through a small window in the bookcase dividing the creative space and the daydreaming room. She turned the metal doorknob of the frosted glass door and entered the daydreaming space where the mid-day sun streamed through the windows and skylights creating a dance of shadows on the floor. Emma could feel the change in temperature between the two spaces; the daydreaming room was much warmer and comforting. She travelled up the white ramp and softly said, "Julie, are you ok?" Julie was lying down among a pile of plush white pillows in the glass room - still tapping her finger against the glass, "No. Go away. I don't need your help." Emma could see the trail of tears running down her pale skin... 


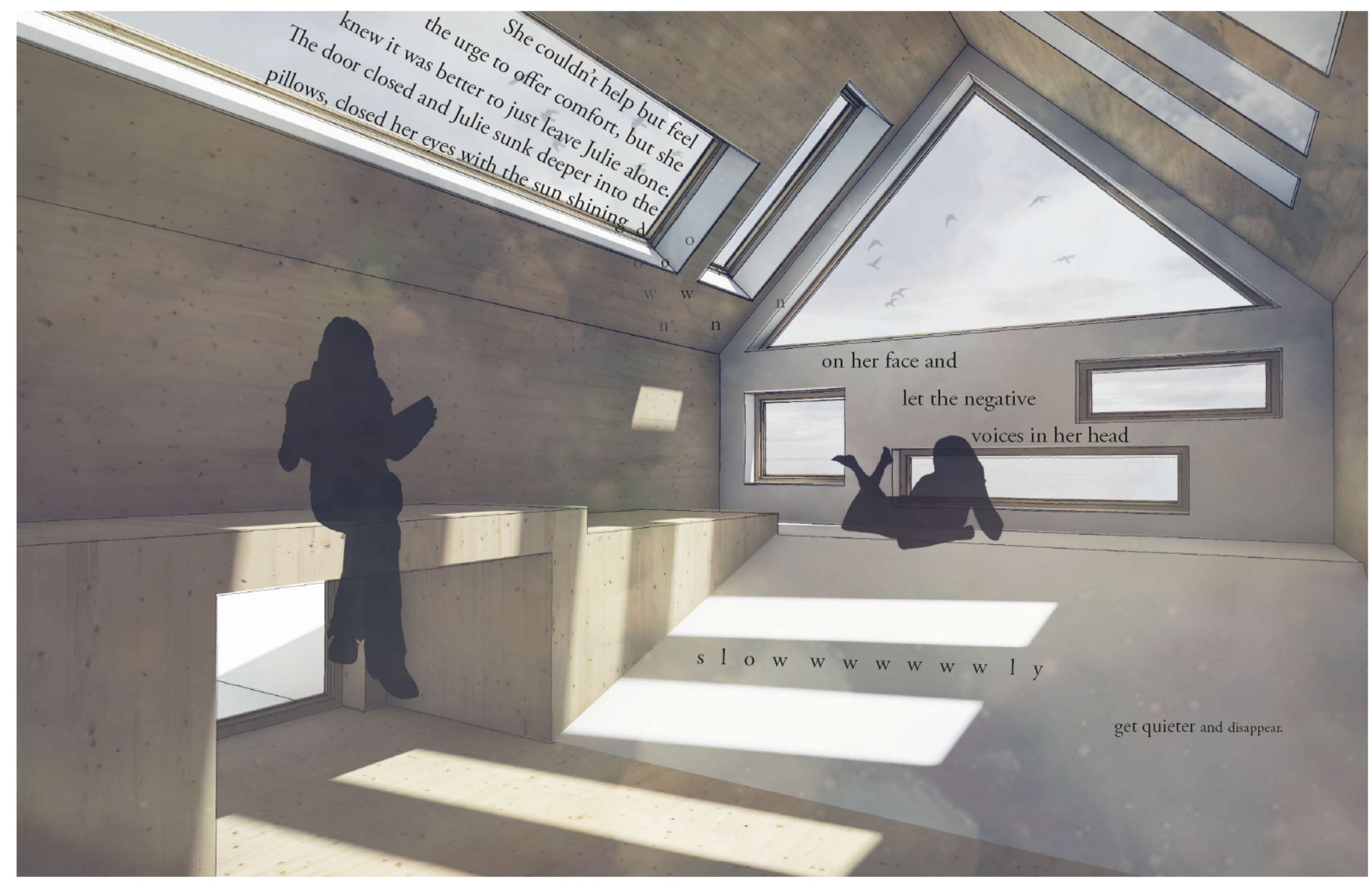

Figure 61: Interior view of daydreaming space. 


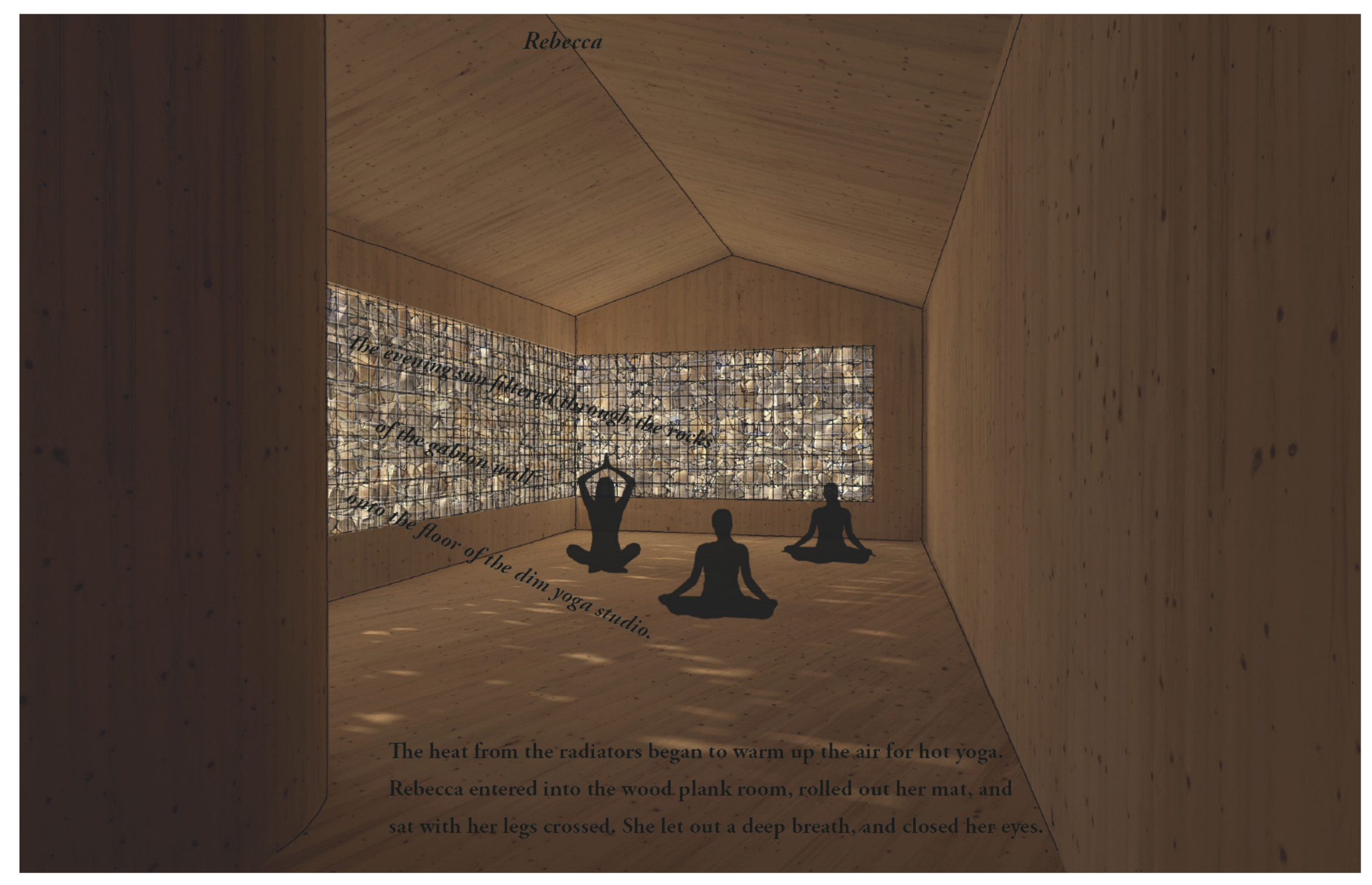

Figure 62: Interior view of yoga / fitness studio. 
The warm air was drawing out the smell and moisture of the cedar walls, and with Rebecca's next breath in she was brought back to her first time practicing yoga at the centre. It was roughly six weeks since the day she first become a resident - she remembered how stressed and anxious she was, her foot began to twitch. A couple more deep breaths in and she thought to her self, "you've come a long way, I'm proud of you." She reminisced over the feeling of accomplishment she had when walked out the front doors and was discharged to become an outpatient. Her head felt so much lighter, clearer - she felt the smallest feelings of happiness again. She barely noticed the yoga instructor step into the room and class began.

Every night following yoga, Rebecca met with Julie in the sauna. She opened the door of the yoga studio and a rush of cold air hitting her body and cool tiles on her toes raised the hairs on her arms. A wave of hot air crashed into her when she opened the small door to the left and entered the bath house. There was Julie, sitting in the dim lighting with her hands clenching the edge of the curved wooden bench. "I really need to tell you something...you're the only person I can trust," whispered Julie. The space deadened the sounds from the exterior, and Julie's whisper was crystal clear. Rebecca climbed up to the second bench of the sauna and with her arms wide open gave Julie a long embracing hug, and she proceeded to tell Rebecca her story. "I was nine years old when..." 


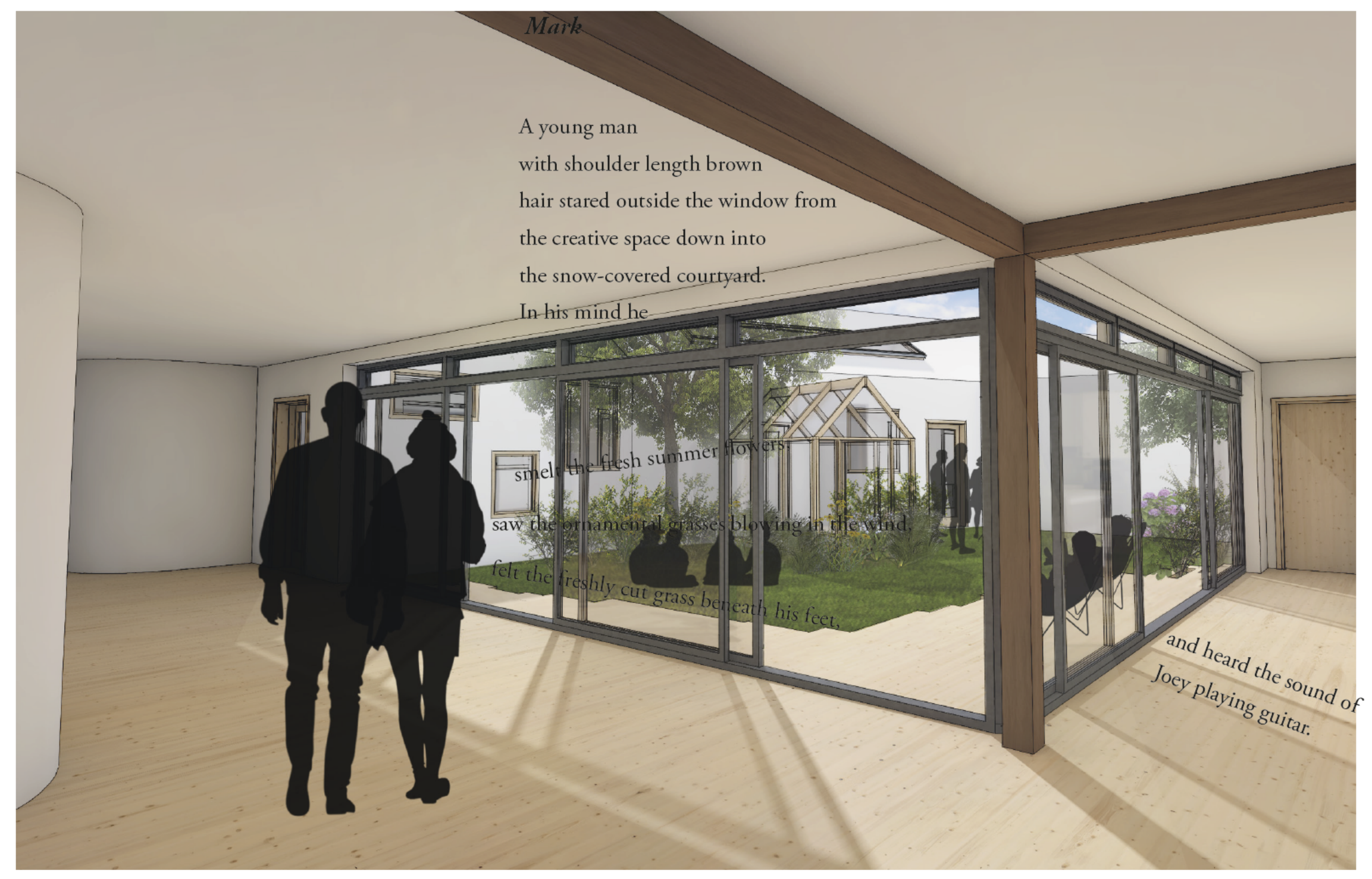

Figure 63: Interior view of central courtyard. 
He sat there, almost frozen, until the closing of a door snapped him out of his daydream. "Mark, cooking class is starting soon," said John, "are you ok?" "Yeah. Fine.” replied Tim. He looked back down into the courtyard, at the art wall where he had graffitied his tag. The peeling red paint made it hard to decipher but beside it said 'M-K 2015'. He sadly faced the reality that he was back again. His eyes began to well up and fists clenched into a tight ball. It was hard to be back, he didn't know anyone except John, the house leader. John could see that Mark was upset. "It's ok Mark, everything will be alright. Sometimes life is unfair, you didn't ask for this, but I know you're strong enough to get through this and I will be here for you." Mark stood up from the wooden yellow chair, he hadn't even noticed Jenna in the room - she was sketching out something in black marker on the sliding sunshade. He followed John over to the glazed wall and opened the door. He could smell garlic cooking and as he walked down the stairs he could hear it sizzling in the frying pan. Standing around the large metal kitchen island chatting was Emma and Julie. The orange winter light began to filter through the large windows on the west side of the house. "Tonight," John said, "were going to learn how to cook and budget for an Italian meal." All of the ingredients were laid out on the island. John handed Mark a bundle of fresh basil that was grown in the greenhouse. As Mark cut up the basil, he remembered sitting in the greenhouse on a humid summer evening when the rain flowed down the glass creating a soft trickling sound, and the aroma's of lavender, basil, and thyme filled the air. He had drifted off again and quickly looked up to see if anyone saw, John smiled. Mark laughed and remembered John was truly there for him, he was one of the people in his life he could trust. I'm not alone, Mark thought to himself and he realized had the support he needed to feel well again. 


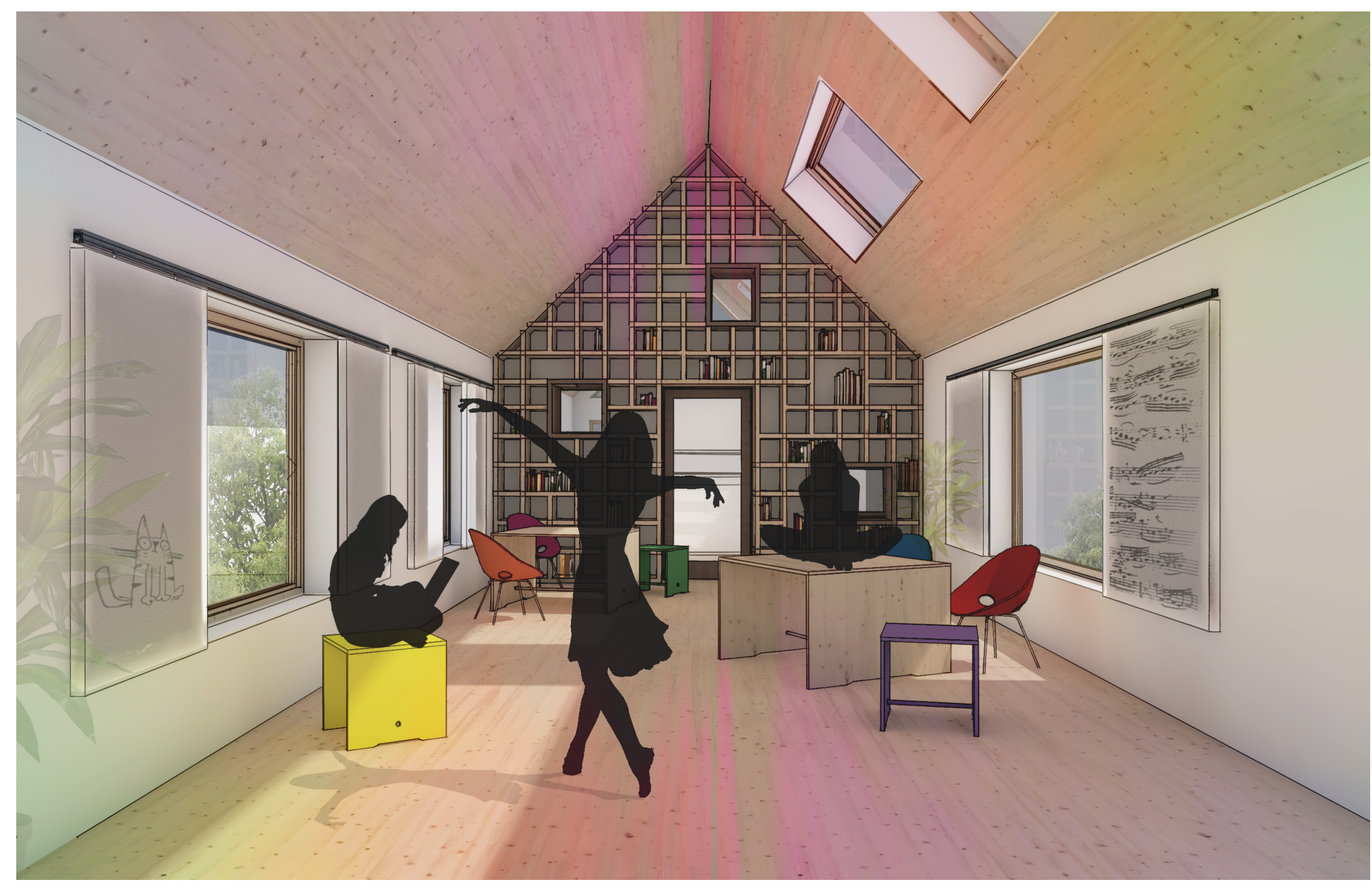

Figure 64: Interior view of Creative Space. 


\section{Conclusion}

Although architecture and design is not any 'cure' for mental illness, the effects of the built environment on the mind and body could play a crucial role within their complex treatment. As seen within enriched environments from neuroscience, the environment has the incredible ability to alter brain structure and chemistry. Emerging biological research such as this will, and should, have a vast impact on the discipline of architecture. This is especially true for healthcare facilities, educational institutions, and office buildings.

Neuroarchitectural theorists such as Marco Frascari, Harry Mallgrave, and Juhani Pallasmaa, have begun to offer an idea as to how this emerging biological research can be applied to architecture. However, how this research will truly influence the discipline of architecture is yet to be seen. It should be understood that neuroarchitecture is not another ism or style of architecture; instead it is a layer of knowledge that can enrich the design of any built space - especially within the realm of healthcare, where current design often places the machine at the centre of design and disregards the physical and psychological well-being of the humans within. Neuroarchitecture attempts to bring together the neurological union of body and mind within the built environment, which as Marco Frascari said is the real project of architecture.

Based upon the research on the design of psychiatric facilities, healing spaces, neuroscience, and neuroarchitecture, the design project within this thesis aims to provide an enriched environment that not only promotes physical wellbeing through healing spaces, but also supports mental wellbeing 
- creating an architecture that supports the mental realm needed for daydreaming, thinking, and imagining. It also addresses the critical gap between the services and facilities offered for transitional youth within Ottawa in hopes of providing continuity of treatment ensuring that patients don't fall through the cracks of the mental health care system. Step-up/step-down facilities are a new emerging type of residential care that not only Ottawa but Canada also severely lacks. These facilities take into consideration the extreme difficulties and stress experienced by transitional youth in life and when they are forced to transition from the child mental health care system to the adult mental health care system. The small scale of the program for step-up/step-down facilities makes it possible for multiple facilities to be placed within the city so transitional youth can access treatment within a familiar community and continue schooling. The scale also allows for the program to fit within residential neighborhoods and promote a deeper connection between the psychiatric centre and surrounding community. This can help reduce the negative stigma associated with psychiatric facilities through the interaction of residents of the facility and residents of the community. Although the stigma attached to these disorders may never fully disappear, as we further our biological understanding of mental illnesses, it may become easier for society to understand and acknowledge that mental illnesses are objectively real illnesses. By means of education, interaction, and understanding, those affected with mental illnesses and those who are in need of help may seek the help and support they need, instead feeling ashamed or be in fear of being labeled.

In conclusion, architects have the ability to significantly shape ones perceptions of space and therefore affect both body and mind. A deeper understanding of whom we are designing for places the human at the centre of design and aims to satisfy our needs and desires instead of producing a fanciful forms, an architecture of commodity. 


\section{[ Endnotes ]}

1 Sturges, James W. "Biological Views.” Abnormal Psychology across the Ages. Ed. Thomas G. Plante. Santa Barbara, CA: Praeger, 2013. Print. p.186.

2 Sternberg, Esther M. Healing Spaces: The Science of Place and Well-being. Cambridge, MA: Belknap of Harvard UP, 2009. Print.

3 Eisch, A. J., H. A. Cameron, J. M. Encinas, L. A. Meltzer, G.-L. Ming, and L. S. Overstreet-Wadiche. "Adult Neurogenesis, Mental Health, and Mental Illness: Hope or Hype?" Journal of Neuroscience 28.46 (2008): 17851791. Web. Pg. 11785.

4 Foucault, Michel. The Order of Things: An Archaeology of the Human Sciences. New York: Pantheon, 1971. Print.

5 Mayers, Linda A, Papiasvili, Eva A. "Perceptions, Thoughts, and Attitudes in the Middle Ages." Abnormal Psychology across the Ages. Ed. Thomas G. Plante. Santa Barbara, CA: Praeger, 2013. Print. p.16.

6 Ibid., p.17.

7 Manderscheid RW, Ryff CD, Freeman EJ, McKnight-Eily LR, Dhingra S, et al. Evolving definitions of mental illness and wellness. Prev Chron Dis. Epub. 2009. Web.

8 Preamble to the Constitution of the World Health Organization as adopted by the International Health Conference, New York, 19 June - 22 July 1946; signed on 22 July 1946 by the representatives of 61 States (Official Records of the World Health Organization, no. 2, p. 100) and entered into force on 7 April 1948.

9 Spitzer, Robert L. DSM-IV Casebook: A Learning Companion to the Diagnostic and Statistical Manual of Mental Disorders, Fourth Edition. Washington, DC: American Psychiatric, 1994. Print.

\section{Manderscheid, 2009. Web.}

11 Diagnostic and Statistical Manual of Mental Disorders: DSM-5. Washington, D.C.: American Psychiatric Association, 2013. Print. p.20

12 "stigma." The Oxford English Dictionary. 2005. Print.

13 "Stigma and Discrimination - Canadian Mental Health Association, Ontario Division." Canadian Mental Health Association Ontario Division. N.p., n.d. Web. 20 Oct. 2014.
14 "Initiatives: Opening Minds." Mental Health Commission of Canada. N.p., n.d. Web. 20 Sept. 2014.

15 Cannon, Brooke J., "Film Portrayl of Psychopathology and Its Treatments." Abnormal Psychology across the Ages. Ed. Thomas G. Plante. Santa Barbara, CA: Praeger, 2013. Print. p. 153

16 "Topics: Stigma." Mental Health Commission of Canada. N.p., n.d. Web. 28 Sept. 2014.

17 Why Investing In Mental Health Will Contribute To Canada's Economic Prosperity And To The Sustainability Of Our Health Care System. Rep. Mental Health Commission of Canada, n.d. Web. <http://strategy.mentalhealthcommission.ca/pdf/case-for-investment-en. pdf>.

\section{Ibid.}

19 Investing in Mental Health. Geneva: World Health Organization, 2003. Print.

20 Smetanin, P., Stiff, D., Briante, C., Adair, C., Ahmad, S. \& Khan, M. (2011). The life and economic impact of major mental illnesses in Canada: 2011 to 2041. RiskAnalytica, on be- 
half of the Mental Health Commission of Canada. Pg. 6.

21 Why Investing In Mental Health Will Contribute To Canada's Economic Prosperity And To The Sustainability Of Our Health Care System.

22 Davidson, Simon, MB, BCh, FRCP(C), and Mario Cappelli, PhD, CPsych. "Transitioning Youth from Child and Adolescent Mental Health Services to Adult Mental Health Services." We've Got Growing up to Do (n.d.): n. pag. May 2011. Web. 10 Dec. 2014.

23 Statistics Canada (2014). Leading causes of death, total population, by age group and sex, Canada, 2011.

24 The Shared Responsibility: Ontario's Policy Framework for Child and Youth Mental Health in 2006, The policy outlines five guiding principles to achieve this: 1 . Child, youth and family-centered: services and supports should be developmentally- and age-appropriate, culturally and linguistically relevant, responsive, and matched to the strengths and needs of children, youth, and their families/caregivers. Community Driven: services and supports should be provided as close to home as possible. A supportive community promotes healthy child and youth development. 2. Accessible: services and supports should be accessible to all children, youth and their families/caregivers who need them in a timely and appropriate manner.. 3. Coordinated and collaborative: the child and youth mental health sector at government and community levels should enhance coordination and collaboration within and across all child- and youth-serving sectors. 4. Evidence-based and accountable: research points to the most effective practices and programs for improving the lives of children, youth and their families/caregivers. Service providers should be educated, trained and supported in evidence-based practices and should consistently evaluate outcomes as part of their continuous quality improvement efforts."

\section{Davidson, Cappelli, 2014: p.17.}

\section{Ibid., p.16.}

27 Canadian Institute for Health Information, Hospital Mental Health Services in Canada, 2009-2010 (Ottawa, Ont.: CIHI, 2012).

\section{Ibid.}

29 "Hospitals: Questions And Answers." FAQ. Ontario Ministry of Health and Long Term Care, 11 July 2014. Web. 2 Oct. 2014. <http:// www.health.gov.on.ca/en/common/system/services/hosp/faq.aspx>.

30 The Human Face of Mental Health and Mental Illness in Canada, 2006. Ottawa: Public Health Agency of Canada, 2006. Print.
31 "Home, Community and Residential Care Services." Assisted Living Services in Supportive Housing Overview. Ontario Ministry of Health and Long Term Care, 29 Nov. 2013. Web. 28 Dec. 2014

32 Sternberg, 2009:p. 3

33 Ibid., p. 24.

34 Sensory Modulation in Acute Mental Health Wards: A Qualitative Study of Staff and Service User Perspectives. The National Centre of Mental Health Research, Information and Workplace development. Auckland, New Zealand. 2011. p. 10.

35 Evans, G. W. "The Built Environment and Mental Health.” Journal of Urban Health: Bulletin of the New York Academy of Medicine 80.4 (2003): 536-55. Web.

36 Sternberg, 2009: p. 46.

37 Ibid., p. 51-52

38 Mood Disorders Society of Canada. "Depression.” (n.d.): 1-16. What Is Depression? Web. 10 Dec. 2014.

39 Evans, 2003: p. 544.

40 Ibid., p. 544 
41 Sternberg, 2009: p.87.

42 Ibid., p.87

43 Perry, E., Perry, N. "Aromatherapy in the Management of Psychiatric Disorders: Clinical and Neuropharmacological Perspectives." CNS Drugs. 2006; 20(4): p. 257-80.

44 Komori, T., Fujiwara, R., Tanida, M., Nomura, J., Yokoyama, MM. "Effects of Citrus Fragrance on immune function and depressive states." Neuroimmunomodulation. 1995 MayJun;2(3):174-80.

45 Betts, T. "Use of aromatherapy (with or without hypnosis) in the treatment of intractable epilepsy: a two-year follow up study." 2003 Dec;12(8):534-8.

46 Schweitzer, Marc, Laura Gilpin, and Susan Frampton. "Healing Spaces: Elements of Environmental Design That Make an Impact on Health." The Journal of Alternative and Complementary Medicine 10.1 (2004): 71-83. Web.

\section{Ibid.}

48 Maller, C., Townsend, M., St. Leger, L., Henderson-Wilson, C., Pryor, A., Prosser, L., \& Moore, M. (2008). Healthy parks, healthy people: the health benefits of contact with nature in a park context. Melbourne, Australia: Deakin University and Parks Victoria.
49 Evans, 2003: p. 546.

50 Department of Veterans Affairs, Office of Construction \& Facilities Management. "Mental Health Facilities - Design Guide December 2010” Rev. Aug. 1, 2014.

\section{Ibid.}

52 In 2013 The National Association of Psychiatric Health Systems developed a design guide for the built environment of behavioural health facilities that classifies the varying levels of security (with level 5 requiring the most precautions) based on the staff's knowledge of the patient and the amount of supervision the patient will have while using that part of the facility: Level 1. Staff and service areas where patients are not allowed. Level 2. Corridors, counseling rooms, interview rooms and smoking roomswhere patients are highly supervised and not left alone for periods of time. Level 3. Lounges and Activity Rooms - where patients may spend time with minimal supervision. Level 4. Patient rooms (semi-private and private) and patient toilets- where patients spend a great deal of time alone with minimal or no supervision. Level 5. Admissions rooms, examination rooms, and seclusion rooms - where staff interact with newly admitted patients that present potential unknown risks and/or where patients may be in a highly agitated condition

53 Southard, Kelly, Ashley Jarrell, Mona M.
Shattell, Thomas P. Mccoy, Robin Bartlett, and Christine A. Judge. "Enclosed Versus Open Nursing Stations in Adult Acute Care Psychiatric Settings: Does the Design Affect the Therapeutic Milieu?" Journal of Psychosocial Nursing and Mental Health Services 50.5 (2012): 28-34. Web.

54 Eberhard, John P. Brain Landscape the Coexistence of Neuroscience and Architecture. Oxford: Oxford UP, 2009. Print. p.56

55 Moller, Clifford B. Architectural Environment and Our Mental Health. New York: Horizon, 1968. Print. p.36

56 Evans, 2003: p.544

57 Moller, 1968: p.97.

58 Evans, 2003: p.544

59 Moller, 1968: p.98.

60 Evans, 2003: p.539

61 "Projects - White." House of Psychiatrics. N.p., n.d. Web. 5 Nov. 2014. <http://www. white.se/en/project/136-house-of-psychiatrics>.

62 Ibid.

63 Ibid. 
64 Peninsula Health. "Youth Prevention and Recovery Care (Y-PARC).” Youth Mental Health Service. N.p., n.d. Web. 19 Nov. 2014. $<$ http \%3A\%2F\%2Fwww.peninsulahealth. org.au $\% 2$ Fservices $\% 2$ Fservices-f-m $\% 2$ Fmental-health-service $\% 2$ Fyouth-mental-health-service $\% 2 \mathrm{~F}>$.

\section{Ibid.}

66 Greater Bendigo in Victoria, Australia. Architect: GSA Group + WMIA. Date Completed: January 2013. Funded: Public \& Private. Client: Department of Health DH. Cost: \$4 Million

67 "Wan Healthcare 2013." Youth Prevention And Recovery Care (Y-Parc). N.p., n.d. Web. 8 Oct. 2014. <http://backstage.worldarchitecturenews.com/wanawards/project/youth-prevention-and-recovery-care-y-parc/?source=search\&keyword=Y-Parc\&selection=all>

68 Ibid.

69 Ibid.

70 Frascari, Marco. Eleven Exercises in the Art of Architectural Drawing Slow Food for the Architect's Imagination. Abingdon, Oxon: Routledge, 2011. Print. p.66

71 Pallasmaa, Juhani, Harry Francis. Mallgrave, and Michael A. Arbib. Architecture and Neuroscience. Espoo, Finland: Tapio Wirkkala-Rut
Bryk Foundation, 2013. Print. p.5

72 Sternberg, 2009: p. 23.

73 Eberhard, 2009: p.19.

74 Pallasmaa, Mallgrave, Arbib, 2013: p.5

75 Frascari, 2011: p.66

76 Lippman, Peter. Evidence-Based Design of Elementary and Secondary Schools: A Responsive Approach to Creating Learning Environments. Wiley. 2010. Print.

77 Frascari, 2011: p.66.

78 Mallgrave, Harry Francis. The Architect's Brain: Neuroscience, Creativity, and Architecture. Chichester, West Sussex, U.K.: Wiley-Blackwell, 2010. Print. p.205.

79 Sternberg, 2009: p.141.

80 The Nobel Assembly at Karolinska Institute. "PRESS RELEASE 2014-10-06." The Nobel Assembly at Karolinska Institute (n.d.): n. pag. The 2014 Nobel Prize in Physiology or Medicine. 06 Oct. 2014. Web. 10 Oct. 2014

\section{Eberhard, 2009: p.125}

82 Berlucchi, G. \& Buchtel, H.A. (2009). Neuronal plasticity: Historical roots and evolution of meaning. Experimental Brain Research,
192(3), $307-319$

83 Bennett, E. L., Diamond, M. L., Krech, D., and Rosenzweig, M. R. (1964). Chemical and anatomical plasticity of brain. Science, 146, 610-619.

84 York AD, Breedlove SM and Diamond MC. 1989. Housing adult male rats in enriched conditions increases neurogenesis in the dentate gyrus. Soc Neurosci Abstracts 15: 962 (\#383.11).

85 Diamond, Marian Cleeves. "Response of The Brain to Enrichment." Neuroscience. John Hopkins School of Education, 2001. Web. 8 Sept. 2014. <http://education.jhu.edu/ $\mathrm{PD} /$ newhorizons/Neurosciences/articles/Response $\% 20$ of $\% 20$ the $\% 20$ Brain $\% 20$ to $\% 20$ Enrichment/>.

\section{Ibid.}

87 Van Praag, Henriette, and Fred H. Gage. "Neural Consequences of Environmental Enrichment.” Nature Reviews 1 (2000): 191-98. Web. 1 Oct. 2014. p.191.

88 Ibid., p.191.

89 Van Praag, Henriette, and Fred H. Gage. "Neural Consequences of Environmental Enrichment." Nature Reviews 1 (2000): 191-98. Web. 1 Oct. 2014. 
90 Moller, 1968: p.34.

91 Reference studies showing the role of the hippocampus include: Sapolsky, 2000; Antonova et al., 2004; Geuze et al., 2005; Lucassen et al., 2006; Keller and Roberts, 2008. References to studies showing normalization of changes in behaviours include: Chen et al., 2000; Malberg et al., 2000; Eisch, 2002; Abrous et al., 2005; Pittenger and Duman, 2008. Eisch, A. J., H.

A. Cameron, J. M. Encinas, L. A. Meltzer, G.L. Ming, and L. S. Overstreet-Wadiche. "Adult Neurogenesis, Mental Health, and Mental Illness: Hope or Hype?" Journal of Neuroscience 28.46 (2008): 1785-1791. Web. p. 11785

92 Eisch, A. J., H. A. Cameron, J. M. Encinas, L. A. Meltzer, G.-L. Ming, and L. S. Overstreet-Wadiche, 2008: Pg. 1785.

93 Gage, Fred H., Dr. "Architecture and Neuroscience." AIA 2003 International Convention \& Expo: Lecture (2003): n. pag. Web. 12 Oct. 2014.

94 Diamond, 2001. Web.

95 Frascari, Marco. De Beata Architecture: Places for Thinking. The Cultural Role of Architecture: Contemporary and Historical Perspectives. Ed. Paul Emmons, John Hendrix, and Jane Lomholt. Milton Park, Abingdon, Oxon: Routledge, 2012. Print. pg. 83.

96 Lehrer, Jonah. “The Virtues of Daydreaming
- The New Yorker." The New Yorker. N.p., 05 June 2012. Web. 10 Feb. 2015. <http://www. newyorker.com/tech/frontal-cortex/the-virtues-of-daydreaming $>$.

\section{Ibid.}

98 Bachelard, Gaston, Maria Jolas, and John R Stilgoe. The Poetics of Space:. Boston: Beacon, 1996. Print. Pg. 6.

99 Moller, 1968: p.22.

100 Mallgrave, 2010: p.143.

101 Ibid., p.129.

102 Ibid., p.136.

103 Pallasmaa, Juhani. The Eyes of The Skin: Architecture and The Senses. 3rd ed. West Sussex: John Wiley \& Sons Ldt, 2014. Print. p.21.

104 Ibid., p. 45

105 Mallgrave, 2010: p.217.

106 Zeki, Semir. "The Neurology of Ambiguity." Consciousness and Cognition 13.1 (2004): 173-96. Web.

107 Mallgrave, 2010: p.149.

108 Zeki, 2004: p.189.
109 Pallasmaa, 2014: p.14.

110 Ibid. Print. p.76.

111 Mallgrave, 2010: p.9

112 Pallasmaa, Juhani. The Embodied Image: Imagination and Imagery in Architecture. Chichester: John Wiley \& Sons, 2011. Print. p. 66.

113 Frascari, 2012: pg. 90.

114 Ibid., pg. 90

115 Bruner, Jerome S. Actual Minds, Possible Worlds. Cambridge, MA: Harvard UP, 1986. Print. p.12.

116 Ibid., pg. 13

117 Frascari, 2012: pg. 90.

118 "Areas of Care." Recovery Programs. The Royal Ottawa - Mental Health Care, n.d. Web. 1 Feb. 2015. <http://www.theroyal.ca/mental-health-centre/mental-health-programs/areas-of-care/recovery-programs/>.

119 Davidson, Cappelli, 2014.

120 Champagne, T., Edward, S., "The effects of the use of the Sensory room in Psychiatry." (2003). Web. http://www.ot-innovations.com/ 
pdf_files/QI_STUDY_Sensory_Room.pdf/.

121 "Promoting Mental Health and Preventing Mental Illness." Mental Health Commission of Canada. N.p., n.d. Web. 1 Jan. 2015. <http:// strategy.mentalhealthcommission.ca/strategy/ promoting-mental-health-and-preventing-mental-illness/>.

122 Bachelard, 1996: Pg. 6.

123 Bar, Moshe, and Maital, Neta. Visual Elements of Subjective Preference modulate Amygdala Activation. Neuropsychologia. 2007. 45 (10): 2191-200

124 Meyers-Levy, J., \& Zhu, R. J. (2007). The Influence of Ceiling Height: The Effect of Priming on the Type of Processing That People Use. Journal of Consumer Research, 34(2), 174-186.

125 Sussman, Ann, and Justin B. Hollander. Cognitive Architecture: Designing for How We Respond to the Built Environment. New York: Routledge, 2015. Print. p.25. 


\section{[ Bibliography ]}

Bachelard, Gaston, Maria Jolas, and John R. Stilgoe. The Poetics of Space:. Boston: Beacon, 1996. Print.

Bar, Moshe, and Maital, Neta. Visual Elements of Subjective Preference modulate Amygdala Activation. Neuropsychologia. 2007. 45 (10): 2191-200.

Berlucchi, G. \& Buchtel, H.A. (2009). Neuronal plasticity: Historical roots and evolution of meaning. Experimental Brain Research, 192(3), $307-319$.

Bruner, Jerome S. Actual Minds, Possible Worlds. Cambridge, MA: Harvard UP, 1986. Print.

Canadian Institute for Health Information, Hospital Mental Health Services in Canada, 2009-2010 (Ottawa, Ont.: CIHI, 2012).

Davidson, Simon, $\mathrm{MB}, \mathrm{BCh}, \mathrm{FRCP}(\mathrm{C})$, and Mario Cappelli, $\mathrm{PhD}$, CPsych. "Transitioning Youth from Child and Adolescent Mental Health Services to Adult Mental Health Services." We've Got Growing up to Do (n.d.): n. pag. May 2011. Web. 10 Dec. 2014.

Diagnostic and Statistical Manual of Mental
Disorders: DSM-5. Washington, D.C.: American Psychiatric Association, 2013

Diamond, Marian Cleeves. "Response of The Brain to Enrichment." Neuroscience. John Hopkins School of Education, 2001. Web. 8 Sept. 2014. <http://education.jhu. edu/PD/newhorizons/Neurosciences/articles/ Response\%20of\%20the\%20Brain\%20to\%20 Enrichment/>.

Drevets, Wayne C., Joseph L. Price, and Maura L. Furey. "Brain Structural and Functional Abnormalities in Mood Disorders: Implications for Neurocircuitry Models of Depression." Brain Structure and Function 213.1-2 (2008): 93-118. Web.

Eberhard, John P. Brain Landscape the Coexistence of Neuroscience and Architecture. Oxford: Oxford UP, 2009. Print.

Eberhard, John P. "Applying Neuroscience to Architecture." Neuron 62.6 (2009): 753-56. Web. 25 Sept. 2014.

Edginton, B. "The Design of Moral Architecture at The York Retreat." Journal of Design History 16.2 (2003): 103-17. JSTOR. Web. 15 Feb. 2014.
Eisch, A. J., H. A. Cameron, J. M. Encinas, L. A. Meltzer, G.-L. Ming, and L. S. OverstreetWadiche. "Adult Neurogenesis, Mental Health, and Mental Illness: Hope or Hype?" Journal of Neuroscience 28.46 (2008): 1785-1791. Web.

Epstein, Russell, Alison Harris, Damian Stanley, and Nancy Kanwisher. "The Parahippocampal Place Area." Neuron 23.1 (1999): 115-25. Web.

Evans, G. W. "The Built Environment and Mental Health." Journal of Urban Health: Bulletin of the New York Academy of Medicine 80.4 (2003): 536-55. Web.

Foucault, Michel. Madness and Civilization; a History of Insanity in the Age of Reason. New York: Pantheon, 1965. Print.

Foucault, Michel. The Order of Things: An Archaeology of the Human Sciences. New York: Pantheon, 1971. Print.

Frascari, Marco. Eleven Exercises in the Art of Architectural Drawing Slow Food for the Architect's Imagination. Abingdon, Oxon: Routledge, 2011. Print. 
Frascari, Marco, Emmons, Paul, John Hendrix, and Jane Lomholt. The Cultural Role of Architecture: Contemporary and Historical Perspectives - Chapter 8 De Beata Architecture: Places for Thinking Milton Park, Abingdon, Oxon: Routledge, 2012. Print.

Gage, Fred H., Dr. "Architecture and Neuroscience." AIA 2003 International Convention \& Expo: Lecture (2003): n. pag. Web. 12 Oct. 2014.

"Home, Community and Residential Care Services." Assisted Living Services in Supportive Housing Overview. Ontario Ministry of Health and Long Term Care, 29 Nov. 2013. Web. 28 Dec. 2014.

"Hospitals: Questions And Answers." FAQ. Ontario Ministry of Health and Long Term Care, 11 July 2014. Web. 2 Oct. 2014. <http:// www.health.gov.on.ca/en/common/system/ services/hosp/faq.aspx>. Web.

"Initiatives: Opening Minds." Mental Health Commission of Canada. N.p., n.d. Web. 20 Sept. 2014.

Maller, C., Townsend, M., St. Leger, L., Henderson-Wilson, C., Pryor, A., Prosser, L., \& Moore, M. (2008). Healthy parks, healthy people: the health benefits of contact with nature in a park context. Melbourne, Australia: Deakin University and Parks Victoria.
Mallgrave, Harry Francis. The Architect's Brain: Neuroscience, Creativity, and Architecture. Chichester, West Sussex, U.K.: Wiley-Blackwell, 2010. Print.

Manderscheid RW, Ryff CD, Freeman EJ, McKnight-Eily LR, Dhingra S, et al. Evolving definitions of mental illness and wellness. Prev Chron Dis. Epub. 2009. Web.

Meyers-Levy, J., \& Zhu, R. J. (2007). The Influence of Ceiling Height: The Effect of Priming on the Type of Processing That People Use. Journal of Consumer Research, 34(2), 174-186.

Moller, Clifford B. Architectural Environment and Our Mental Health. New York: Horizon, 1968. Print.

Neurobiology of Mental Illness. Vol. 4. S.1.: Oxford UP, 2014. Print.

Pallasmaa, Juhani. The Eyes of The Skin: Architecture and The Senses. 3rd ed. West Sussex: John Wiley \& Sons Ldt, 2014. Print. p.24.

Pallasmaa, Juhani. The Embodied Image: Imagination and Imagery in Architecture. Chichester: John Wiley \& Sons, 2011. Print.

Pallasmaa, Juhani, Harry Francis. Mallgrave, and Michael A. Arbib. Architecture and Neuroscience. Espoo, Finland: Tapio Wirkkala-
Rut Bryk Foundation, 2013. Print.

Perry, Elaine, and Nicolette Perry. "Aromatherapy in the Management of Psychiatric Disorders: Clinical and Neuropharmacological Perspectives." CNS Drugs 20.4 (2006): 257-80. Pub Med. Web. 12 Nov. 2014.

Peninsula Health. "Youth Prevention and Recovery Care (Y-PARC)." Youth Mental Health Service. N.p., n.d. Web. 19 Nov. 2014. <http\%3A\%2F\%2Fwww.peninsulahealth.org. au $\% 2$ Fservices $\% 2$ Fservices- $\mathrm{f}-\mathrm{m} \% 2 \mathrm{Fmental}$ health-service $\% 2$ Fyouth-mental-healthservice $\% 2 \mathrm{~F}>$.

Plante, Thomas G. Abnormal Psychology across the Ages. Vol. 1. Santa Barbara, CA: Praeger, 2013. Print. History and Conceptualizations

"Projects - White." House of Psychiatrics. N.p., n.d. Web. 5 Nov. 2014. <http://www.white.se/ en/project/136-house-of-psychiatrics $>$.

Rae-Grant, Quentin. Psychiatry in Canada: 50 Years (1951 to 2001). Ottawa, ON: Canadian Psychiatric Association, 2001. Print.

Sternberg, Esther M. Healing Spaces: The Science of Place and Well-being. Cambridge, MA: Belknap of Harvard UP, 2009. Print.

Schweitzer, Marc, Laura Gilpin, and Susan Frampton. "Healing Spaces: Elements of 
Environmental Design That Make an Impact on Health." The Journal of Alternative and Complementary Medicine 10.1 (2004): 71-83. Web.

Spitzer, Robert L. DSM-IV Casebook: A Learning Companion to the Diagnostic and Statistical Manual of Mental Disorders, Fourth Edition. Washington, DC: American Psychiatric, 1994. Print.

"Stigma and Discrimination - Canadian Mental Health Association, Ontario Division." Canadian Mental Health Association Ontario Division. N.p., n.d. Web. 20 Oct. 2014.

Sussman, Ann, and Justin B. Hollander. Cognitive Architecture: Designing for How We Respond to the Built Environment. New York: Routledge, 2015. Print.

Thagard, Paul. "Mental Illness from the Perspective of Theoretical Neuroscience. " Perspectives in Biology and Medicine 51.3 (2008): 335-52. Web.

The Human Face of Mental Health and Mental Illness in Canada, 2006. Ottawa: Public Health Agency of Canada, 2006. Print.

The Nobel Assembly at Karolinska Institute. "PRESS RELEASE 2014-10-06." The Nobel Assembly at Karolinska Institute (n.d.): n. pag. The 2014 Nobel Prize in Physiology or
Medicine. 06 Oct. 2014. Web. 10 Oct. 2014

"Topics: Stigma." Mental Health Commission of Canada. N.p., n.d. Web. 28 Sept. 2014.

Van Praag, Henriette, and Fred H. Gage. "Neural Consequences of Environmental Enrichment." Nature Reviews 1 (2000): 19198. Web. 1 Oct. 2014

"Wan Healthcare 2013." Youth Prevention And Recovery Care (Y-Parc). N.p., n.d. Web. 8 Oct. 2014. <http://backstage. worldarchitecturenews.com/wanawards/ project/youth-prevention-and-recoverycare $-y-$ parc $/$ ? source $=$ search $\&$ keyword $=Y$ Parc\&selection $=$ all $>$.

Why Investing In Mental Health Will Contribute To Canada's Economic Prosperity And To The Sustainability Of Our Health Care System. Rep. Mental Health Commission of Canada, n.d. Web. <http://strategy.mentalhealthcommission. $\mathrm{ca} / \mathrm{pdf} /$ case-for-investment-en.pdf $>$.

Wright, David, and James E. Moran. Mental Health and Canadian Society: Historical Perspectives. Montreal: McGill-Queen's UP, 2006. Print

Yanni, Carla. The Architecture of Madness: Insane Asylums in the United States. Minneapolis: U of Minnesota, 2007. Print.
York AD, Breedlove SM and Diamond MC. 1989. Housing adult male rats in enriched conditions increases neurogenesis in the dentate gyrus. Soc Neurosci Abstracts 15: 962 (\#383.11).

Zeki, Semir. "The Neurology of Ambiguity." Consciousness and Cognition 13.1 (2004): 173-96. Web. 


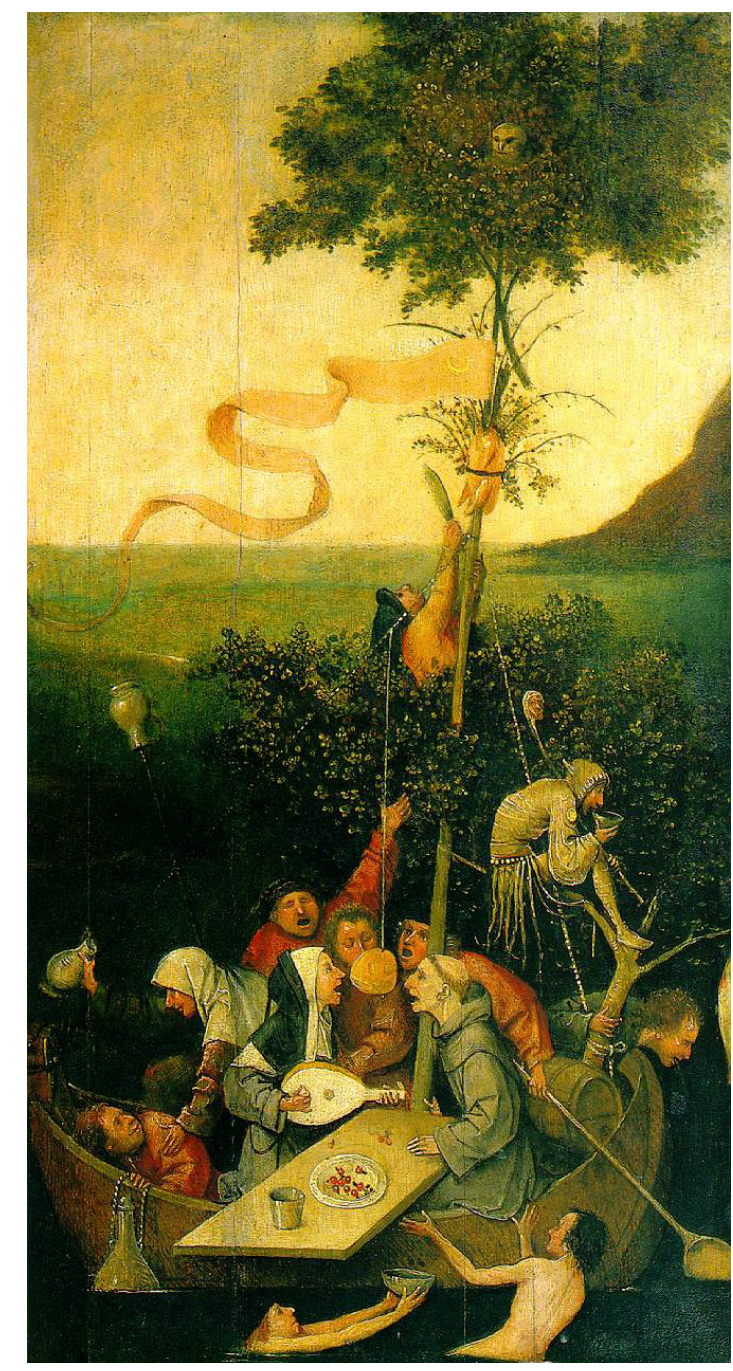

Figure 1: "The Ship of Fools" by Hieronymus Bosch, c. 1490-1500, oil on board.

\section{[ Appendix One ]}

History of Mental Illness from Antiquity to Anti-Psychiatry

\section{Antiquity - Middle Ages - Renaissance}

The recording of abnormal mental phenomena existed since ancient times. The father of western medicine, Hippocrates of Cos (460-377 BC), believed that abnormal behavior was a result of an imbalance of the four humors, black bile, yellow bile, phlegm, and blood. People suffering from an excess of a certain bile could experience mania, extreme sadness or melancholia. He connected the imbalances in the four humors to environmental factors such as air and water quality, and time of the year. Hippocrates also developed a bio-psychosocial theory, in contrast to many of his colleague's mythical reasoning, and believed that both somatic and mental illnesses should be treated in a similar manner. Treatments recommended by Hippocrates included dream analysis, removing the patient from his current environment, exercise, and a vegetarian diet. It was not uncommon at this time for people to assign causes of mental illness to mythical phenomena. The Greek philosopher Plato (429-347) believed that it originated in the soul since it controlled reason and also suggested that another type of mental illness was given by the divine breath of gods and gave the person the ability to see into the future. Similar to today's naturopathic and homeopathic treatments, there was also a strong tradition of using natural herbal remedies to treat mental illness during the antiquity. 


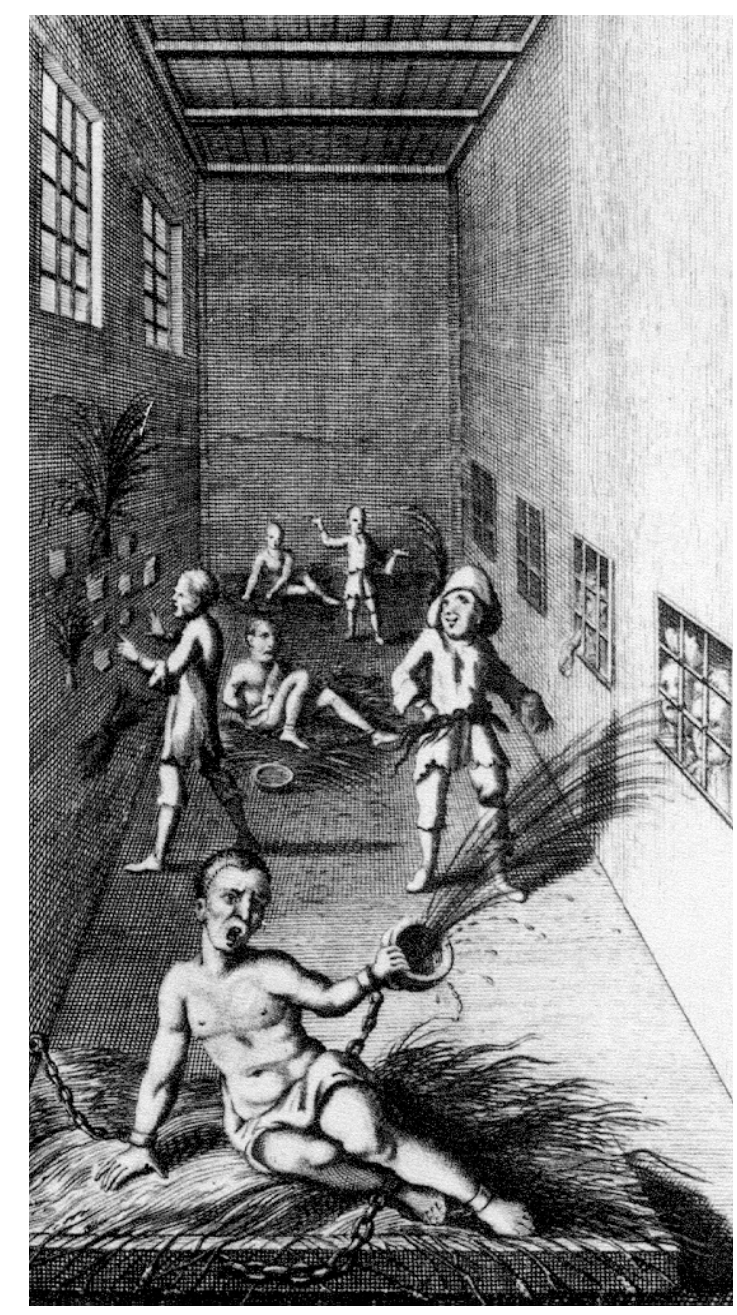

Figure 2: Engraving of Bedlam by William Hogarth, c. 1735.
The Middle Ages have been criticized as a detour between the Classical and the Renaissance. During the early middle ages, early European Christian theology models favored faith over reason and approached abnormal mental phenomena from a theological, moral, and supernatural point of view. People believed that the mentally ill were being punished for committed sins and therapies such as fasting, music, or prayer were used. Most were treated within the family home, or in churches and monasteries functioning as unofficial asylums. In more extreme cases, possession was believed to be the predominant cause and various forms of exorcism were practiced. In contrast, the Middle East, parts of North America, and non-Christian Spain retained classical knowledge and treated abnormal mental phenomena in psychiatric hospitals as early as 707 CE. ${ }^{4}$ Classical reason was combined with Muslim influences to create treatments that addressed physiological, psychological, moral, and spiritual causes.

The High Middle ages saw an influence on medicine from Islamic medical texts and mental illnesses once again adopted the classical notion of imbalanced humors proposed by Hippocrates. ${ }^{5}$ Classical remedies reappeared along with the use of restraints, and surgical techniques involving bleeding for more serious cases. During this time the development of hospitals exclusively for the mentally ill began. St. Mary of Bethlehem, notoriously known as Bedlam, was founded in 1247 becoming exclusive to mentally ill patients in $1402 .^{6}$

During the Renaissance a passionate interest and understanding of the human consciousness arose with a new awareness of the self. Yet, mental disorders were still greatly misunderstood and causes combined medical reason from the classical era and supernatural beliefs from the middle ages. Additionally, a long list of environmental causes grew including anxiety of loss, 
marital problems, and financial distress. Treatments were largely dependent on the cultural and religious contexts, for instance Catholic priests preformed exorcisms, while astrologers utilized charms, and medical treatments included whipping, purging, and solitary confinement. As Foucault described, persons with mental disorders were often viewed as subhuman, disheveled, and deprived of reason:

...there was a certain image of animality that haunted the hospitals of the period. Madness borrowed its face from the mask of the beast. Those chained to the cell walls were no longer men whose minds had wandered, but beasts preyed upon by a natural frenzy: as if madness, at its extreme point, free from the moral unreason in which its most attenuated forms are enclosed, managed to rejoin, by a paroxysm of strength, the immediate violence of animality. ${ }^{7}$

The care of the mentally ill was still the responsibility of the family, however a number of specialized treatment facilities were emerging. By 1547 the most notorious Asylum, Bedlam, was titled a must see attraction in London with over 96,000 visitors in a year. Patients were often tortured and confined, and subjected to inhumane practices. Visitors were entertained and shocked over the abnormalities of patients who were exhibited like circus animals (Fig. 5). ${ }^{8}$ 


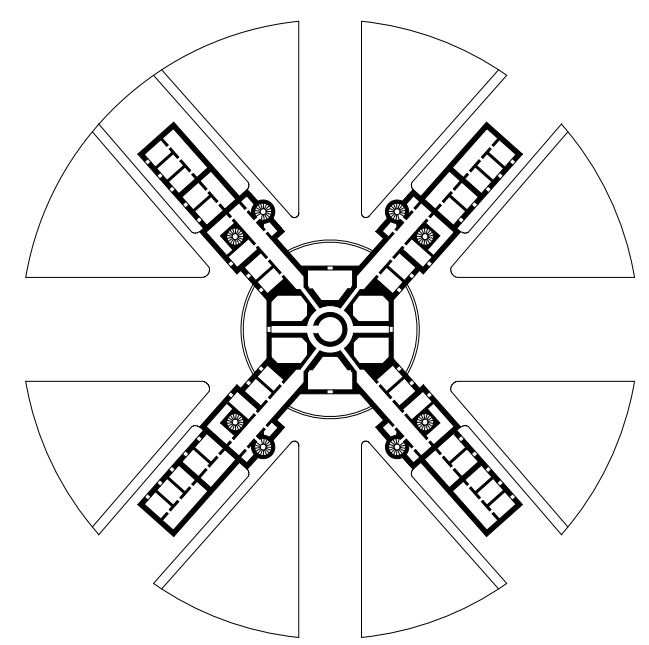

Figure 3: Glasgow Asylum, first floor plan drawing.

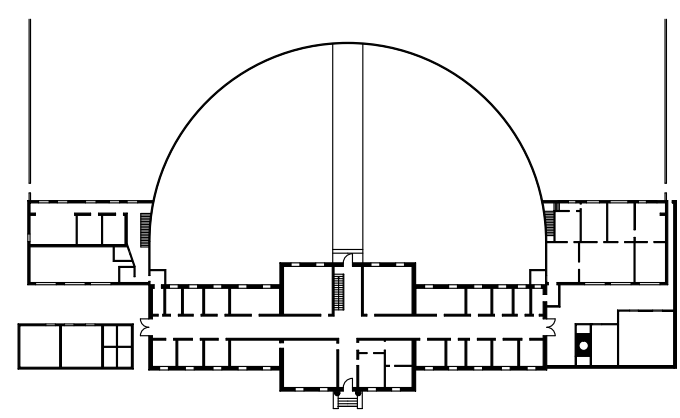

Figure 4: York Retreat Asylum, first floor plan drawing.

\section{Early Asylum - Moral Treatment}

Specialized institutional facilities called asylums flourished in the late 18th century. Alienists, known today as psychiatrists, claimed that insanity could not be properly treated in the family home and could only be cured in special institutions under their supervision. The glimmer of hope for a cure, plus the rising number of mentally ill in jails, prisons, churches, and almshouses, and the industrial revolution causing an increase in the number of people working away from home, lead to the rapid development of asylums. The evolving view of mental illness was then imparted within the design of the asylums and reveals an implicit history of mental illness in built form.

Early asylum design such as the Glasgow Asylum, designed by William Stark in 1814, reveals society's ways of trying to manage difficult populations. The prison-like design was modeled after Jeremy Bentham's Panopticon, a prison designed for control, security and surveillance (Fig. 6). As with other early asylums, the Glasgow Asylum was divided by social class and gender where wealthy patients were able to afford individual lavishly furnished rooms while the poor shared accommodations.

The 19th century brought reform in the treatment of mental illnesses throughout Europe and North America. The raised awareness of the inhumane treatment of the mentally ill in improper facilities such as prisons and jails independently encouraged French physician Phillippe Pinel and English philanthropist William Tuke to pioneer a humanistic approach to mental illness called 


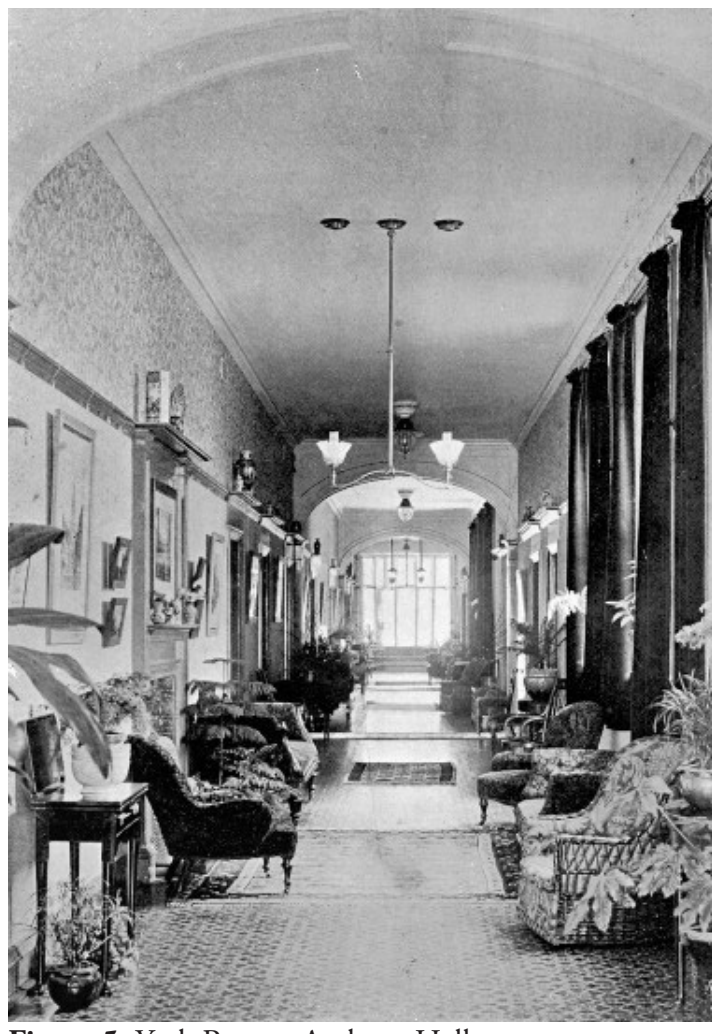

Figure 5: York Retreat Asylum, Hallway.
Moral Treatment. Moral treatment rejected the use of isolation and confinement, and instead proposed well-ordered daily routines containing a therapeutic regiment of work and leisure activities. It meant mild, humane treatments with minimal restraints, and a concentration on the rational and emotional rather than the organic causes of insanity. 'The belief in environmental determinism - the idea that the environment including architecture, shapes behavior - assigned therapeutic value to the building itself and played a large part in treatment. The buildings for the mentally ill then evolved from tools of confinement to buildings capable of providing healing.

The York Retreat, designed by John Bevans and William Tuke in 1796, was the first asylum design instilled with the principles of moral treatment (Fig. 7). The Retreat's designers proposed that the asylum should not only reflect the true nature of a sane environment but that it should also function as an active method of treatment. ${ }^{10}$ The safe haven would provide patients with comfort, care, and kindness and in turn contribute to their treatment and healing. The location of the asylum was situated just outside the City of York surrounded by acres of green space and pleasant rural surroundings. To evoke a sense of normalcy help and re-integrate patients back into society once their treatment was complete the form of the building resembled a small family home (Fig. 8). The design also emphasized the healing ability and therapeutic value of the natural and social environments by incorporating large windows, verandas, day rooms, gardens, greenhouses, and sports facilities. 


\section{Kirkbride Asylum - Cottage Plan}

In no class of building can an architect make himself more felt as a lasting benefactor to the occupants then in a lunatic asylum, and in order that he may be armed with every possibility of success in arranging his plans, he must to some extent study the ways and mode of life of those for whom he provides. ${ }^{11}$

- George Henry Bibby (The Housing of Pauper Lunatics)

At the turn of the 19th century multiple disciplines dedicated to the study of understanding human behaviour and mental processes emerged. A group of physicians referring to themselves as "alienists" pioneered the discipline of psychiatry, a new branch of medicine focused on the study, diagnosis, treatment, and prevention of mental disorders viewed through biological and psychological means. Another discipline of study, Psychology, was divided at the time between clinical psychology and abnormal psychology. The aim of clinical psychology was to integrate science, theory, and clinical knowledge for the purpose of assessing and treating psychological conditions and mental disorders. The second theoretical branch of psychology, abnormal psychology, studied the unusual patterns of behavior, emotion, and thought that may or may not be understood as precipitating a mental disorder. ${ }^{12}$ Evolving theories and research began recognizing mental disorders as complex interconnected relationships between biological, social, environmental, organic, hereditary, physical, neurological and psychological factors, making treatments more diverse than before. A combination of existing treatments such as hydrotherapy, restraints, herbal remedies, and exercise were prescribed along with new emerging therapies like psychotherapy (1880). 
In the progression of environmental determinism popularized by proponents of moral treatment, Dr. Thomas Kirkbride, a Quaker alienist and superintendent of the Philadelphia Hospital for the Insane, believed that good architecture could help cure insanity. In his treatise The Construction, Organization, and General Arrangements of Hospitals for the Insane (1848) Kirkbride promoted a set of detailed design principles and guidelines for asylums that were published and promoted by The Association of Medical Superintendents of American Institutions for the Insane (AMASII) in 1851. Kirkbride's plan, a shallow V-shaped form, divided by gender and severity of mental illness accommodating a maximum of 250 patients (Fig. 9). The plan optimized natural ventilation and sunlight since he believed that abundant fresh air and natural light not only contributed to a healthy environment, but also served to promote a more cheerful atmosphere. Additionally, the treatise explored design subjects ranging from the height of hospitals, materiality, and the number of patients per ward. In 1866, the Association of Medical Superintendents of American Institutions for the Insane (AMASII) increased the maximum suggested number of patients from 250 to 600 (Fig. 10). This lead to the evolution of the Kirkbride Plan to a larger Modified Kirkbride Plan that still emphasized design principles described in Kirkbride's 1848 Treatise.

Although the intentions and youthful optimism of Moral Treatment and Dr. Kirkbride were noble, Foucault had revealed the true actions behind the closed doors of the York Retreat in his novel Madness and Civilization: "One of Samuel Tuke's most active disciples, Godfrey Higgins, had obtained the right, which cost him at twenty pounds, to visit the asylum of York as a volunteer inspector. In the course of a visit, he discovered a door that had been carefully concealed and found behind it a room, not eight feet on a side, which thirteen women occupied during the night, by day they lived in a room scarcely larger". ${ }^{13}$ The overcrowding of asylums 


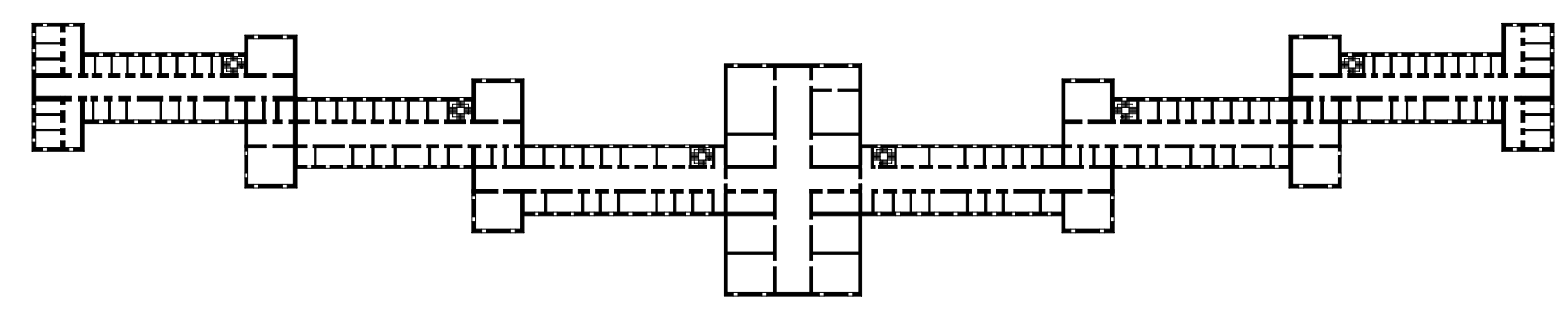

Figure 6: Kirkbride Asylum Floor Plan.

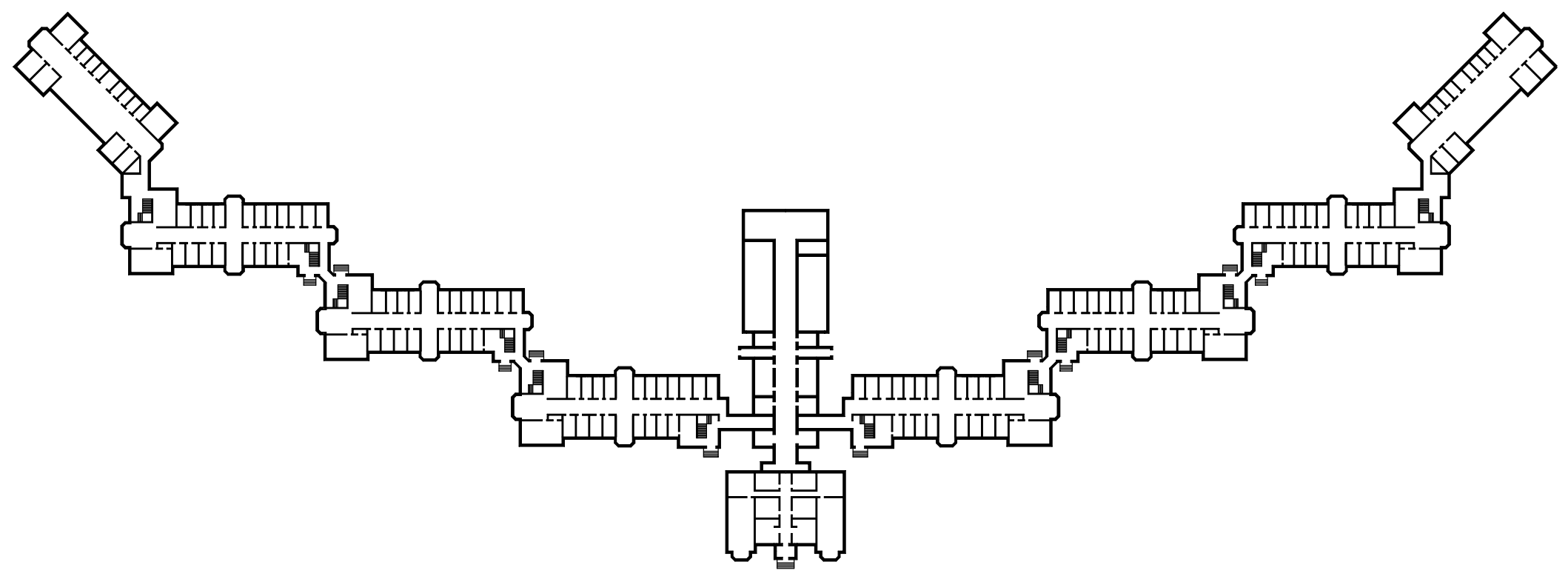

Figure 7: Modified Kirkbride Asylum Floor Plan. 


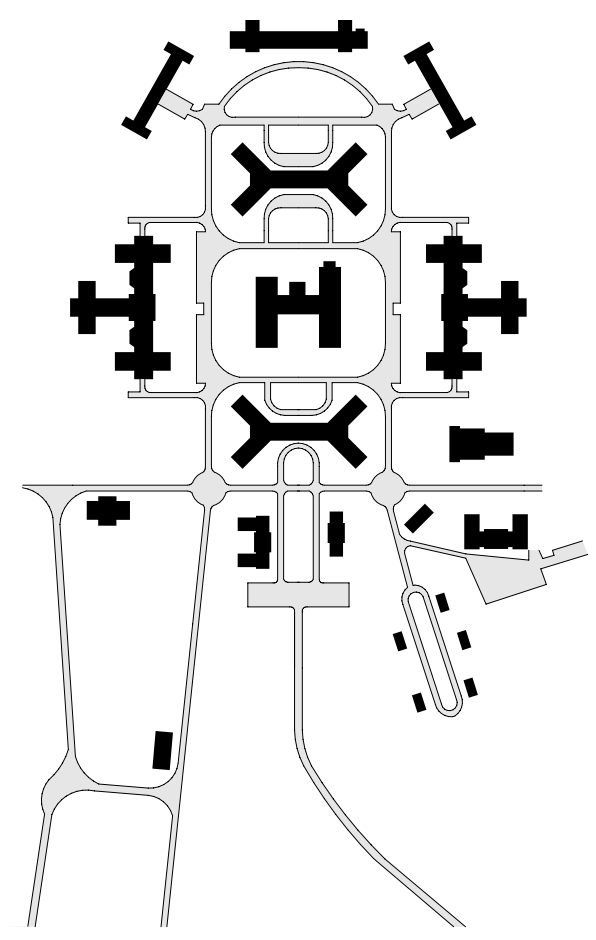

Figure 8: Fairfield Psychiatric Hospital, Bedforshire England, site plan. was not uncommon, historical records show some institutions reaching double to triple the recommended maximum number of patients. This can be attributed to a growing concern in society that the "lower and more degraded types" of people may hold back social advancement, and asylums soon became repositories for not only mentally ill persons, but also the poor and immigrant classes. ${ }^{14}$

Asylums continued to flourish during the 19th century to the mid 20th century with the design and plan continually evolving. The cottage plan created a freer and more sociable atmosphere. The site of a cottage plan asylum resembled that of a college campus with multiple buildings set on large, well-manicured grounds (Fig. 11). Each building housed a single type of disorder with two sets of buildings for each sex.

For treatment, psychotherapy, the understanding of the psychological bases of mental illnesses, dominated the field of mental health from 1900 to $1950 .{ }^{15}$ Sigmund Freud (1856-1939), a Viennese neurologist, developed the first form of psychotherapy during the early 20th century called psychoanalysis. Freud's psychoanalytic theories studied the subconscious mind, childhood traumas, and sexual events through dream analysis, transference and analysis of the id, ego, and super ego in search for the origins of the mental illness. The treatment was an interactive process between the mental health care professional and the patient where patients explored thoughts, feelings, and behaviors. Freud's theories proliferated in society and the traditional image of man changed, "Freud dethroned the human race from its fictitious position if rational supremacy and undermined the narcissistic illusions by his disclosure of unconscious (and irrational) motivation in human conduct". ${ }^{16}$ 
Simultaneously, developing biological theories attempting to understand the relationship between the central nervous system and mental illnesses initiated experimental research focused on the brain including the testing of experimental drugs and post-mortem dissections. ${ }^{17}$ Treatments targeting the central nervous system such as neurosurgical procedures including lobotomies (1930), and electroconvulsive shock therapy (1949) became popular treatments practiced across Europe and North America. 


\section{Deinstitutionalization - Antipsychiatry}

Following World War II frustrations rose within the psychiatric community among both patients and professionals. Increasing branches of therapies gave rise to multimodal therapeutic approaches tailored to each individual patient. However, biological and psychoanalytic treatments did not see substantial progress in "curing" the severely ill.

The pharmacological revolution dawned in the 1950's and saw the first psychotropic drugs Chlorpromazine, (branded Thorazine) and imipramine transform the mental health landscape. Psychotropic drugs including antidepressants, stimulants, antipsychotics, mood stabilizers, anxiolytics, and sedatives made it possible for the severely mentally ill to be controlled within institutions and patients with mild to moderate mental illness the opportunity to continue life outside the asylum. The importance of the asylum diminished since both psychotropic drugs and psychotherapies could be administered to patients anywhere - hospital, community care facilities, and at home. Additionally, the asylum's reputation became tarnished due to awareness of overcrowding, unethical treatments, and the rising cost of the institution, eventually leading to the closure of numerous asylums during in the mid 1950's and 1960's: the deinstitutionalization era. To compensate for the closure of traditional institutional based care, the mentally ill were promised a system of services within the community along with psychiatric care at general hospitals. Another consequence of the pharmacological revolution, was the anti-psychiatry movement following a series of influential publications in the 1960's and 1970's. These publications included studies by psychologist David Rosenhan questioning the validity of psychiatric diagnoses, and 
British anti-psychiatry writer Ronald D. Laing who believed that mental illness was a sane response to a made society. ${ }^{18}$ The anti-psychiatry movement believed that mental illnesses were a scientifically worthless social construct and not objectively real illnesses. However, during the last few decades of the 20th century, advancements in neuroscience, the study of the central nervous system, accumulated large bodies of knowledge concerning the brains anatomy, physiology, and chemistry in connection with mental processes. One objective of neuroscience was to try to explain mental processes and behavior in terms of brain activities. ${ }^{19}$ The success of psychotropic drugs alluded to brain chemistry and the processes of neurotransmission as a cause for abnormal mental phenomena and chemical theories such as the Serotonin Model for Depression and Dopamine Model for Schizophrenia were advanced. ${ }^{20}$ Additional neuroscientific research revealed major discoveries such as neuroplasticity and polygenetic patterns in relation to mental abnormalities, which continue to be built upon into the 21 st century.

Following deinstitutionalization, the community-based care system that was promised was never successfully implemented. A lack of funding meant that the mentally ill failed to receive proper treatment and were left with nowhere to go. General hospitals could accommodate short hospitalization periods, but most cities lacked intermediate structures like day-hospitals for after-treatment and rehabilitation services resulting in a high frequency of relapse, increased homelessness, and increased criminal behavior and incarceration. Ironically, the cost cutting politicians saw a rise in budgets from overcrowded prisons, mental health professionals realized psychotropic drugs were not the cure all answer they once hoped, and the once infamous asylum protested by misguided do-gooders were now believed to have provided the severely mentally ill with a safe haven and routine. ${ }^{21}$ 


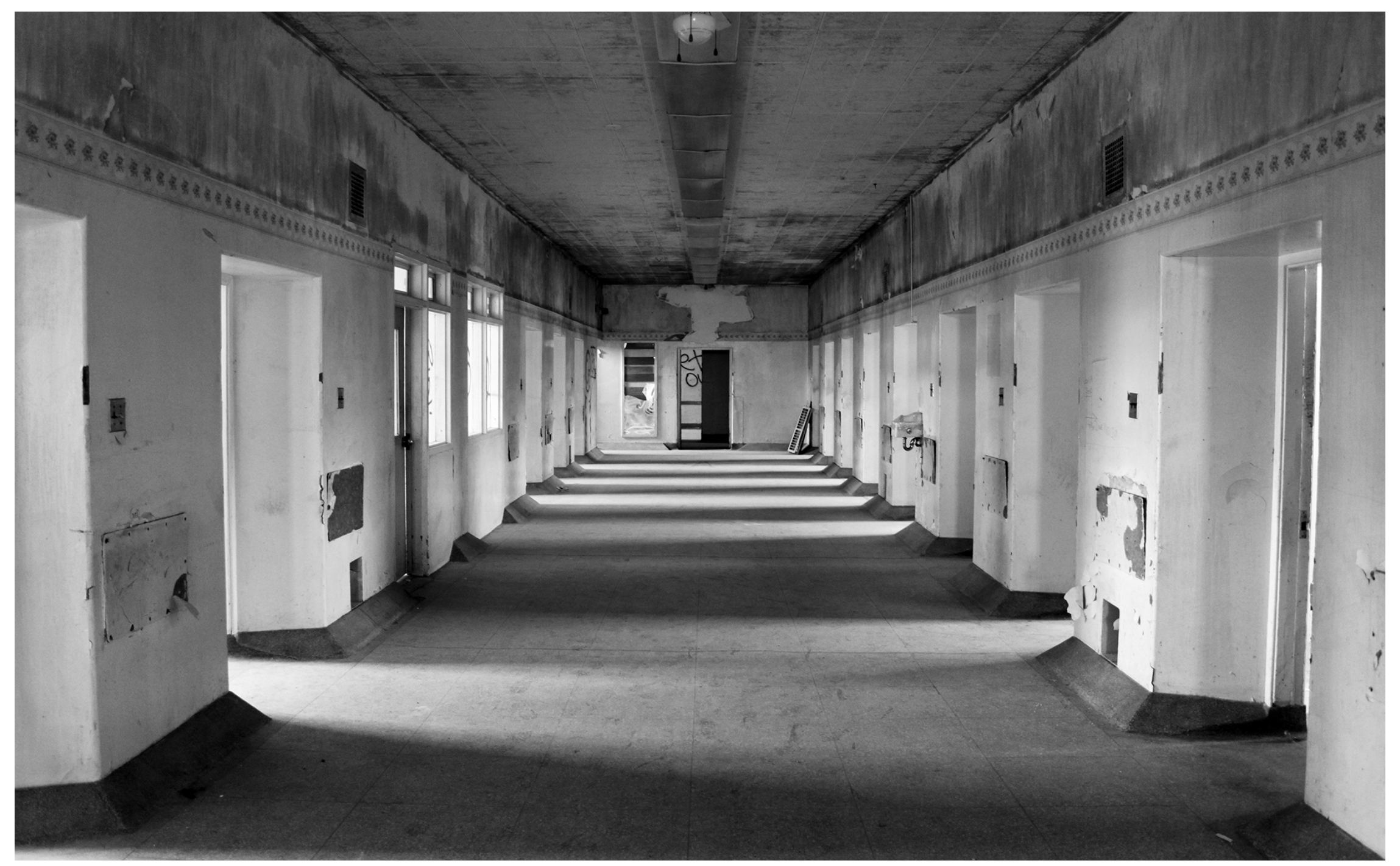

Figure 9: Rockwood Asylum for the criminally insane. 


\section{Endnotes}

Appendix 1

1 Sturges, James W. "Biological Views." Abnormal Psychology across the Ages. Ed. Thomas G. Plante. Santa Barbara, CA: Praeger, 2013. Print. p.186.

2 Mayers, Linda A, Papiasvili, Eva A. "Perceptions, Thoughts, and Attitudes in the Middle Ages." Abnormal Psychology across the Ages. Ed. Thomas G. Plante. Santa Barbara, CA: Praeger, 2013. Print. p.16.

3 Ibid., p.17.

4 Ibid., p.23.

5 Ibid., p.27.

6 Ibid., p.29.

7 Foucault, Michel. Madness and Civilization; a History of Insanity in the Age of Reason. New York: Pantheon, 1965. Print. p.72.

8 Dreher, Diane E. "Abnormal Psychology in the Renaissance." Abnormal Psychology across the Ages. Ed. Thomas G. Plante. Santa Barbara, CA: Praeger, 2013. p.34.

9 Digby, Madness, Morality and Medicine. Cambridge University Press, 1985, p.53.
10 Edginton, B. "The Design of Moral Architecture at The York Retreat." Journal of Design History 16.2 (2003): 103-17. JSTOR. Web. 15 Feb. 2014. p.104.

11 Bibby, George Henry. The Housing of Pauper Lunatics. London: B.T. Batsford, 1895. Print. p.7.

12 Mayers, Linda A, Papiasvili, Eva A. "The Ascent of Psychiatry and Psychology in 18001945." Abnormal Psychology across the Ages. Ed. Thomas G. Plante. Santa Barbara, CA Praeger, 2013. Print. p.89.

13 Foucault, Michel. Madness and Civilization; a History of Insanity in the Age of Reason. New York: Pantheon, 1965. Print. p.71.

14 King, Brett D., Niess, Anne B., Maddi, Alexandra E., Perkins, Layne S.,"The Rise of Abnormal Psychology during the Progressive Era: Reflections from an American Scientific Periodical." Abnormal Psychology across the Ages. Ed. Thomas G. Plante. Santa Barbara, CA: Praeger, 2013. Print. p.73.

15 Mayers, Linda A, Papiasvili, Eva A. "The Ascent of Psychiatry and Psychology in 18001945." Abnormal Psychology across the Ages.
Ed. Thomas G. Plante. Santa Barbara, CA: Praeger, 2013. Print. p.95.

16 Ibid., p.99.

17 Ibid., p.92.

18 Ibid., p.108.

19 Ibid., p.114.

20 Ibid., p.107.

21 Callaway, Enoch. "Reflections on Psychiatry in the Mid-20th Century." Abnormal Psychology across the Ages. Ed. Thomas G. Plante. Santa Barbara, CA: Praeger, 2013. Print. p.124. 


\section{[ Appendix Two ]}

Definitions \& Etymology of Mental Illness

\section{The Architecture}

pris.on (priz-uhn) noun [late Old English, from Old French prisun, from Latin prensio(n-), variant of prehensio(n-) 'laying hold of', from the verb prehendere.] a building to which people are legally committed as a punishment for a crime or while awaiting trial

jail (jeyl) noun [Middle English: based on Latin cavea (see cage). The word came into English in two forms, jaiole from Old French and gayole from Anglo-Norman French gaole] a place for the confinement of people accused or convicted of a crime

home (hohm) noun [before 900; Middle English hom, Old English hām (noun and adv.); cognate with Dutch heim, Old Norse heimr, Danish hjem, Swedish hem, German Heim home, Gothic haims village; akin to haunt] the place where one lives permanently, especially as a member of a family or household

alms-house (ahmz-hous) noun [Middle English from alms + house] a house founded by charity, offering accommodation for poor people

pan-op.ti-con (pan-op-ti-kon) noun [mid 18th century: from pan- 'all' + Greek optikon, neuter of optikos 'optic'] a circular prison with cells arranged around a central well, from which prisoners could at all times be observed.

mad-house (mad-hous) noun [1680-90; mad + house] an institution for the care of mentally ill people

a.sy.lum (uh-sahy-luhm) noun [late Middle English (in the sense 'place of refuge,' esp. for criminals): via Latin from Greek asulon 'refuge,' from asulos 'inviolable,' from a- 'without' + sulon 'right of seizure.' The current senses date from the 18th cent.] an institution offering shelter and support to people who are mentally ill

in.sti-tu-tion (in-sti-too-shuhn) noun [early 18th century] an organization founded for a religious, educational, professional, or social purpose

hos.pi.tal (hos-pi-tl) noun [1250-1300; Middle English hospitale < Medieval Latin, noun use of neuter of Latin hospitālis hospitable, equivalent to hospit- (see hospitium) + -ālis -al1] an institution providing medical and surgical treatment and nursing care for sick or injured people

\section{The Person}

an·i-mal (an-uh-muhl) noun [Middle English: the noun from Latin animal, based on Latin animalis 'having breath' from anima 'breath'; the adjective via Old French from Latin animalis] a person without human attributes or civilizing influences, especially someone who is very cruel, violent, or repulsive

in-mate (in-meyt) noun [late 16th century (denoting a person who shared a house, specifically a lodger or subtenant): probably originally from inn +1$)$ ] a person living in an institution such as a prison or hospital

im.be-cile (im-buh-sil) noun [mid 16th century (as an adjective in the sense 'physically weak'): via French from Latinimbecillus, literally 'without a supporting staff', from in- (expressing negation) + baculum 'stick, staff. The current sense dates from the early 19th century.] a stupid person

mad.man (mad-man) noun [1300-50; Middle English madd man] a man who is mentally ill

re.tard (ri-tahrd) noun [late 15th century: from French retarder, from Latin retardare, from re'back' + tardus 'slow'] a mentally handicapped person (often used as a general term of abuse)

lu.na-tic (loo-nuh-tik) noun [Middle English: from Old French lunatique, from late Latin luna- 
ticus, from Latin luna 'moon' (from the belief that changes of the moon caused intermittent insanity] a person who is mentally ill, a person unable to conduct civil transactions

suf.fer-er (suhf-er-er) noun [Middle English: from Anglo-Norman French suffrir, from Latin sufferre, from sub- 'from below' + ferre 'to bear'] a person suffering from an illness

pa-tient (pey-shuhnt) noun [Middle English: from Old French, from Latin patient- 'suffering', from the verb pati] a person receiving or registered to receive medical treatment

cli-ent (klahy-uhnt) noun [1350-1400; Middle English < Latin client-, stem of cliēns person seeking the protection or influence of someone powerful] a person being dealt with by social or medical services

guest (gest) noun [Middle English: from Old Norse gestr, of Germanic origin; related to Dutch gast and German Gast, from an Indo-European root shared by Latin hostis 'enemy' (originally 'stranger')] a person who receives the hospitality of a government, establishment, or organization

\section{The Illness}

pos-sessed (puh-zest) adjective [late Middle English: from Old French possesser, from Latin possess- 'occupied, held', from the verb possidere, from potis 'able, capable' + sedere 'sit'] (of a per- son) completely controlled by an evil spirit, the state of being controlled by a demon or spirit mad.ness (mad-nis) noun [1350-1400; Middle English madnesse. See mad, -ness] the state of having a serious mental illness

lu.na.cy (loo-nuh-see) noun [1535-45; lun(atic) + -acy] the state of being a lunatic; insanity (not in technical use)

in.san.i.ty (in-san-i-tee) noun [1580-90; < Latin insānitās] the state of being seriously mentally ill; de-range-ment (dih-reynj-muhnt) noun [late 18th century: from French déranger, from Old French desrengier, literally 'move from orderly rows'.] make (someone) insane

al-ien·a.tion (eyl-yuh-ney-shuhn) noun [late Middle English: from Latin alienatio(n-), from the verb alienare 'estrange', from alienus (seealien). The term alienation effect (1940s) is a translation of German Verfremdungseffekt.] psychiatry a state of depersonalization or loss of identity in which the self seems unreal, thought to be caused by difficulties in relating to society and the resulting prolonged inhibition of emotion

ma.ni.a (mey-nee-uh) noun [late Middle English: via late Latin from Greek, literally 'madness', from mainesthai 'be mad'.] mental illness marked by periods of great excitement or euphoria, delusions, and over activity

\section{The Treatment}

in.car-cer-a.tion (in-kahr-suh-rey-shuhn) noun [Medieval Latin incarcerāre, from Latin in- ${ }^{2}+$ carcer prison] the act of incarcerating, or putting in prison or another enclosure

re-straint (ri-streynt) noun [Middle English: from Old French restreign-, stem of restreindre, from Latin restringere, from re-'back' + stringere 'to tie, pull tight'.] deprivation or restriction of personal liberty or freedom of movement, a device which limits or prevents freedom of movement

tor-ture (tawr-cher) noun [late Middle English (in the sense 'distortion, twisting', or a physical disorder characterized by this): via French from late Latin tortura 'twisting, torment', from Latin torquere 'to twist'] the act of inflicting excruciating pain, as punishment or revenge, as a means of getting a confession or information, or for sheer cruelty

i.so-la-tion (ahy-suh-ley-shuhn) noun [mid 18th century: from French isolé, from Italian isolato, from late Latin insulatus 'made into an island', from Latin insula 'island'] to set or place apart; detach or separate so as to be alone

ca.thar-sis (kuh-thahr-sis) noun [late Middle English: from Old French purgacion, from Latin purgatio(n-), from purgare 'purify] 1 . the purging of the emotions or relieving of emotional tensions, especially through certain kinds of art, as tragedy 
or music. 2. psychotherapy that encourages or permits the discharge of pent-up, socially unacceptable affects 3. purification or cleansing

star-va·tion (stahr-vey-shuhn) noun [1770-80; starve + -ation] the act or an instance of starving or state of being starved

ex-er-cise (ek-ser-sahyz) noun [1300-50; Middle English (noun) < Middle French exercice < Latin exercitium, ( ex- ex-1 + -ercit-, stem of combining form of arcēre to restrain) + -ium] activity requiring physical effort, carried out to sustain or improve health and fitness

hy.dro-ther-a.py (hahy-druh-ther-uh-pee) noun [1875-80; hydro-1 + therapy] the treatment of physical disability, injury, or illness by immersion of all or part of the body in water to facilitate movement, promote wound healing, relieve pain, etc., usually under the supervision of a trained therapist

al-ien-ism (eyl-yuh-niz-uhm) noun [mid 19th century: from French aliéniste, based on Latin alienus 'of another' (see alien). alienus: belongs to another, mad, unworthy] former term for psychiatrist.

hyp-no-sis (hip-noh-sis) noun [late 19th century: from Greek hupnos 'sleep' + -osis] the induction of a state of consciousness in which a person apparently loses the power of voluntary action and is highly responsive to suggestion or direction. Its use in therapy, typically to recover suppressed memories or to allow modification of behaviour, has been revived but is still controversial

en.vi.ron·ment.al de.ter.min.ism (en-vahy-ruhnmuhnt-al dih-tur-muh-niz-uhm) noun the idea that the environment, including architecture, shapes behaviour, the architecture of an institution has the ability to cure

psy.cho-a.nal.y.sis (sahy-koh-uh-nal-uh-sis) noun [1905-10; < German Psychoanalyse] a system of psychological theory and therapy which aims to treat mental disorders by investigating the interaction of conscious and unconscious elements in the mind and bringing repressed fears and conflicts into the conscious mind by techniques such as dream interpretation and free association.

psy·cho-sur.ger·y (sahy-koh-sur-juh-ree) noun [1935-40; psycho- + surgery] treatment of mental disorders by means of brain surgery

lo.bot·o my (luh-bot-uh-mee) noun [1936, coined from lobe (in the brain sense) + medical suffix -tomy, from Gk. tome "a cutting," from temnein "to cut"] a surgical operation involving incision into the prefrontal lobe of the brain, formerly used to treat mental illness

Wphre-nol-o.gy (fri-nol-uh-jee) noun [early 19th century: from Greek phrēn, phren- 'mind' + -logy] the detailed study of the shape and size of the cranium as a supposed indication of character and mental abilities e.lec.tro·con·vul-sive ther-apy (ih-lek-troh-kuhnvuhl-siv) noun [1945-50; electro- + convulsive] a treatment for serious mental illnesses, as severe depressive disorders, involving the application to the head of electric current in order to induce a seizure: usually administered after sedatives and muscle relaxants

in-su.lin-co.ma ther-apy (in-suh-lin-koh-muh) noun [1945-50; electro- + convulsive] a former treatment for mental illness, especially schizophrenia, employing insulin-induced hypoglycemia as a method for producing convulsive seizures.

psy·chi-a.try (si-kahy-uh-tree) noun [mid 19th century: from Greek psukhē 'soul, mind' + iatreia 'healing' (from iatros 'healer')] the study and treatment of mental illness, emotional disturbance, and abnormal behaviour.

an-ti.psy.chot.ic (an-tee-sahy-kot-ik) noun [1950-55; anti- + psychotic] of or pertaining to any of various substances used in the treatment of psychosis, especially schizophrenia, and acute or severe states of mania, depression, or paranoia.

an-ti.de.pres.sant (an-tee-di-pres-uhnt) noun [1960-65; anti- + depressant] of or pertaining to a substance that is used in the treatment of mood disorders, as characterized by various manic or depressive affects 


\section{THE ILLNESSES}

\section{Adjustment Disorders}

ad·just-ment dis·or.der (AD) (a-jest-ment dis-ôrder) noun all of the disorders in this category relate to a significantly more difficult adjustment to a life situation than would normally be expected considering the circumstances. When this adjustment causes significant problems for an abnormal length of time, it may be considered an adjustment disorder. The disorders in this category can present themselves quite differently. Types of Adjustment Disorders: Adjustment Disorder with Anxiety, Adjustment Disorder with Depressed Mood, Adjustment Disorder with Disturbance of Conduct, Adjustment Disorder with Mixed Anxiety and Depressed Mood, Adjustment Disorder with Mixed Disturbance of Emotions and Conduct

\section{Anxiety Disorders}

anx.i.e.ty (ang-zì-itē) noun [early 16th century: from French anxiété or Latin anxietas, from anxius] (Anxiety Disorder) persist feeling of dread, apprehension, and impending disaster. An acute anxiety state is a sudden reaction to a frightening or worrying situation whereas a chronic anxiety state is a more prolonged response to stress. Types of Anxiety Disorder: Agoraphobia, Generalized Anxiety Disorder (GAD), Obsessive-Compulsive Disorder (OCD), Panic Disorder (with or without Agoraphobia), Phobias (including Social Phobia) ag.o.ra.pho·bi·a (ag-e-re-fō-bē-a) noun [late 19th century: from Greek agora 'place of assembly, marketplace' + -phobia] obsessive, persistent, intense fear of open places.

com·bat fa-tigue (käm-bat fa-tēg) noun [World War I: with reference to exposure to shellfire] formally known as shell shock and is also known as battle fatigue. A neurotic disorder caused by the stress involved in war. This anxiety-related disorder is characterized by hypersensitivity to stimuli such as noises, movements, and light accompanied by overactive responses that include involuntary defensive jerking or jumping (startle reactions), easy irritability progressing even to acts of violence, and sleep disturbances including battle dreams, nightmares, and inability to fall asleep.

gen.er.al-ized anx.i.e.ty dis.or.der (GAD) noun a psychological disorder characterized by excessive or disproportionate anxiety about several aspects of life, such as work, or financial matters.

ob-ses.sive-com.pul-sive adjective/noun (Obsessive Compulsive Disorder (OCD)) denoting or relating to an anxiety disorder in which a person feels compelled to perform certain stereotyped actions repeatedly to alleviate persistent fears or intrusive thoughts, typically resulting in severe disruption of daily life.

pan.ic dis.or.der noun characterized by sudden attacks of intense fear or anxiety, usually associated with numerous physical symptoms such as heart palpitations, rapid breathing or shortness of breath, blurred vision, dizziness, and racing thoughts.

pho.bi·a (fō-bē-a) noun [late 18th century: independent usage of -phobia] an irrational fear of an object or situation.

post-trau.mat.ic stress dis.or.der (PTSD) (pōsttrô-mat-ik dis-ôr-der) noun a psychological disorder that develops in some individuals after a major traumatic experience such as war, rape, domestic violence, or accident. Symptoms include re-experiencing the trauma through nightmares, obsessive thoughts, and flashbacks.

so.cial pho·bi.a (sōSHel fōbēa) noun situational specific phobia where fear is induced by real or anticipated contact with other people. This can apply to any type of social contact, but commonly large groups and performance under pressure make symptoms worse.

\section{Dementia}

de.men-tia (di-men-SHea) noun [late 18th century: from Latin, from demens, dement- 'out of one's mind'.] loss of intellectual abilities of sufficient severity to interfere with social or occupational functioning. The dysfunction is multifaceted and involves memory, behaviour, personality, judgment, attention, spatial relations, language, abstract thought, and other executive functions. 
alz-hei-mer's dis.ease (AD) (älts-hīm-rz di-zēz) noun [early 20th century: named after Alois Alzheimer (1864-1915), German neurologist who first identified it] progressive mental deterioration that can occur in middle or old age, due to generalized degeneration of the brain. It is the most common cause of premature senility. And is the most common form of dementia in the elderly.

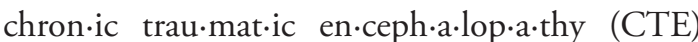
(krän-ik trô-mat-ik en-sefe-läp-a-THē) noun also known as Dementia Pugilistica. CTE affects about $20 \%$ of professional boxers and also other regular participants in high-impact sports such as rugby or American football.

creutz-feldt-ja.kob dis-ease (CJD) (kroits-feltyäkôb di-zēz) noun [named after H. G. Creutzfeldt (1885-1964) and A. Jakob (1882-1927), the German neurologists who first described cases of the disease in 1920-21. Creutzfeldt is credited with the first description of the disease in 1920 , although the case is atypical by current diagnostic criteria; a year later Jakob described four cases, at least two of whom had clinical features suggestive of CJD as it is currently described] a fatal degenerative disease affecting nerve cells in the brain, causing mental, physical, and sensory disturbances such as dementia and seizures.

de.men.tial with lew.y bod.ies (DLB) noun also known as Lewy Body Dementia (LBD). A progressive degenerative dementia of the elderly.

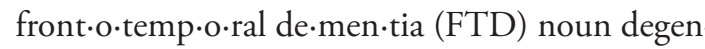
eration affects the frontal and anterior tempora lobes at early stages. Over time, the degeneration may advance to the temporal lobe. FTD accounts for approximately $10 \%$ of dementia cases.

hun-ting.ton's cho-re.a (hen-tiNG-tenz ke-rēa) noun [late 19th century: named after George Huntington (1851-1916), the US neurologist who first described it] also known as Huntington's Disease. A hereditary disease marked by degeneration of the brain cells and causing chorea and progressive dementia. [Oxford]

par-kin-son's dis-ease (PD) (pär-kin-sonz di-zēz) noun [late 19th century: named after James Parkinson (1755-1824), English surgeon] also known as Parkinsonism. A condition in which there is impairment of voluntary movement, rigidity of muscles and a characteristic tremor. It is caused by damage to, or disease of, the basal ganglia of the brain or the interconnections between them and the rest of the brain. There are biochemical abnormalities in this condition including a deficiency of dopamine.

pri-on dis.ease (prī-än di-zēz) noun also known as prionopathy(ies). A group of rapidly progressive neurodegenerative disorders that are cause by misfiled proteins.

vas.cu.lar de-men.tia (VD) (vas-kye-ler di-menSHea) noun also known as Leukoaraiosis and/ or Binswanger's Disease. Second most common form of dementia, and by far the most common non-degenerative form. Caused by an impaired supply of blood to the brain.

\section{Dissociative disorders}

dis-so-ci·ate dis·or-der (di-sō-SHē-āt dis-ôr-der) noun also known as multiple personality disorder. Main symptom cluster for dissociative disorders include a disruption in consciousness, memory, identity, or perception.

am.ne-sia (am-nē-ZHa) noun [late 18th century: from Greek amnēsia 'forgetfulness'] also known as dissociative amnesia. A partial or total loss of memory related to traumatic or stressful events which are too extreme to be accounted for by normal forgetting.

de·per-son·al.i.za $\cdot$ tion (dē-per-sen-el-e-zā-SHen) noun alteration in the perception of the self so that the usual sense of one's own reality is lost, manifested in a sense of unreality or self-estrangement, in changes of body image, or in a feeling that one does not control his own actions and speech.

de.re-al.i.za·tion (dē-rē-el-e-zā-SHen) noun is characterized by the loss of the sense of reality concerning one's surroundings.

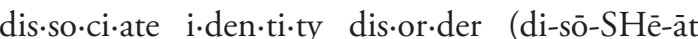
ì-den-ti-tē dis-ôr-der) noun formally known as Multiple Personality Disorder. The existence of more than one distinct identity or personality 
within the same individual.

fugue (fyoōg) noun [late 16th century: from French, or from Italian fuga, from Latin fuga 'flight', related to fugere 'flee'] also known as dissociative amnesia. This disorder is very rare and occurs most often during extreme stress (such as wartime or after a natural disaster).

psy·chop·a·thy (sī-käp-e-THē) noun (Psychopathic Disorder) a type of personality disorder in which antisocial behaviours occur without remorse or shame.

\section{Eating Disorders}

eat.ing dis·or·der (ēt-ing dis-ôr-der) noun characterized by disturbances in eating behaviour. This can mean eating too much, not eating enough, or eating in an extremely unhealthy manner (such as binging).

an·o·rex $\cdot \mathbf{i} \cdot a$ (an-e-rek-sē-a) noun [late 16th cent.: via late Latin from Greek, from an- 'without' + orexis 'appetite.'] also known as Anorexia Nervosa (AN). Lack or loss of appetite for food. Appetite is psychologic, dependent on memory and associations. Characterized by failure to maintain body weight of at least $85 \%$ of what is expected, fear of becoming 'fat.'

binge eat.ing (binj èt-ing) noun (Binge-Eating Disorder (BED)). Periodic intake of excessive amounts of food, often high calorie food. bu.lim.i.a (boō-lim-ē-a) noun [late Middle English (as bolisme, later bulimy): modern Latin, or from medieval Latin bolismos, from Greek boulimia 'ravenous hunger', from bous 'ox' + limos 'hunger'] also known as Bulimia Nervosa (BN). An emotional disorder characterized by a distorted body image and an obsessive desire to lose weight, in which bouts of extreme overeating (binge eating) are followed by fasting or self-induced vomiting.

\section{Impulse Control Disorders}

im.pulse con-trol dis.or.der (ICD) (im-pels kentrōl dis-ôr-der) noun disorders in this category include the failure or extreme difficulty in controlling impulses despite the negative consequences.

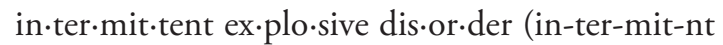
ik-splō-siv dis-ôr-der) noun characterized by frequent and often unpredictable episodes of extreme anger or physical outbursts.

klep·to·ma·ni·a (klep-te-mā-nya) noun [mid 19th century: from Greek kleptēs 'thief' + -mania] failure to resist impulses to steal things that are not needed for either personal use or for their monetary value.

path·o·log·i·cal gam bl·ing (paTH-e-läj-i-kel gambel-ing) noun persistent and maladaptive pattern of gambling which causes difficulties with interpersonal, financial, and vocational functioning. py·ro·ma·ni·a (pī-rō-mā-nē-a) noun involves deliberate and purposeful fire setting on at lease two occasions

trich.o.til.lo·ma.ni.a (trik-e-tile-mā-nē-a) noun [early 20th century: from French trichotillomanie, from Greek thrix, trikhos 'hair ' + tillein 'pull out (hair)' + -mania] recurrent pulling out of one's own hair which results in significant hair loss.

\section{Mental Disorder of Childhood and} Adolescence

men.tal dis·or.der of child.hood and ad·o.les.cence noun clinically and biologically heterogeneous group that are mainly joined by an age of onset between infancy and early adolescence.

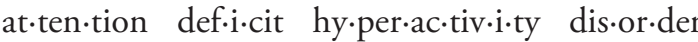
(ADHD) noun any of a range of behavioural disorders occurring primarily in children, including such symptoms as poor concentration, hyperactivity, and impulsivity.

au-tism (ô-tiz-em) noun [early 20th century (originally with reference to a condition in which fantasy dominates over reality, regarded as a symptom of schizophrenia and other disorders): from Greek autos 'self' + -ism. ] also known as Autistic Disorder and Asperger's Disorder. Characterized by great difficulty in understanding and using language and by impaired imagination and social relationship skills. 
con-duct dis-or-der (CD) (kän-dekt dis-ôr-der) noun consists in the persistent violation of social norms and basic rules of behaviour towards others, although the perpetrator is intellectually mature enough to understand these norms and rules.

\section{Mood Disorders}

mood dis-or-der (moōd dis-ôr-der) noun also known as Affective Disorder. Disorders in this category include those where the primary symptom is a disturbance in mood.

bi.po-lar dis-or-der (bī-pō-ler dis-ôr-der) noun also known as Manic Depression. Severe mood swings (manic or major depressive episodes) and a tendency to remission and recurrence.

cy·clo·thy·mi·a dis·or·der (sī-kle-THī-mēa dis-ôrder) noun [1920s: from cyclo- + Greek thumos 'temper'] symptoms include periods of hypomania. Depressive symptoms are also present as the hypomania fades.

de.pres.sion (di-pre-SHen) noun [late Middle English: from Latin depressio(n-), from deprimere 'press down'] also known as Depressive Disorder. An affective disorder manifested by either a low mood or loss of interest or pleasure in usual activities.

dys·thy-mi-a dis·or.der (dis-THī-mēa dis-ôr-der) noun [mid 19th century: from Greek dusthumia] persistent mild depression. ma.ni·a (mā-nēa) noun [late Middle English: via late Latin from Greek, literally 'madness', from mainesthai 'be mad'] excitement of psychotic proportions manifested by mental and physical hyperactivity, disorganization of behaviour, and elevation of mood.

man.ic (man-ik) adjective relating to or affected by mania.

man-ic de.pres.sive psy·cho-sis (man-ik di-pres-iv sī-kō-ses) noun a severe psychiatric illness characterized by episodes of mania and episodes of depression. These mood swings may be on a sporadic basis or, less commonly, on a regular cycle.

post.na.tal de.pres.sion (pōst-nātl di-pre-SHen) noun depression suffered by a mother following childbirth, typically arising from the combination of hormonal changes, psychological adjustment to motherhood, and fatigue.

\section{Personality Disorders}

per-son·al·itty dis·or.der (per-sen-al-itē dis-ôr-der) noun a major deviation from normal patterns of behaviour. Types of Personality Disorders in 3 Clusters: Cluster A 'Odd-Eccentric': Paranoid, Schizoid, Schizotypal. Cluster B 'Dramatic-Emotional': Antisocial, Borderline, Narcissistic, Histrionic. Cluster C 'Anxious-Fearful': Avoidant, Dependent, Compulsive

an·ti·so-cial (an-tē-sō-SHel) adjective/noun (Anti- social Personality Disorder) longstanding pattern (after the age of 15) of disregard for the rights of others.

a.void-ant (e-void-ent) adjective/noun (Avoidant Personality Disorder) relating to or denoting a type of personality or behaviour characterized by the avoidance of intimacy or social interaction.

bord-er-line (bôrd-er-līn) adjective/noun (Borderline Personality Disorder) major symptoms of this disorder revolve around unstable relationships, poor or negative sense of self, inconsistent moods, and significant impulsivity.

de.pend-ent (di-pend-ent) adjective/noun (Dependent Personality Disorder) [late Middle English dependant 'hanging down', from Old French, present participle of dependre] does not take responsibility, needs reassurance, lack of confidence in own judgements, actions and opinions, needs company, submissive and clinging behaviour.

his.tri-on·ic (his-trē-än-ik) adjective/noun (Histrionic Personality Disorder) [mid 17th century (in the sense 'dramatically exaggerated, hypocritical'): from late Latin histrionicus, from Latin histrio(n-) 'actor'] denoting a personality disorder marked by shallow, volatile emotions, and attention-seeking behaviour.

nar.cis·sis·tic (när-se-sis-tik) adjective/noun (Narcissistic Personality Disorder) symptoms revolve around a pattern of grandiosity, and sense of en- 
titlement. Often individuals feel overly important and will exaggerate achievements and will accept, and often demand, praise and admiration despite worthy achievements.

ob-ses.sive-com.pul-sive adjective/noun (Obsessive Compulsive Personality Disorder (OCPD)) preoccupation with orderliness, perfectionism, devotion to work, conscientiousness, hoarding of money and objects, lack of flexibility and efficiency. Not be confused with obessive-compulsive disorder (OCD).

par-a.noid (par-e-noid) adjective/noun (Paranoid Personality Disorder) suspiciousness, lack of trust, reads hidden meanings, bears grudges, perceives attaches on character or reputations.

schiz.oid (skit-soid) adjective/noun (Schizoid Personality Disorder) having qualities resembling those found in greater degree in schizophrenics; a person of schizoid personality.

schiz.o.ty.pal (skits-e-tīpel) adjective/noun (Schizotypal Personality Disorder) a personality type in which mild symptoms of schizophrenia are present and characterized by a need for social isolation, anxiety in social situations, and odd behaviour and thinking.

\section{Psychotic Disorders}

psy·chot-ic dis·or-der (sī-kät-ik dis-ôr-der) noun the major symptoms of these disorders is psycho- sis, or delusions and hallucinations. Delusions are false beliefs that significantly hinder a person's ability to function. Hallucinations are false perceptions.

brief psy·chot-ic dis·or.der (brēf sī-kät-ik dis-ôrder) noun presence of psychotic symptoms (delusions, hallucinations, disorganized speech, and/ or disorganized behaviour) which lasts at least one day but no more than one month.

de.lu-sion.al (di-loō-ZHen-al) adjective/noun (Delusional Disorder) [late Middle English (in the sense 'act of deluding or of being deluded'): from late Latin delusio(n-), from the verb deludere] a false belief regarding the self or persons or objects outside the self that persists despite the facts, and is not considered tenable by one's associates.

hal.lu.ci.na.tion (he-loō-se-nā-SHen) noun [mid 17 th century (in the sense 'be deceived, have illusions'): from Latin hallucinat- 'gone astray in thought', from the verb hallucinari, from Greek alussein 'be uneasy or distraught'] an experience involving the apparent perception of something not present.

par-a.noid schiz.o.phre.ni-a (par-e-noid skits-efrē-nēe) noun a condition in which there is a firmly held but false belief (delusion) which includes ideas of persecution or jealousy. This may be a sign of a serious psychiatric illness.

psy.cho·sis (sī-kō-ses) noun [mid 19th century: from Greek psukhōsis 'animation', from psukhoun 'give life to', from psukhē 'soul, mind'] a mental disorder characterized by gross impairment in reality testing as evidence by delusions, hallucinations, markedly incoherent speech, or disorganized and agitated behaviour without apparent awareness on the part of the patient of the incomprehensibility of his behaviour.

psy.chot-ic (sī-kät-ik) adjective/noun a person suffering from a psychosis.

schiz-o-af.fec-tive (skits-ō-a-fek-tiv) adjective/ noun (Schizoaffective Disorder) a type of psychiatric illness in which there are symptoms of schizophrenia and affective disorder.

schiz.o.phre.ni·a (skits-e-frēnēe) adjective/noun [early 20th century: modern Latin, from Greek skhizein 'to split' + phrēn 'mind'] a psychiatric illness with the onset most usually in the second or third decade. The person may have ideas that he or she is being influenced by other people or objects, have disjointed thoughts or may have hallucinations or delusions.

schiz-o.phre-ni.form (skits-e-frēnēa-form) noun used as a preliminary diagnosis for schizophrenia. Due to the complexities of schizophrenia, an initial diagnosis is very often tentative and schizophreniform is therefore used. Like schizophrenia, schizophreniform disorder is a type of "psychosis" in which a person cannot tell what is real from what is imagined. 
share-ed psy·chot-ic dis·or·der (SHeer-ed ssī-kät-ik dis-ôr-der) noun primary symptoms are delusions such as in delusional disorder which are similar in content to those of an individual who already has an established delusion.

\section{Sexual and Gender Identity Disorders}

dys.pa·reu.ni·a (dis-pa-roō-nēa) noun [late 19th century: from dys- 'difficult' + Greek pareunos 'lying with'] recurrent or persistent genital pain associated with sexual intercourse.

ex.hi.bi.tion.ism (eksa-bi-SHa-nizem) noun characterized by either intense sexually arousing fantasies, urges, or behaviours in which the individual exposes his or her genitals to an unsuspecting stranger.

fet-ish.ism (fet-iSH-izem) noun [early 17 th century (originally denoting an object used by the peoples of West Africa as an amulet or charm): from French fétiche, from Portuguese feitiço 'charm, sorcery' (originally an adjective meaning 'made by art'), from Latin factitius] characterized by either intense sexually arousing fantasies, urges, or behaviours in which the individual uses a nonliving object in a sexual manner.

frot-teu.rism (frô-ter-izem) noun [1930s: French, 'rubbing, friction'] characterized by either intense sexually arousing fantasies, urges, or behaviors in which the individual touches or rubs against an non-consenting person in a sexual manner. gen-der i.den.ti.ty dis.or.der (jen-der i-den-ti-tē dis-ôr-der) noun a strong and persistent identification with the opposite gender. There is a sense of discomfort in their own gender and may feel they were 'born the wrong sex.'

hy.po-ac.tive sex.u.al de.sire dis.or.der noun deficient or absent sexual fantasies and desire for sexual activity.

ma·le e.rec.tile dis·or·der (mälā i-rek-tîl dis-ôr-der) noun (formally known as Impotence) [late Middle English: via Old French from Latin impotent'powerless', from in- 'not' + potent-] recurring inability to achieve or maintain an erection until completion of the sexual activity.

par-a.phil-i.a (para-fil-ēa) adjective/noun defined by promotion of sexual excitement through specific fantasies, behaviours or objects (typically involving extreme or dangerous activities) that causes clinically significant distress or impairment.

pe-do.phil.i.a (pe-de-filēe) adjective/noun [from Greek pais, paid- 'child, boy'] characterized by either intense sexually arousing fantasies, urges, or behaviours involving sexual activity with a prepubescent child (typically age 13 or younger).

pre-ma.ture e.jac.u.la.tion (prē-me-CHoōr i-jakye-lāSHen) noun ejaculation with minimal sexual stimulation before or shortly after penetration and before the person wishes it. sex-u.al a-ver-sion dis·or-der (sek-SHoō-el a-verZHen dis-ôr-der) noun persistent or recurring aversion to or avoidance of sexual activity.

sex-u.al mas·och·ism (sek-SHoō-el maz-kizem) noun behaviours are typically evident by early adulthood, and often start with masochistic or sadistic play in childhood. The disorder is characterized by either intense sexually arousing fantasies, urges, or behaviours in which the individual is humiliated, beaten, bound, or made to suffer in some way.

sex·u·al sa.dism (sek-SHoō-el sā-dizem) noun behaviours are typically evident by early adulthood, and often start with masochistic or sadistic play in childhood. The disorder is characterized by either intense sexually arousing fantasies, urges, or behaviours in which the individual is sexually aroused by causing humiliation or physical suffering of another person.

tran-sves.tic fet-ish.ism noun this diagnosis is used for heterosexual males who have sexually arousing fantasies, urges, or behaviours involving cross-dressing.

\section{Sleep Disorders}

sleep dis·or-der (slēp dis-ôr-der) noun primary sleep disorders can be classified into disorders with abnormal sleep (dyssomnias) and those with abnormal behaviour during sleep (parasomnias). 
hyp.er-som·ni.a noun (Primary Hypersomnia) criteria for primary hypersomnia include excessive sleepiness for at least one month as evidences by prolonged sleep during the night or excessive daytime sleep.

in·som·ni·a (in-säm-nēa) noun (Primary Insomnia) [early 17th century: from Latin, from insomnis 'sleepless', from in- (expressing negation) + somnus 'sleep'] criteria for a diagnosis of primary insomnia include a difficulty falling asleep, remaining asleep, or receiving restorative sleep for a period no less than one month.

nar·co-lep·sy (när-ke-lep-sē) adjective/noun [late 19th century: from Greek narkē 'numbness', on the pattern of epilepsy.] a condition characterized by an extreme tendency to fall asleep whenever in relaxing surroundings.

par-a.som·ni·a (pare-säm-nēa) adjective/noun [1930s: blend of para and insomnia] relate to abnormal behaviour or physiological events that occur during the process of sleep or sleep-wake transitions.

\section{Somatoform Disorders}

bod.y dys.mor·phic dis·or.der (BDD) (bädē dismôr-fēek dis-ôr-der) noun a psychological disorder in which a person becomes obsessed with imaginary defects in their appearance.

con·ver-sion dis·or·der (ken-ver-ZHen dis-ôr-der) noun symptoms such as deficits in voluntary motor or sensory functions which are not intentionally produced but which cannot be fully explained by a physician.

hy·po-chon·dri-a.sis (hī-pō-ken-drīe-sis) noun (Hypochondriasis Disorder) [late Middle English (in the Greek sense): via late Latin from Greek hupokhondria, denoting the soft body area below the ribs, from hupo 'under' + khondros 'sternal cartilage'. Melancholy was originally thought to arise from the liver, gallbladder, spleen, etc.] preoccupation with fears of having a serious disease based upon a misinterpretation of bodily sensations.

pain dis-or·der (pān dis-ôr-der) noun pain which causes significant distress or impairment in functioning which cannot be fully explained by a physician. It must be judged to be related to psychological factors and cannot be better explained by another disorder.

so-mat.i.za.tion dis.or.der (sō-mate-zā-SHen disôr-der) noun includes a history of physical complaints prior to age 30 which occur over a period of several years. There must be a significant impairment in functioning or a history of resulting medical treatment.

\section{Substance Related Disorders}

sub-stance re.lat.ed dis.or-der (seb-stens ri-lāt-id dis-ôr-der) noun refers to either the abuse or de- pendence on a substance. A substance can be anything that is ingested in order to produce a high, alter one's senses, or otherwise affect functioning.

sub-stance a.buse (seb-stens e-byoōz) noun a pattern of substance use leading to significant impairment in functioning. The 11 Classes of Substance Abuse: Alcohol, Sedatives, Amphetamines or similarly acting sympathomimetics, Cocaine, Caffeine, Cannabis, Hallucinogens, Inhalants, Nicotine, Opioids Phencyclidine (PCP)

sub-stance de.pend-ence (seb-stens di-pend-ens) noun substance use history which includes the following: (1) substance abuse; (2) continuation of use despite related problems; (3) increase in tolerance (more of the drug is needed to achieve the same effect); and (4) withdrawal symptoms. 